DOE/NASA/3230-1

NASA CR-165324

NASA-CR-165324

19820005634

\title{
Transient Catalytic Combustor Model
}

James S. T'ien

Case Western Reserve University

LIRRARY COPY

12831982

May 1981

Prepared for

National Aeronautics and Space Administration Lewis Research Center

Under Grant NSG-3230

LANGLEY RESEARCH CENTER LIBRARY, NASA

HAMPTON, VIRGINIA

for

U.S. DEPARTMENT OF ENERGY

Conservation and Renewable Energy Office of Vehicle and Engine R\&D 


\section{NOTICE}

This report was prepared to document work sponsored by the United States Government. Neither the United States nor its agent, the United States Department of Energy, nor any Federal employees, nor any of their contractors. subcontractors or their employees. makes any warranty. express or implied. or assumes any legal liability or responsibility for the accuracy, completeness, or usofulness of any information. apparatus, product or process disclosed. or represents that its use would not infringe privately owned rights 


\section{Transient Catalytic Combustor Model}

James S. T'ien

Case Western Reserve University

Cleveland, Ohio

May 1981

Prepared for

National Aeronautics and Space Administration

Lewis Research Center

Cleveland, Ohio 44135

Under Grant NSG-3230

for

U.S. DEPARTMENT OF ENERGY

Conservation and Renewable Energy

Office of Vehicle and Engine R\&D

Washington, D.C. 20545

Under Interagency Agreement DE-AI01-77CS51040 



\section{ACKNOWLEDGEMENT}

This project is supported by the Department of Energy under NASA Grant NSG-3230 administered by NASA Lewis Research Center.

The author wishes to express his sincere thanks to Dr. David $\mathrm{N}$. Anderson for helpful advice and his review of the manuscript. 

$\begin{array}{ll}\text { INTRODUCTION } & 2\end{array}$

Chapter I. Transient Catalytic Combustor Mode1 4

I.1 Nonsteady Combustion Model $\quad 4$

Consideration of Time Scales $\quad 4$

Quasisteady Gas Phase $\quad 5$

Unsteady Solid with Thin-wall Substrate 9

Initial and Boundary Conditions 11

Numerical Solution Procedure $\quad 12$

I.2 Computed Results 13

Steady State 13

$\begin{array}{ll}\text { Transient Response } & 19\end{array}$

Chapter II. Steady-State Computation and Comparison with Experiments 29

II.1 Three-step Semi-global Gas-phase Chemical Reactions 29

II.2 Computed Results $\quad 34$

Effects of Catalytic Bed Length, Downstream Reaction 36

Distance, Reference Velocity and Adiabatic

Flame Temperature

Effect of Inlet Temperature and Pressure 43

$\begin{array}{ll}\text { SUMMARY } & 47\end{array}$

$\begin{array}{lr}\text { REFERENCE } & 49\end{array}$

NOMENCLATURE

Appendix I Listing of Computer Programmes for Chapter I. 55

Appendix II Listing of Computer Programmes for Chapter II. 72 

A lean combustion model for monolithic catalytic combustors is given. The model, consisting of several semi-global chemical reaction steps in the gas phase and on the surface, is capable of analyzing $c 0$ and THC emissions and combustor efficiency in both steady and unsteady states.

In the steady-state model computation presented, the influence of operating and design parameters on the minimum combustor length is studied. Special attention is given to the effect of after-bed gas phase reaction space. Comparison with experimental data by Anderson indicates good agreement in the range of parameters covered.

In the transient analysis, a quasisteady gas phase and a thermallythin substrate are assumed. The combustor response delay is due to the substrate thermal inertia. Fast response is found to be favored by thin substrate, short catalytic bed length, high combustor inlet and final temperatures and, in most cases, small gas channel diameters. The calculated gas and substrate temperature time history at different axial positions provide an understanding of how the catalytic combustor responds to an upstream condition change. The computed results also suggest that the gas residence times in the catalytic bed and in the after-bed space are correlatable with the nondimensional combustor response time. When fast transient responses are required, both steady and unsteady studies have to be made to achieve a meaningful compromising design. 
INTRODUCTION

The operation and the design of catalytic combustors are limited on one end by the high temperature that the catalysts can tolerate and on the other end (low temperature) by the acceptable emission levels of co and unburnt hydrocarbons. The aim of the combustion engineer is to design a compact and durable combustor capable of efficient and clean combustion. Catalytic combustor modeling can contribute to this objective by providing more understanding to the detail processes occurring in the reactor and to serve as a design guidance for minimizing the numbers of experimental tests needed.

There are several steady-state catalytic combustor models in existence (Ablow and Wise, 1979, Cerkanowicz, et a1, 1977,Kelley et a1, 1977, Kenda11 et al, 1979) and they show a high degree of success in describing the events occurring in the combustor. In particular, the model by Kelley et at (1977) containing detailed gas phase chemistry for methane/air reactions can predict pollutant emissions. Detailed kinetics, unfortunately, are not yet avallable for most other practical fuels. Since emission characteristics are important considerations for catalytic combustor design, in the absence of more detailed information, models consisting of several key semi-global chemical steps seem appropriate.

In addition to the emission characteristics, the transient behavior of catalytic combustors is expected to be different from that of a conventional gas turbine burner, due to the large thermal inertia of the substrate. Non-steady operations are obviously important to transportation engines since their power levels have to be changed frequently. Transients may also be a concern with stationary gas turbine applications, since the 
ignition/shutdown operation can produce excessive thermal stress or thermal shock if the combustor is not designed or operated properly and the substrate can fail as a result (DeCorso and Car1, 1979).

Typical questions concerning transient operations include the combustor response time, the type of response, the unsteady substrate temperature history and the resultant thermal stress distribution. At the present time, both experiment and theory on transient catalytic combustion are lacking. A model is presented here attempting to analyze the problem theoretically. In Chapter I of this report, the transient combustion model will be formulated and numerical solution will be presented as a parametric study. Since the transient computer code can also yield steady-state results, in Chapter II, a detailed computation of steady states is given and a comparison with Anderson's data is made. As far as the combustion models are concerned, the one in Chapter II has a three-step global gas-phase chemical reaction vs. a two-step one in Chapter II. The reason for using the three-step scheme is discussed in the beginning of Chapter II. 
CHAPTER I TRANSIENT CATALYTIC COMBUSTOR MODEL

\section{I.1 Nonsteady Combustion Mode1}

\section{Consideration of Time Scales}

For a monolithic catalytic combustor with uniform cell distribution in the plane normal to the approaching flow direction, if the combustor wall is well insulated, then the study of the whole reactor can be reduced to the consideration of a single cell unit. Referring to Fig. I.1, each cell unit consists of an open gas channel, the associated substrate volume and an after-bed gas reaction space.

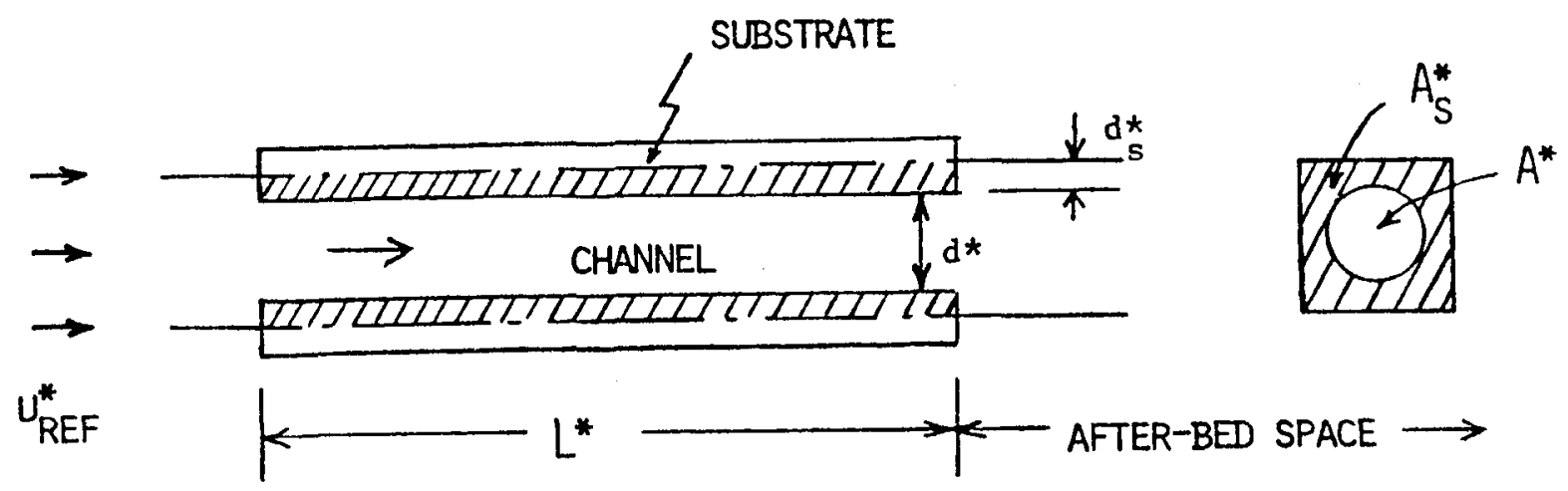

Figure I.1 Schematic Drawing of One Cell Unit 
Considering first the steady-state combustion, the relevant time scales are the gas residence time in the reactor, the heat and mass transfer time between the gas and the solid surface inside the channel and the gasphase and surface reaction times. When a transient is caused by an upstream parameter variation, then the new time scales involved include the input characteristic time, the time for the temperature wave to reach the central plane of the substrate and the time for heating-up (or cooling-down) the substrate.

TableIldefines these characteristic times and their estimated magnitudes. It should be noted that some of the time scales vary along the channel of the reactor bed. For example, the heat/mass transfer time and the substrate heat-up time are shorter at the flow entrance region than those for far downstream, and the ones used in Table I are those based on fully-developed flow profiles. However, the estimation from Table I does serve the purpose of order-of-magnitude comparison. From this table we see that the longest time is the solid heat-up time, being of the order of seconds. If the time scale we are interested in is much greater than the gas residence time $(\sim 15 \mathrm{msec})$, then the gas phase processes (including heat/mass transfer and chemical reactions) can be regarded as in a quasisteady state. If furthermore the substrate half-thickness is smaller than about $.2 \mathrm{~mm}$, then the substrate temperature distribution in the direction normal to the channel axis can be regarded as uniform at any given time. In this limiting case then, a "quasi-steady-gas-phase and thermallythin-substrate" model is applicable with the only transient process being the substrate heating-up or cooling-down. In the following section, this model will be described in mathematical form.

\section{Quasisteady Gas Phase}

Quasisteady gas phase implies that the differential equations for the 
Table I.1 Estimate of Transient Time Scales in Catalytic Monolith Combustor

\begin{tabular}{|c|c|c|}
\hline Time & Definition & Estimated Magnitude \\
\hline $\begin{array}{l}\text { Gas residence time in } \\
\text { reactor bed }\end{array}$ & $\left(L * / u_{\text {ref }}^{*}\right)\left(A^{*} / A_{T}^{*}\right)$ & $1-15 \mathrm{msec}$ \\
\hline $\begin{array}{l}\text { Gas residence time in } \\
\text { after-bed space }\end{array}$ & $\mathrm{L}_{\mathrm{as}}^{*} / \mathrm{u}_{\mathrm{ref}}^{*}$ & $0-15 \mathrm{msec}$ \\
\hline $\begin{array}{l}\text { Heat/mass transfer time } \\
\text { between gas and solid } \\
\text { surface in channel }\end{array}$ & $\frac{1}{N u_{\infty}} \frac{1}{\pi} \frac{d \star^{2}}{4 \alpha^{*}(0,0)}$ & $\begin{array}{l}.5-7.5 \mathrm{msec} \text { for } \\
\mathrm{d}^{*} \leq 3.6 \mathrm{~mm}\end{array}$ \\
\hline $\begin{array}{l}\text { Chemical reaction times } \\
\text { (gas-phase and heteroge- } \\
\text { neous) }\end{array}$ & & $\begin{array}{l}\text { Same order of magnitude } \\
\text { as gas residence times }\end{array}$ \\
\hline $\begin{array}{l}\text { Time for temperature wave } \\
\text { to reach the substrate } \\
\text { center plane }\end{array}$ & $\frac{d t^{2}}{\alpha_{s}^{*}}$ & $\begin{array}{l}0.5-25 \mathrm{msec} \text { for } \\
\mathrm{d} t \mathrm{~s} \leq .2 \mathrm{~mm}\end{array}$ \\
\hline $\begin{array}{l}\text { Substrate heat-up } \\
\text { time }\end{array}$ & 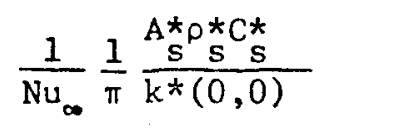 & $0.5 \mathrm{sec}-20 \mathrm{sec}$ \\
\hline $\begin{array}{l}\text { Transient input } \\
\text { time }\end{array}$ & & variable, specified \\
\hline
\end{tabular}


gas-phase processes are the same as those for the steady state. Only the boundary conditions on the solid surface are different. There are several steady-state catalytic combustor models in existence [Cerkanowicz et a1, 1977, Ke1ly et a1, 1977, 1979] and they show a high degree of success in describing the events occurring in the combustor. In particular, the model by Kelley et al (1977) containing detailed chemistry for methane/air reactions can predict pollutant emissions. Detailed kinetics, unfortunately, are not yet available for most other practical fuels. Since emission characteristics are important considerations for catalytic combustor design, in the absence of more detailed information, a model consisting of several key semi-global chemical steps is proposed.

For fuel-lean catalytic combustion using nitrogen-free hydrocarbon fuels, the $\mathrm{NO}_{x}$ emission is negligible because of low flame temperatures. The only pollutants needed to be considered are unburnt hydrocarbons (UHC) and carbon monoxide (CO). For this reason, the two semi-global chemical reactions used in the gas phase are:

(A)

$$
\begin{aligned}
& \mathrm{C}_{\mathrm{n} m} \mathrm{H}_{\mathrm{m}}+1 / 2(\mathrm{n}+\mathrm{m} / 2) \mathrm{O}_{2} \rightarrow \mathrm{n} \mathrm{CO}+\mathrm{m} / 2 \mathrm{H}_{2} \mathrm{O} \\
& \frac{\mathrm{d}\left[\mathrm{C}_{\mathrm{n} m} \mathrm{H}_{\mathrm{m}}\right]}{\mathrm{d} \mathrm{t}^{*}}=-\mathrm{C}_{1}^{*} \mathrm{p}^{\alpha^{\alpha}}\left[\mathrm{C}_{\mathrm{n} m} \mathrm{H}\right]^{\alpha_{2}}\left[\mathrm{O}_{2}\right]^{\alpha_{3}} \mathrm{~T}^{\alpha_{4}} \exp \left(-\mathrm{E}_{1}^{*} / \mathrm{RT} *\right)
\end{aligned}
$$

(B) $\quad \mathrm{CO}+1 / 2 \mathrm{O}_{2} \rightarrow \mathrm{CO}_{2}$

$$
\frac{\mathrm{d}[\mathrm{CO}]}{\mathrm{d} \mathrm{t}^{*}}=-\mathrm{C}_{2}^{*} \mathrm{p} *^{\beta_{1}}[\mathrm{CO}]^{\beta_{2}}\left[\mathrm{O}_{2}\right]^{\beta_{3}}\left[\mathrm{H}_{2} \mathrm{O}\right]^{\beta_{5}} \mathrm{~T} *^{\beta_{4}} \exp \left(-\mathrm{E}_{2}^{*} / \mathrm{RT} *\right)
$$

In describing the flow in the reactor channel, we follow previous investigators in using the plug flow approximation. For transient cases, in general, the fluid properties are functions of $\mathrm{x}$, the distance along the channel axis and $t$, the time. For example, density of the gas will be 
expressed as $\rho(x, t)$. The nondimensional forms of these equations are summarized in the following (supscript * denotes dimensional quantity and without * denotes nondimensional quantities).

$$
\begin{aligned}
& \text { Continuity: } \quad p u=\hat{p}(0, t) u(0, t) \\
& \text { Momentum: } \quad p=p(o, t) \\
& +\mathrm{q}_{2} \mathrm{Y}_{\mathrm{HC}}(0,0) \mathrm{w}_{2}
\end{aligned}
$$

Species:

Hydrocarbon:

$$
\rho u \frac{\partial y_{H C}}{\partial x}+J_{D_{1}}\left(y_{H C}-y_{H C, S}\right)=-w_{1}
$$

Carbon monoxide:

$$
\rho u \frac{\partial{ }_{C O}}{\partial x}+J_{D_{2}}\left(y_{C O}-y_{C O, s}\right)=w_{1} c_{n}-w_{2}
$$

Oxygen:

$$
y_{\mathrm{O}_{2}}=1-\phi\left(1-y_{\mathrm{HC}}+\frac{1}{2} \quad y_{\mathrm{CO}}\left(\frac{\mathrm{Y}_{\mathrm{HC}}(0,0)}{\mathrm{Y}_{\mathrm{O}_{2}}(0,0)} \frac{\mathrm{w}_{\mathrm{O}_{2}}}{\mathrm{w}_{\mathrm{CO}}}\right)\right.
$$

Equation of state: $p=\rho T$

The reaction rates are given by

$$
\begin{aligned}
& w_{1}=B_{1} p^{\alpha_{1}}{ }^{\left(\alpha_{2}+\alpha_{3}\right)} \mathrm{T}^{\alpha_{4}} \zeta_{\mathrm{HC}}^{\alpha_{2}} \gamma_{\mathrm{O}_{2}}^{\alpha_{3}} \mathrm{e}^{-\left(E_{1} / \mathrm{T}\right)} \\
& w_{2}=B_{2} p^{B_{1}} \rho^{\left(B_{2}+B_{3}+B_{5}\right)_{T}^{B_{4}}} y_{C O}^{B_{2}} \quad y_{O_{2}}^{B_{3}} y_{\mathrm{H}_{2} \mathrm{O}}^{B_{5}} e^{-\left(E_{2} / T\right)} \\
& \text { and } \mathrm{Y}_{\mathrm{H}_{2} \mathrm{O}}(\mathrm{x}, \mathrm{t})=\frac{\mathrm{m}}{2} \frac{\mathrm{w}_{\mathrm{H}_{2} \mathrm{O}}}{\mathrm{w}_{\mathrm{HC}}} \mathrm{Y}_{\mathrm{HC}}(0,0) \quad\left[y_{\mathrm{HC}}(\mathrm{o}, \mathrm{t})-\xi_{\mathrm{HC}}^{(\mathrm{x}, t)}\right]
\end{aligned}
$$

The definition of $B_{1}$ and $B_{2}$ can be found in the nomenclature. 
In deriving Eqns (5-8), heat conduction and mass diffusion in the axial direction are neglected because the Peclet number based on typical gas velocity ( $>10 \mathrm{M} / \mathrm{sec}$ ) is much greater than unity [Ablow and Wise, 1979]. The dimensionless lateral heat and mass transfer coefficients $\mathrm{J}_{\mathrm{H}}$ and $\mathrm{J}_{\mathrm{Di}}$, in Eqns (5-7) are derived from Nusse1t number calculation in entrance flow in a tube of constant surface temperature [Kays, 1966]. Following Kelly et al (1977), a modification is made at the entrance point based on local stagnation flow estimation. The use of entrance flow transport properties, rather than fully-developed constant values, make a great difference in the temperature and species distributions in the flow entrance region.

The above system of equations can also be applied to the after-bed space where only gas-phase reactions occur. This is done by putting $\mathrm{J}_{\mathrm{H}}$ and $J_{D i}$ equal to zero in Eqns (5-7) and by properly changing the mass flux per unit area in Eq (3) due to area change.

\section{Unsteady Solid with Thin-Wa11 Substrate}

When the substrate wall is thermally thin, the solid temperature can be regarded as a function of axial distance and time only, i.e., $T_{S}(x, t)$. The energy balance of the solid, including the solid surface, results in the following equation:

$$
A_{S}^{*} \rho_{S}^{*} C_{S}^{*} \frac{\partial T_{S}^{*}}{\partial t^{*}}-h_{T^{*}}^{*}\left(T^{*}-T_{S}^{*}\right)=S^{*}\left[q_{3}^{*} J_{3}^{*}+q_{4}^{*} J_{4}^{*}\right]
$$

In Eq (13) the heat conduction in the axial direction in the solid is neglected in comparison with the heat transfer rate between the gas and solid across the gas channel. 
Two semf-global catalytic surface reactions are assumed. They are

(C) $\mathrm{C}_{\mathrm{n}} \mathrm{H}_{\mathrm{m}}+\left(\mathrm{n}+\frac{\mathrm{m}}{4}\right) \mathrm{O}_{2}+\mathrm{nCO}_{2}+\frac{\mathrm{m}}{2} \mathrm{H}_{2} \mathrm{O}$

with the corresponding surface reaction rate $\mathrm{J}_{3}^{\star}$ given by

$$
J_{3}^{*}=C_{3}^{*}\left[C_{n} H_{m}\right] s e^{-E_{3}^{*} / R T_{s}^{*}}
$$

and (D) $\mathrm{CO}+\frac{1}{2} \mathrm{O}_{2}+\mathrm{CO}_{2}$

with $\quad J_{4}^{*}=C_{4}^{*}[\mathrm{CO}]_{s} e^{-E_{4}^{*} / R T_{s}^{*}}$

In surface reaction (C), the hydrocarbon is oxidized to form $\mathrm{CO}_{2}$ and $\mathrm{H}_{2} \mathrm{O}$, not $\mathrm{CO}$ such as in gas-phase reaction (A). This is based on the present available experimental evidence in oxygen-rich systems, only $\mathrm{CO}_{2}$, not $\mathrm{CO}$, is found on or close to the catalytic surface [Schwartz et al, 1971, Anderson, 1976 and Marteney, 1979].

Eq (13) is non dimensionalized by first defining a proper reference time scale $\tau^{*}$.

$$
\tau^{*} \equiv \frac{1}{N u_{\infty}} \frac{1}{\pi} \frac{A_{S}^{*} \rho_{S}^{*} C_{s}^{*}}{k^{*}(0,0)}
$$

and

$$
t \equiv t^{*} / \tau^{*}
$$

$$
r_{n k} \equiv \frac{N u_{x}}{N u_{\infty}} \frac{k^{\star}}{k^{\star}(0,0)}
$$

Eq (13) becomes

$$
\begin{gathered}
\frac{\partial \mathrm{T}_{s}}{\partial t}-\mathrm{r}_{\mathrm{nk}}\left(\mathrm{T}-\mathrm{T}_{\mathrm{s}}\right)=\mathrm{B}_{3} \mathrm{Y}_{\mathrm{HC}}(0,0) \mathrm{q}_{3} \rho \mathcal{Y}_{\mathrm{HC}, \mathrm{s}} \exp \left(-\mathrm{E}_{3} / \mathrm{T}_{\mathrm{s}}\right) \\
+\mathrm{B}_{4} \mathrm{Y}_{\mathrm{HC}}(0,0) \mathrm{q}_{4} \rho \mathcal{Y}_{\mathrm{CO}, \mathrm{s}} \exp \left(-\mathrm{E}_{4} / \mathrm{T}_{\mathrm{s}}\right)
\end{gathered}
$$


Neglecting transient accumulation on the surface, the surface hydrocarbon and carbon monoxide are given by

$$
\begin{aligned}
& r_{\mathrm{nk}}\left(y_{\mathrm{HC}}-y_{\mathrm{HC}, \mathrm{s}}\right)=\frac{1}{\left(\mathrm{~L}_{\mathrm{e}_{1}}\right)^{2 / 3} \mathrm{~B}_{3} \rho y_{\mathrm{HC}, \mathrm{s}}} \exp \left(-\mathrm{E}_{3} / \mathrm{T}_{\mathrm{s}}\right) \\
& r_{\mathrm{nk}}\left(y_{\mathrm{CO}}-y_{\mathrm{CO}, \mathrm{s}}\right)=\frac{1}{\left(\mathrm{~L}_{\mathrm{e}_{2}}\right)^{2 / 3}} \mathrm{~B}_{4} \rho y_{\mathrm{CO}, \mathrm{s}} \exp \left(-\mathrm{E}_{4} / \mathrm{T}_{\mathrm{s}}\right)
\end{aligned}
$$

\section{Initial and Boundary Conditions}

The system of equations (3-12, 18-20) neefs inftial and boundary conditions. Initial conditions $(a t t=0)$ are required for $\mathrm{T}_{\mathrm{S}},\left(\zeta_{\mathrm{HC}}\right)_{\mathrm{S}}$ $\left(y_{\mathrm{CO}}\right)_{\mathrm{s}}$ as a function of $x$ and upstream boundary conditions (at $x=0$ ) should be specified for $\zeta_{\mathrm{HC}}, \xi_{\mathrm{CO}}, \zeta_{02}, \mathrm{~T}, \mathrm{p}$ and $\mathrm{u}$ as a function of time. These conditions depend on the types of transient input which can vary with engine designs and mode of operations. In the present paper, a simple start-up transient is investigated, i.e. catalytic combustor response to a step-wise fuel injection.

The substrate temperature at time $t=0$ is specified. This temperature can be the result of external heating of the substrate, say, by a torch. The fuel and afr are then supplied at upstream. The model is intended to describe the events from $t=0$ to the final steady state. Mathematically, the conditions used are 


$$
\begin{aligned}
& T_{s}(x, 0)=\text { specified } \\
& y_{H C, s}(x, 0)=0 \\
& y_{C O, s}(x, 0)=0 \\
& T(0, t)=1 \\
& y_{H C}(0, t)=1 \\
& y_{C O}(0, t)=0 \\
& y_{02}(0, t)=1 \\
& p(0, t)=1 \\
& u(0, t)=1
\end{aligned}
$$

\section{Numerical Solution Procedure}

Although most dependent variables in this problem are function of both $x$ and $t$ which, in general, results in partial differential equations, the assumption of quasisteady gas phase and thermally thin substrate greatly simplifies the mathematical property of the system and results in a simpler solution procedure.

The gas-phase differential equations (5-7) have only first derivative in $x$ with $t$ as a parameter, the solid equation (18) has only derivative in $t$ with $x$ as a parameter; therefore, they can be irtegrated at each time ( $t)$ or position $(x)$ as ordinary differential equations using Runge-Kutta method. The procedure is started by first integrating Eqns (5-7) forward in $x$ from upstream to the end of combustor for $\mathrm{T}, \xi_{\mathrm{HC}}, \xi_{\mathrm{CO}}$ using the solid surface 
quantities specified by the initial conditions, then $\mathrm{Eq}$ (18) is integrated for one time step $(\Delta t)$ to find $T_{s}(x, \Delta t)$ and Eqns $(19,20)$ are solved algebraically to find $y_{\mathrm{HC}, \mathrm{s}}(x, \Delta t)$ and $y_{\mathrm{CO}, \mathrm{s}}(x, \Delta t)$. These surface quantities are substituted back to Eqns (5-7) to start another cycle of integration. Steady-state and transient solutions are obtained using the same code. The computational time ranges from 10-50 seconds in a VAX-11 computer. The numerical scheme is an efficient one and it is suitable for parametric studies.

\section{I.2 Computed Resu1ts}

Steady State

Selected steady-state results will be presented first to facilitate the discussion on the transient response. Specifically, the relative importance of the catalytic bed length and the after-bed-gas-phase-reaction distance will be shown. In previous theoretical models, emphasis was placed on the combustion inside the catalytic bed only. The contribution of gasphase reactions in the downstream space after the bed has been demonstrated in the experiments by $\mathrm{T}^{\prime}$ ien and Anderson (1979) and Anderson (1980). Utilization of the pure gas-phase reactions in the downstream of the monolith to replace a portion of the catalytic bed will be shown to be crucial in reducing the catalytic combustor transient response time.

Table I.2 lists the values of chemical kinetic constants for reactions $A$ to $D$ used in this ohapter. The hydrocarbon fuel chosen is propane. Semiglobal kinetics for hydrocarbon and co oxidation are from Edelman (1969) and Dryer and Glassman (1973) respectively, with the pre-exfonential factors 
Table I.2 Chemical Kinetic Constants for Chapter I

\begin{tabular}{llll} 
Reaction (A) & Reaction (B) & Reaction (C) & Reaction (D) \\
\hline$C_{1}^{*}=1.5 \times 10^{5}$ & $C_{2}^{*}=0.71 \times 10^{14}$ & $C_{3}^{*}=2.5 \times 10^{3}$ & $C_{4}^{*}=10^{5}$ \\
$\alpha_{1}=0.3$ & $B_{1}=0$ & $E_{3}^{*}=10$ & $(\mathrm{kcal} / \mathrm{mole})$ \\
$\alpha_{2}=0.5$ & $B_{2}=1$ & $E_{4}^{*}=17.8$ \\
$\alpha_{3}=1$ & $B_{3}=0.25$ & \\
$\alpha_{4}=1$ & $B_{4}=0$ & \\
$E_{1}^{*}=24$ & $B_{5}=0.5$ & \\
$(\mathrm{kca} / \mathrm{mole})$ & $E_{2}^{*}=40$ & \\
& $(\mathrm{kcal} / \mathrm{mole})$
\end{tabular}


adjusted. The activation energies for reactions $C$ and $D$ are obtained from the data of Marteney (1979) and Kuo and Morgan (1971) respectively with adjusted pre-exponential factors. It should be noted that the surface reaction rates contain information on catalyst type and loading density as well as the washcoat properties.

The design parameters considered are $\mathrm{d}^{*}$, channel hydraulic diameter, $A^{*} / A_{T}^{*}$, the percentage of open area (or equivalently, $A^{*} / A_{S}^{*}$, the ratio of open-to-close areas), $L^{*}$, the catalytic bed length and $L_{a s}^{*}$, after-bed gas-phase reaction length. The minimum catalytic combustor length required to reach the emission goal in steady-state operations is denoted using the subscript EG. The emission goal is chosen to be $1.64 \mathrm{~g} / \mathrm{kg}$ of fuel for UHC and 13.6 $\mathrm{g} / \mathrm{kg}$ of fuel for $\mathrm{CO}$ [Anderson, 1977]. The operating parameters include $\mathrm{p} *$, the pressure, $\mathrm{T}_{\text {in }}^{*}$, combustor inlet temperature, $\mathrm{T}_{\mathrm{af}}^{*}$, adiabatic flame temperature (or equivalently the fuel/air equivalence ratio $\phi$ ) and $\mathrm{U}_{\text {ref }}^{*}$, the reference velocity of the approach gas upstream of the reactor bed.

Fig. I.2 gives the profiles for one sample calculation. In this case, the propane fuel is oxidized quick1y on the catalyst surface upon entering into the reactor channel and resulting in a high surface temperature, the gas temperature is raised by heat transfer from the substrate, gas-phase oxidation of propane is accelerated to form $\mathrm{CO}$, and $\mathrm{CO}$, in turn, is oxidized by both gas-phase and surface reactions to $\mathrm{CO}_{2}$. Actually, two cases are shown in Fig.I.2. In one case, the reactor bed length is $4 \mathrm{~cm}$, in the other, $8 \mathrm{~cm}$. When the bed length is cut short at $4 \mathrm{~cm}$, the surface oxidation reactions for the hydrocarbon fuel and $\mathrm{CO}$ stop there. This results in a higher $\mathrm{CO}$ concentration as shown by the dotted curve. The hydrocarbon curve 


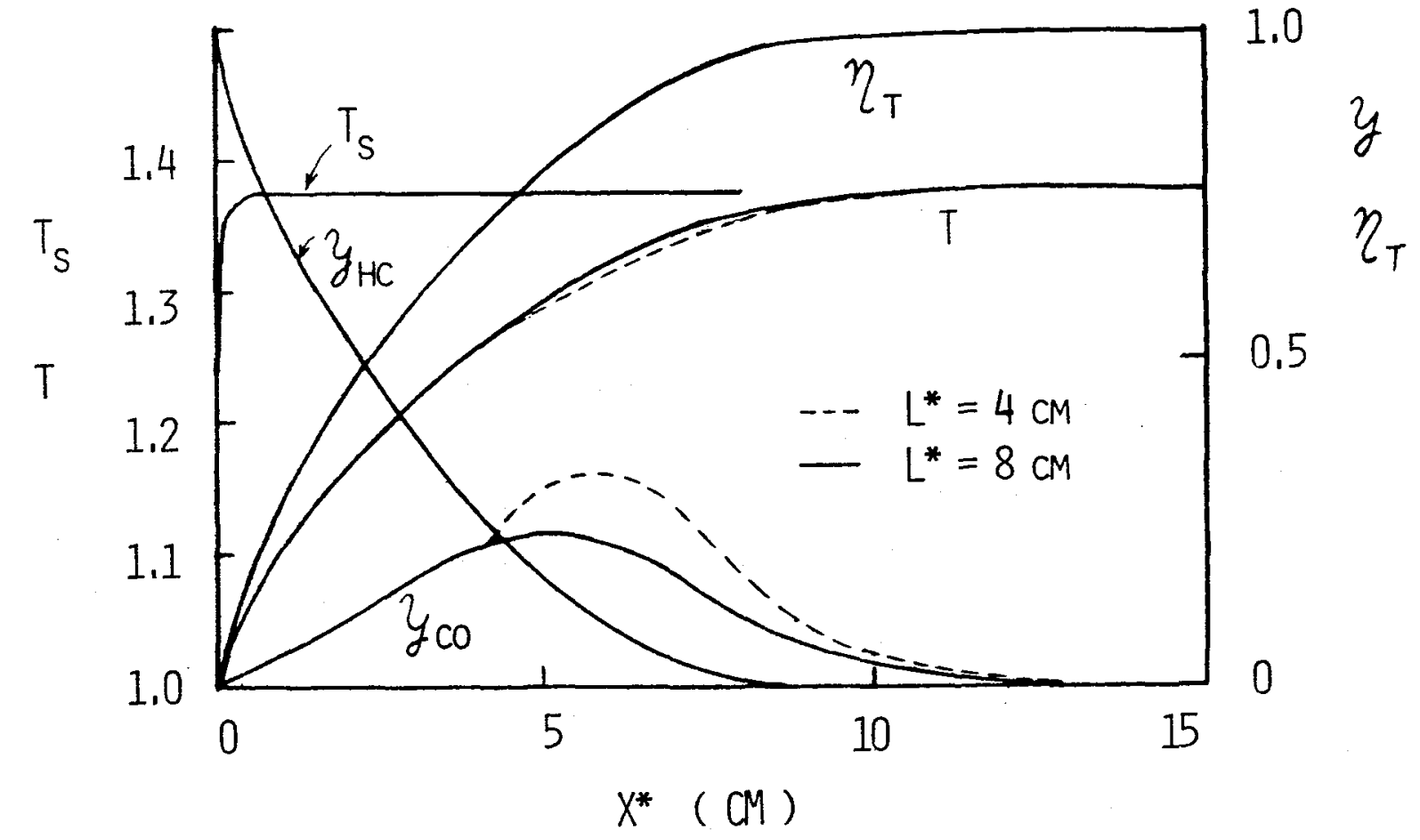

Figure I.2 Detailed steady-state profiles showing the effect of catalytic bed length. Operating conditions: $\mathrm{p}^{*}=3 \mathrm{~atm}, \mathrm{~T}_{\text {in }}^{*}=1000^{\circ} \mathrm{K}$, $\mathrm{u}_{\text {ref }}^{*}=10 \mathrm{~m} / \mathrm{s}, \phi=0.15, \mathrm{~d}^{*}=1.8 \mathrm{~mm}$ and $\mathrm{A}^{*} / \mathrm{A}_{\mathrm{T}}^{*}=.667$. 
also shows a difference after $4 \mathrm{~cm}$ but the difference is too small to be shown clearly in this figure. The gas temperature is also lower in a portion of the combustor for the $4 \mathrm{~cm}$ case.

Fig. I.3 gives the combustor residence time required to reach the emission goal vs. the residence time in the catalytic bed. The "catalytic bed residence time", $t_{b}^{*}$, is defined by $I^{*} A^{*} / U_{\text {ref }}^{*} A_{T}^{*}$, where $U_{\text {ref }}^{*}$ is the gas velocity upstream of the bed and the gas velocity inside the catalytic channel at the channel entrance is $U_{\text {ref }}^{*} A_{T}^{*} / A^{*}$, due to the area change. To be exact, the gas residence time in the bed should be $\int_{0}^{L^{*}} 1 / U^{*} d x^{*}$ since the gas velocity in the channel, $U^{*}$, is changing continuously downstream due to the heat release. However, since $U^{*}(x)$ is not known until the solution is achieved, the catalytic bed residence time, $t_{b}^{*}$, as defined in Fig. I. 3 is a good reference quantity and it is with this understanding when we use the terms of "bed residence time" and "combustor residence time". Referring to the curve and the calculated points corresponding to $\mathrm{T}_{\text {in }}^{*}=1000 \mathrm{~K}$ in Fig. I. 3 we see that the residence times provide an exce11ent correlation for different values of $U_{\text {ref }}^{*}, L^{*}, A^{*} / A_{T}^{*}$ and the required $L_{\text {as }}^{*}$ to reach emission goals. As the catalytic bed residence time, $t_{b}^{*}$, increases, the total combustor residence time required to reach emission goals, $t_{E G}^{*}$, first decreases sharply and then levels off. The two other curves in Fig. I.3 give the effects of different combustor inlet temperatures. Higher inlet temperature required lower combustor residence time to reach emission goals for a fixed catalytic bed residence time. At $1200 \mathrm{~K}$ inlet temperature, no catalytic element is needed; emission goa?s can be reached in an acceptable gas residence time for a plug flow combustor without flame stabilizer $\left(t_{b}{ }^{*}=0\right.$ and $T_{E G}^{*}=14$ seconds $)$. This has been verified by the recent 


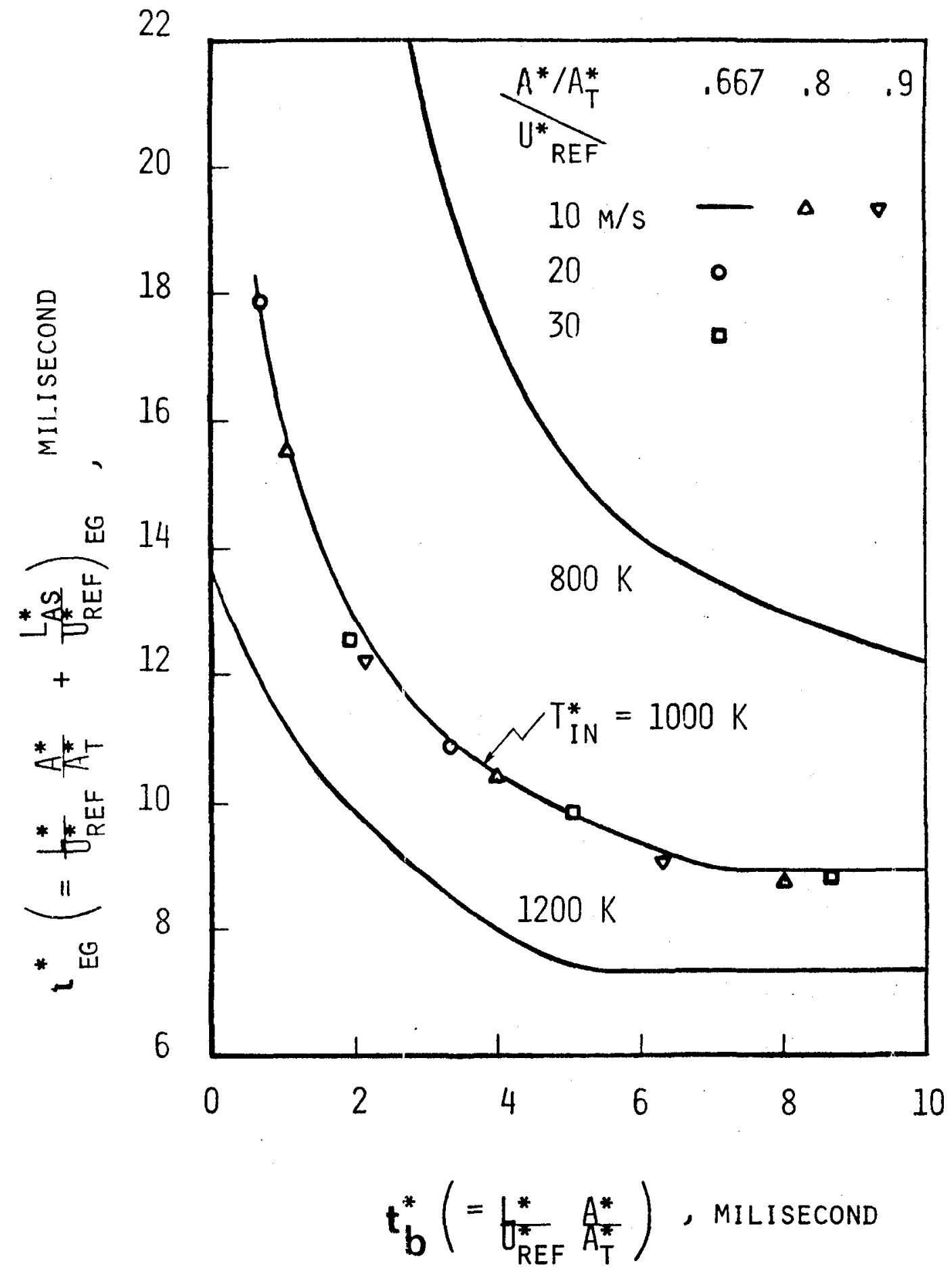

Fig. I.3 Minfmum total combustor gas residence time for reaching emission goals $\left(t_{\mathrm{EG}}^{*}\right)$ vs. reactor bed residence time $\left(t_{b}^{*}\right)$ as a function of combustor ${ }^{\mathrm{E}}$ inlet temperature in steady-state operation. $\mathrm{p}^{*}=3 \mathrm{~atm}$, $\mathrm{d}^{*}=1.8$ mon and $\mathrm{T}_{\mathrm{af}}^{*}=1370 \mathrm{~K}$. 
experimental results of Anderson (1980b). Anderson's study also suggested the correlation using gas residence times (1980a).

\section{Transient Response}

One of the major concerns of the catalytic combustor application to transportation gas turbine engines is that the response time might be long. The computed transient results to be presented are combustor response to a stepwise increase of fuel flow rate (zero to a fixed value). Its purpose is to guide the search for "fast-response" catalytic combustor designs.

Some indication of the order of magnitude of the response time can be obtained from the definition of the characteristic time $r *$ as defined in $\mathrm{Eq}$ (16). Small $\tau^{*}$ requires small thermal inertia, $\mathrm{AS}_{\mathrm{S}}^{*} \mathrm{~S}_{\mathrm{S}}^{*}$. If the substrate density and heat capacity are fixed, small $\tau *$ can be achleved with small solid crossectional area $A_{\mathrm{S}}^{*}$, see Fig.I.l for definition of $\mathrm{A}_{\mathrm{S}}^{*}$. It should be noted that there are other parameters such as catalytic bed length and channel diameter which will influence the response time and they are not contained in $\tau^{*}$. This will be discussed later as we see the computed results.

The combustion efficiency at the end of the combustor will be used to characterize the combustor response time. There are two ways to define the combustion efficiency. One is the so-called "carbon-balanced" efficiency, ${ }^{\eta_{C B}}$ [Anderson, 1975], where the combustion inefficiency is measured by the emission levels of CO and UHC and the energy carried away by them. The other efficiency is the ordinary one defined by the enthalpy rise across the combustor divided by the chemical energy available. If the gas specific heat is approximated as a constant, this efficiency, $\eta_{T}$, is given by $\left(\mathrm{T}^{*}-\mathrm{T}_{\text {in }}^{*}\right) /\left(\mathrm{T}_{\text {af }}^{*}-\mathrm{T}_{\text {in }}^{*}\right)$ where $\mathrm{T}^{*}$ is measured at the same location as the efficiency. For a perfectly insulated catalytic combustor in steady state, 
${ }^{\eta_{C B}}$ and $\eta_{T}$ are the same. However, the two are different in transient operations when there is a thermal lag in the substrate.

For the following transient calculation, the initial surface temperature condition is given by $T_{S}(x, 0)=1$, see $\mathrm{Eq}(21)$. For $1000^{\circ} \mathrm{K}$ inlet temperature, two bed lengths, $4 \mathrm{~cm}$ and $8 \mathrm{~cm}$, are chosen for the transient calculation and efficiency is evaluated at their individual minimum combustor lengths according to Fig.I.3. Fig.I.4 shows the combustion efficiencies as a function of non-dimensional time. Looking at the curves for $\eta_{T}$ (efficiency based on temperatures), the shorter bed $(4 \mathrm{~cm}$ ) combustor has a faster response than that of the longer bed $(8 \mathrm{~cm})$. If we take the time for $\eta_{T}$ to reach $80 \%$ as an indication of characteristic response time, for the $4 \mathrm{~cm}$ bed, $t_{C h}=1.5$ and for the $8 \mathrm{~cm}$ bed, $t_{\mathrm{ch}}=2.5$; namely, the response time of $4 \mathrm{~cm}$ bed combustor is only $60 \%$ of that of the $8 \mathrm{~cm}$ bed combustor. From the consideration of steady-state operation alone, one would choose the $8 \mathrm{~cm}$ catalytic bed since, as can be deduced from Fig.I.3, this produces the shortest required combustor length $(11 \mathrm{~cm})$. However, combining transient and steady-state considerations, the $4 \mathrm{~cm}$ bed combustor may be a better choice as its response time is $60 \%$ of that of the $8 \mathrm{~cm}$ bed, with the total combustor length only slightly longer.

To understand why longer reactor bed results in a longer response time, surface and gas temperature distributions are plotted in Fig. T.5 as a function of time. From the substrate temperature distribution we see that during start-up transient, the solid temperature is higher in the flow entrance region as a result of higher mass transport and surface reaction rates. Comparing the solid and gas temperature histories for the case when catalytic bed length is $8 \mathrm{~cm}$, we see that at $t=0.5$, the solid is 


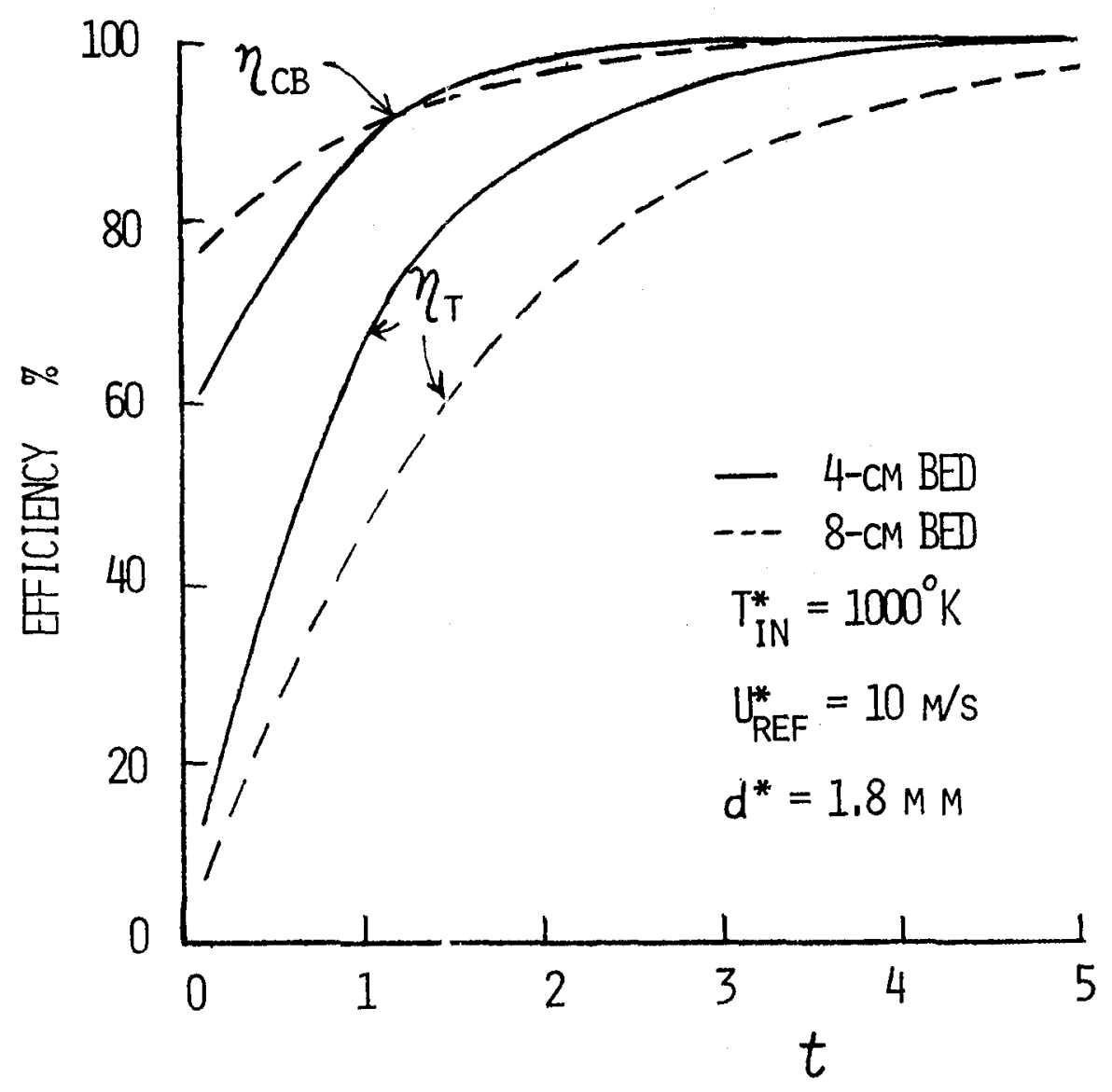

Fig. I.4 Combustion efficiencies as a function of time during start-up transient. $\mathrm{p}^{*}=3 \mathrm{~atm}, \phi=0.15$ and $\mathrm{A}^{*} / \mathrm{A}_{\mathrm{T}}^{*}=.667$. 

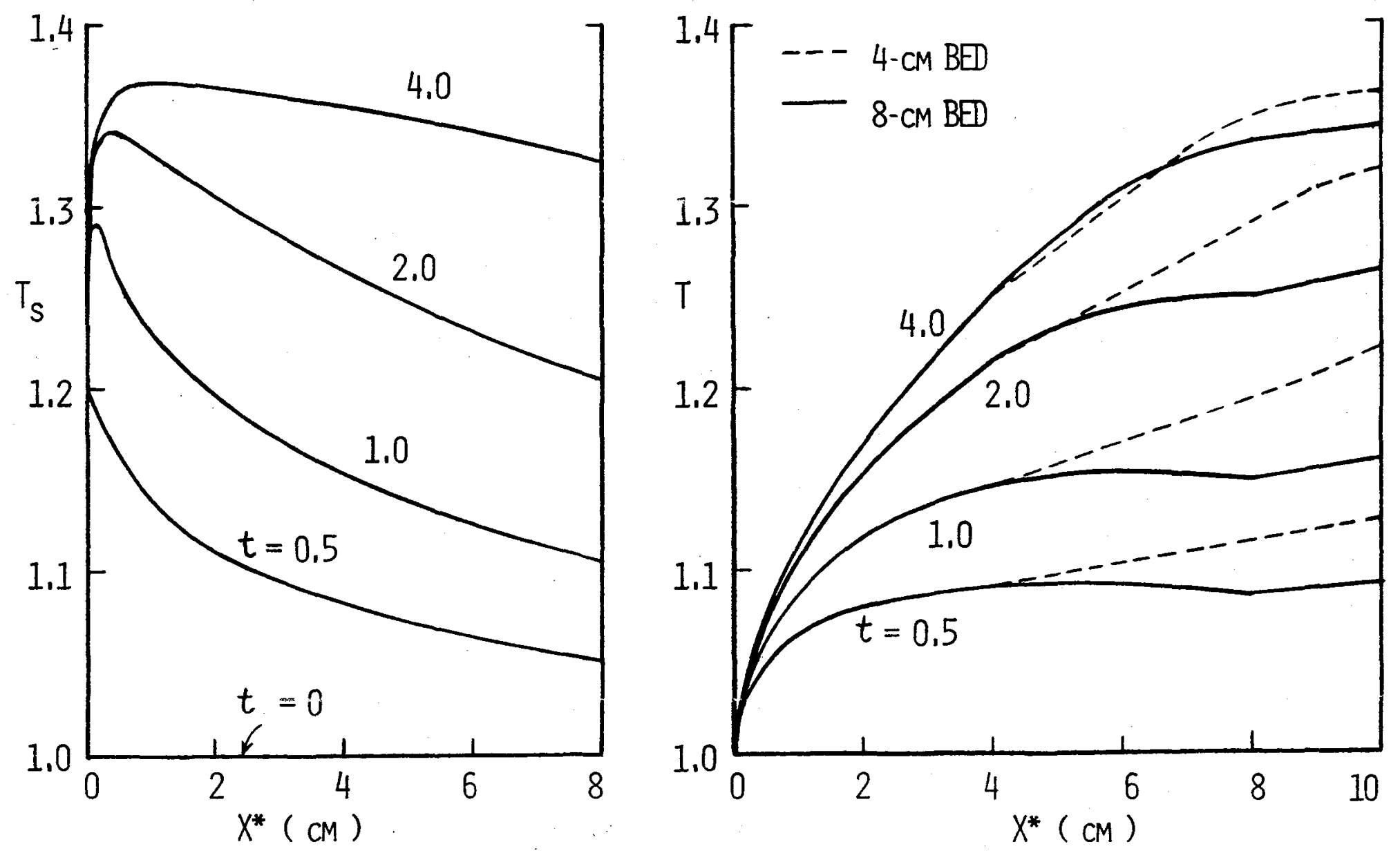

Fig.I.5 Gas and substrate temperature history during transient start-up for two bed lengths. Same operating and design parameters as those in Fig. I.4. 
transfering heat to the gas in the upstream region in the bed. At $\mathrm{x}^{*}=3.5 \mathrm{~cm}$, the gas temperature becomes higher than the substrate temperature, heat is then transferred from the gas to the solid in the down-stream portion of the reactor channel. If the heat loss rate is greater than heat generation rate due to gas phase reactions, then the gas temperature will drop as shown in Fig.I.5. If we cut the reactor bed short at $4 \mathrm{~cm}$, a portion of this heat 10 ss can be eliminated and the downstream gas temperature $\left(x^{*}>4 \mathrm{~cm}\right)$ will be higher as indicated by the dotted curves in Fig.I.5. This explains why a shorter reactor bed can have a faster response.

More computation of the response time dependence on the catalytic bed length, gas velocity and combustor inlet temperature is shown in Fig. I.6. As will be shown later, the nondimensional transient response also correlates well with the gas residence times in the reactor bed and the after-bed space. Therefore the results will be presented using residence times rather than length and velocity. In Fig.1.6, the adiabatic flame temperature, pressure, channel diameter, open area fraction and $\mathrm{L}_{\mathrm{c}}^{*} \mathrm{U}_{\text {ref }}^{*}$ are held constant. The solid line in Fig.I.6 gives the response time if the reactor-bed-gas-residence time is the minimum to reach emission goals in steady-state operations. When the combustor inlet temperature is increased, the minimum required reactorbed-residence time is decreased and the combustor response time is shortened drastically. If a more conservative design is used, i.e. longer bed residence time than is required, the combustor response time is increased for a fixed inlet temperature. The increase is very slight in the beginning when the bed residence time is close to the optimum value but becomes larger as the bed residence time increase further. This implies that a conservative 


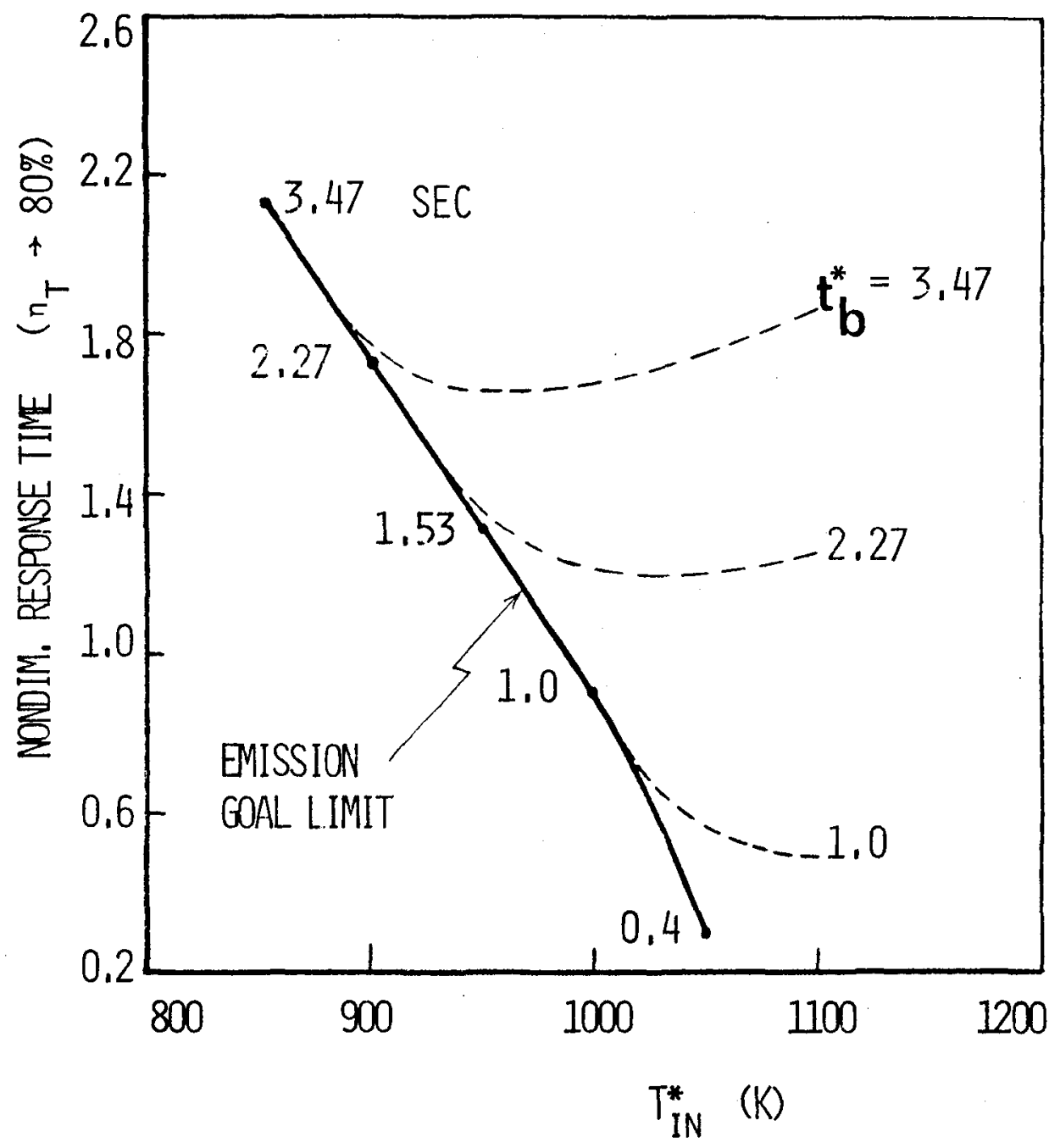

Fig.I.6 Nondimensional response time ( $\eta_{\text {T }}$ goes to $80 \%$ ) as a function of combustor inlet temperature and reactor bed residence time. $\mathrm{L}_{\mathrm{c}}^{*} / \mathrm{U}_{\mathrm{ref}}^{*}=15 \mathrm{msec}, \mathrm{T}_{\mathrm{af}}^{*}=1370 \mathrm{~K}, \mathrm{~A}^{*} / \mathrm{A}_{\mathrm{T}}^{*}=.667, \mathrm{~d}^{*}=1.8 \mathrm{~mm}$ and $\mathrm{p}^{*}=3 \mathrm{~atm}$. 
design with reactor bed length somewhat longer that that of the optimal one will not greatly increase the combustor response time.

Fig.I.7 gives the nondimensional response time as a function of channel hydraulic diameter and flame temperature. For all the calculations in Fig.I.7 the residence time in the catalytic bed, $t_{b}^{*}$, is held constant at 1 milisecond and the residence time in the after-bed space, $t_{a s}^{*}$, is 13.5 miliseconds. The computation for $1370 \mathrm{~K}$ and $1590 \mathrm{~K}$ includes different combinations of $\mathrm{L}^{*}$, $\mathrm{L}_{\text {as }}^{*}$, $U_{\text {ref }}^{*}$ and $A^{*} / A_{S}^{*}$ and it can be seen from Fig.I.7 that the nondimensional response time correlates well with the residence times. It can, therefore, be concluded that the primary influence of the catalytic bed and after-bed lengths, the approaching gas velocity and the open area percentage is contained in the gas residence times in the catalytic bed and in the after-bed space for both steady and transient operations.

Fig. I.7 also shows that for a given flame temperature, the nondimensional response time increases with decreasing channel diameter $d^{*}$. This, however, does not necessarily mean that the dimensional response time increases with decreasing $d^{*}$. If the open area percentage (or equivalently $A^{*} / A_{S}^{*}$ ) is fixed, decreasing $d^{*}$ decreases $A_{\mathrm{S}}^{*}$ which is used in the reference time scale as defined in Eq (16) and the dimensional response time may actually decrease. Table I.3 gives selected dimensiona? response times for ceramic and Kanthal metal alloy substrates using the computed results from Fig.I.7. It can be seen that in general the dimensional response time decreases with decreasing channel diameter but the amount of decrease vanishes when the channel diameter becomes too sma11. In special cases such as the $1590 \mathrm{~K}$ flame temperature case, the response time actually reaches a minimum and increases with further diameter decrease. 


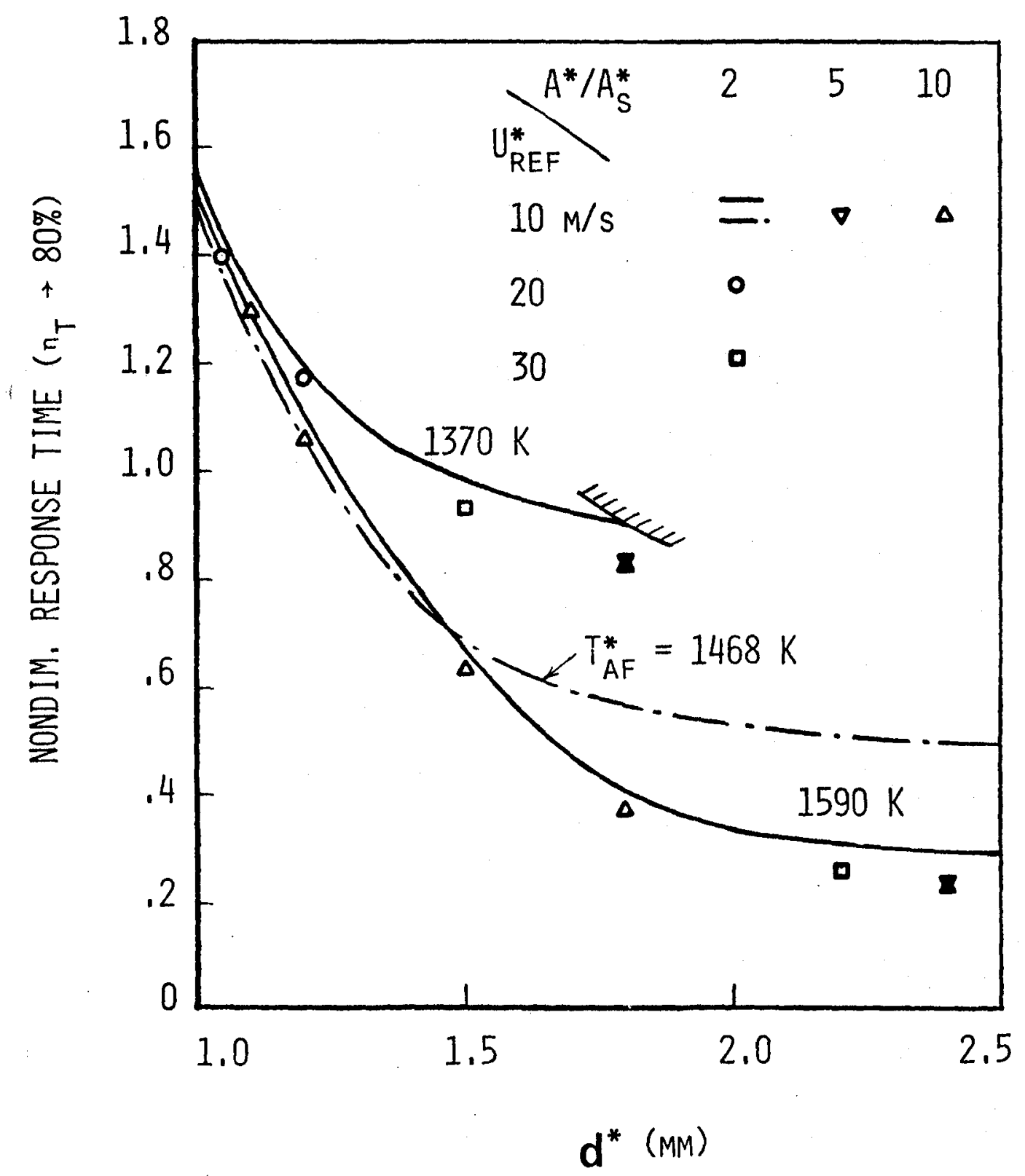

Fig. I.7 Computed nondimensional catalytic combustor response time correlation with gas residence times for various channel diameters and flame temperatures. $p^{*}=3 \mathrm{~atm}, t_{b}^{*}=1 \mathrm{msec}$, $t_{\text {as }}^{*}=13.5 \mathrm{msec}, \mathrm{T}_{\text {In }}^{*}=1000 \mathrm{~K}$. 
Table I.3 Computed Catalytic Combustor Response TIme Using Ceramic and Kanthal Meta1 Substrates.

$t_{b}^{*}=1 \mathrm{msec}, \mathrm{t}_{\mathrm{as}}^{*}=13.5 \mathrm{msec}, \mathrm{p}^{*}=3 \mathrm{~atm}, \mathrm{~T}_{\text {in }}^{*}=1000 \mathrm{~K}$

\begin{tabular}{lcccc}
$\mathrm{T}_{\mathrm{af}}^{*}(\mathrm{~K})$ & $\mathrm{A}^{*} / \mathrm{A}_{\mathrm{s}}^{*}$ & $\mathrm{~d}^{*}(\mathrm{~mm})$ & $\begin{array}{c}\mathrm{t}_{\mathrm{r}}^{*}(\mathrm{sec}) \\
\text { ceramic }\end{array}$ & $\begin{array}{c}\mathrm{t}_{\mathrm{r}}^{*}(\mathrm{sec}) \\
\text { Kantha1 alloy }\end{array}$ \\
\hline 1370 & 10 & 1.8 & .848 & 1.52 \\
1370 & 10 & 1.0 & .451 & .807 \\
1468 & 10 & 2.5 & .909 & 1.63 \\
1468 & 10 & 1.8 & .533 & .956 \\
1468 & 10 & 1.0 & .454 & .813 \\
1590 & 10 & 2.5 & .527 & .944 \\
1590 & 10 & 1.8 & .377 & .675 \\
1590 & 10 & 1.0 & .448 & .802 \\
1590 & 5 & 1.8 & .754 & 1.35 \\
1590 & 2 & 1.8 & 1.88 & 3.37
\end{tabular}


If the gas residence times and channel diameter are held constant, varying the open area percentage (or $A^{*} / A_{S}^{*}$ ) changes the dimensional response time by a factor of $\mathrm{A}_{\mathrm{S}}^{*} / \mathrm{A}^{*}$. This is the direct consequence of the correlation between nondimensional response time and residence times as just discussed. Large open area percentage (or thin substrate), therefore, favors fast response. FigI.7 indicates higher flame temperature shortens the response time for large diameter channel but flame temperature makes little difference in response time for very small diameter channels as all curves converge. 
CHAPTER II STEADY STATE COMPUTATTON AND COMPARISON WITH EXPERTMINTS

\section{II.1 Three-step Semi-global gas-phase Chemical Reactions}

Gas phase reaction studies between hydrocarbons and air in lean mixtures have shown (Dryer and Glassman, 1978) that the hydrocarbon fuel first decomposes into a number of lower hydrocarbons with the simulataneous formation of some water vapor. The combination of these "pyrolysis" steps results in an almost isothermal region after which $\mathrm{CO}$ is formed and temperature begins to rise. The carbon monoxide is then oxidized and the reactions are completed. These kinetic studies are very useful for the development of semi-global kinetic schemes.

Two recent catalytic combustion models, by Bracco et al (1980) and $T^{\prime}$ ien (1980), have utilized the gas phase semi-global modeling concept. The study by $\mathrm{T}^{\prime}$ ien was actually for transient response but a quasisteady gas phase was assumed. The gas phase reactions consist of two semi-global steps; the hydrocarbon reacts with oxygen to form $\mathrm{CO}$ and $\mathrm{H}_{2} \mathrm{O}$ and $\mathrm{CO}$ then reacts with oxygen to form $\mathrm{CO}_{2}$. On the surface, both hydrocarbon and co react with oxygen to form $\mathrm{CO}_{2}$ and or $\mathrm{H}_{2} \mathrm{O}$. The steady-state prediction of that model agrees qualitatively with the experimental trend of $\mathrm{CO}$ and hydrocarbon emissions, but a quantitative comparison has not been made. From a pure gas phase reaction point of view, two-step semi-global scheme predicts too high a level of CO in the initial pyrolysis region even though the co peak level and the decay curve can be made to agree with the experimental data by kinetic parameter adjustment. This early $C O$ appearance problem can be alleviated to a certain 
extent by increasing the number of appropriate semi-global gas reaction steps. In the work by Bracco et al (1980), for example, a three-step reaction scheme was used for propane oxidation. Propane $\left(\mathrm{C}_{3} \mathrm{H}_{8}\right)$ was assumed to form $\mathrm{C}_{2} \mathrm{H}_{4}$ first, $\mathrm{C}_{2} \mathrm{H}_{4}$ to $\mathrm{CO}$ next and then $\mathrm{CO}$ to $\mathrm{CO}_{2}$.

For most practical fuels, the pyrolysis intermediates are numerous, and a dominant intermediate species may or may not exist. Since in high inlet temperature operations $\left(\mathrm{T}_{\text {in }}^{*}>800^{\circ} \mathrm{K}\right.$ ), the catalytic combustor length required is Iimited by the emission level of CO, not hydrocarbons (Anderson, 1980a), it seems reasonable to develop a scheme which gives the correct co characteristics without being tied down by the uncertain nature of the hydrocarbon intermediates.

In this chapter, the steady-state computation will be based on a threestep gas-phase kinetic scheme. The semi-global reactions are:

$$
\begin{aligned}
& \text { (A') } C_{n} H_{m} \rightarrow C_{n} H_{m}^{(p)} \\
& \frac{d\left[C_{n} H_{m}\right]}{d t^{\star}}=-C_{0}^{\star} p^{\star \gamma} I\left[C_{n} H_{m}\right]^{\gamma_{2} T^{\star} \gamma_{3} \exp \left(-E_{0}^{\star} / R T^{\star}\right)}
\end{aligned}
$$

$\left(A^{\prime \prime}\right)$

$$
\begin{aligned}
& C_{n} H_{m}(p)+\frac{1}{2}\left(n+\frac{m}{2}\right) O_{2} \rightarrow n C O+\frac{m}{2} H_{2} 0 \\
& \left.\frac{d\left[C_{n} H_{m}^{(p)}\right]}{d t^{*}}=-C_{1}^{*} p^{*}{ }_{1}^{\alpha} C_{n} H_{m}^{(p)}\right]^{\alpha}\left[O_{2}\right]^{\alpha} T^{* \alpha}{ }_{4} \exp \left(-E_{1}^{*} / R T^{\star}\right)
\end{aligned}
$$


(B) $\mathrm{CO}+\frac{1}{2} \mathrm{O}_{2} \rightarrow \mathrm{CO}_{2}$

$$
\begin{aligned}
\frac{d[\mathrm{CO}]}{d t^{*}}=- & C_{2}^{*} \mathrm{p}^{\star \beta_{1}}[\mathrm{CO}]_{2}^{\beta_{2}}\left[\mathrm{O}_{2}\right]^{\beta_{3}}\left[\mathrm{H}_{2} \mathrm{O}\right]^{\beta} 5 T^{* \beta_{4}} \times \\
& \exp \left(-E_{2}^{\star} / \mathrm{RT}^{\star}\right)
\end{aligned}
$$

In reaction $\left(A^{\prime}\right), E q .(22)$, the original hydrocarbon fuel forms the "pyrolyzed hydrocarbon", $\mathrm{C}_{\mathrm{n}} \mathrm{H}(\mathrm{p})$, in an isothermal reaction. The "pyrolyzed hydrocarbon" then reacts with oxygen to form $\mathrm{CO}$ and $\mathrm{H}_{2} \mathrm{O}$ in reaction ( $\mathrm{A}^{\prime \prime}$ ). In reaction (B), $\mathrm{CO}$ is oxidized to $\mathrm{CO}_{2}$. The introduction of reaction ( $\mathrm{A}^{\prime}$ ) serves to decrease the amount of early co appearance as found using the two-step model. The identity of $\mathrm{C}_{\mathrm{n}} \mathrm{H}_{\mathrm{m}}^{(\mathrm{P})}$ is of no great consequence for the purpose of this modeling work, if the mass diffusion coefficient is properly evaluated. For convenience, in the present calculation we take $\mathrm{C}_{n} \mathrm{H}_{\mathrm{m}}^{(\mathrm{P})}$ to have the same $\mathrm{n}$ and $\mathrm{m}$ as the original fuel.

Corresponding to the reactions given by Eqs. (22-24), the species equations are:

Original Hydrocarbon:

$$
\rho u \frac{d y_{H C}}{d x}+J_{D_{I}}\left(y_{H C}-y_{H C, s}\right)=-w_{0}
$$


"pyrolyzed" Hydrocarbon:

$$
\rho u \frac{d Y_{H C}^{(p)}}{d x}+J_{D 1}\left(y_{H C}^{(p)}-y_{H C, s}^{(p)}\right)=w_{0}-w_{1}
$$

Carbon monoxide:

$$
\rho u \frac{d y_{C O}}{d x}+J_{D_{2}}\left(y_{C O}-y_{C O, s}\right)=w_{1} c_{n}-w_{2}
$$

Oxygen:

$$
y_{0_{2}}=1-\phi\left(1-\xi_{T H C}\right)+\frac{1}{2} \quad y_{C O}\left(\frac{Y_{H C}(0)}{Y_{O_{2}}(0)} \frac{W_{O_{2}}}{W_{C O}}\right)
$$

where

$$
y_{T H C}=y_{H C}+y_{H C}
$$

The reaction rates are given by

$$
\begin{aligned}
& w_{0}=B_{0} p^{\gamma_{1}} \gamma_{2} T^{\gamma_{3}} y_{H C}^{\gamma_{2}} \exp \left(-E_{0} / T\right) \\
& w_{1}=B_{1} p^{\alpha_{1}}\left(\alpha_{2}+\alpha_{3}\right)_{T^{\alpha}} y_{H C}^{\alpha_{2}} y_{0}^{\alpha_{3}} \exp \left(-E_{1} / T\right) \\
& w_{2}=B_{2} p^{\beta_{1}}\left(\beta_{2}+\beta_{3}+\beta_{5}\right)_{T} \beta_{4} y_{C D}^{\beta_{2}} y_{0}^{\beta_{3}} Y_{H_{2}}^{\beta_{5}} \exp \left(-E_{2} / T\right)
\end{aligned}
$$

and

$Y_{H_{2} O}(x)=\frac{m}{2} \frac{W_{H_{2}} O}{W_{H C}} Y_{H C}(0)\left[y_{T H C}(0)-y_{T H C}(x)\right]$ 
Three global catalytic surface reactions are assumed to occur on the surface. They are:

(c') $\mathrm{C}_{n} \mathrm{H}_{m}+\left(\mathrm{n}+\frac{\mathrm{m}}{4}\right) \mathrm{O}_{2}+\mathrm{nCO}_{2}+\frac{m}{2} \mathrm{H}_{2} \mathrm{O}$

with the corresponding surface rate $J_{3}^{\star}$ given by

$$
J_{3}^{*}=C_{3}^{*}\left[C_{n} H_{m}\right]_{s} \exp \left(-E_{3}^{*} / R T_{s}^{*}\right)
$$

(c") $\mathrm{C}_{n} \mathrm{H}_{m}^{(p)}+\left(n+\frac{m}{4}\right) \mathrm{O}_{2}+n \mathrm{CO}_{2}+\frac{m}{2} \mathrm{H}_{2} \mathrm{O}$

with $J_{4}^{*}=C_{3}^{\star}\left[C_{n} H_{m}^{(p)}\right]_{S} \exp \left(-E_{3}^{*} / R T_{s}^{*}\right)$

(D) $\mathrm{CO}+\frac{1}{2} \mathrm{O}_{2}+\mathrm{CO}_{2}$

with $J_{5}^{*}=C_{4}^{*}[C O]_{S} \exp \left(-E_{4}^{*} / R T_{S}^{*}\right)$

Other equations are similar to those in Chapter $I$. The steady solution is obtained from the transient combustion code as discussed in Chapter I. 


\section{II.2 Computed Results}

The design parameters of a catalytic combustor include the catalytic bed length, the after-bed reaction distance, the channe1 hydraulic diameter, the open area percentage, the catalyst variables (catalyst type, loading density, washcoat type) and staging arrangements (graded cel1, for example). The operating parameters include inlet temperature and pressure, the approaching (reference) mixture velocity, the fuel/air equivalence ratio or the adiabatic flame temperature and fuel types. An exhaustive parametric study will not be practical for this report. Instead, selected computations are presented. Since emphasis is placed on automotive gas turbine application, we are most interested in higher inlet temperature, above atmospheric pressure and high reference velocity operations with thin substrate and large open area percentage design. The total combustor length (bed plus after-bed) required to meet the emission goal $(13.6 \mathrm{~g} \mathrm{Co} / \mathrm{kg}$ fuel, $1.64 \mathrm{~g} \mathrm{THC} / \mathrm{kg}$ fuel) as a function of these parameters is the main output of the model calculation.

The chosen fuel is No. 2 Diesel which was used by Anderson (1977a, 1978, 1980a). Its hydrogen-carbon atom ratio is 1.8 with $27.55 \%$ aromatics. The molecular weight is taken to be 138 for the purpose of estimating the diffusion coefficient which is assumed to vary as one over the square root of molecular weight. Other properties can be found in Anderson (1977a). The catalytic combustor used for reference calculation is the one by Matthey Bishop which was also described by Anderson (1980a) (MBI-2.5 and MBI-5.4). The values of kinetic parameters are listed in Table II.1. Expressions in Reactions $A^{\prime \prime}$ to D are taken from Edelman and Fortune (1969), Dryer and Glassman (1973), Marteney (1979) and Kuo and Morgan (1971) respectively, all with adjusted pre-exponential 
Table II.1 Chemica1 Kinetic Constants

(for Chapter II)

\begin{tabular}{|c|c|c|c|c|}
\hline Reaction $\left(A^{\prime}\right)$ & Reaction ( $A^{\prime \prime}$ ) & Reaction (B) & Reactions $\left(\mathrm{C}^{\prime}\right)\left(\mathrm{C}^{\prime \prime}\right)$ & Reaction (D) \\
\hline$C_{0}^{*}=1.6 \times 10^{6}$ & $C_{1}^{*}=1.8 \times 10^{5}$ & $\begin{array}{l}\mathrm{C}_{2}^{*} \mathrm{p}^{{ }^{\beta}}{ }^{1}=.54 \times 10^{14} \\
(\text { at } 3 \mathrm{~atm})\end{array}$ & $C_{3}^{*}=1.5 \times 10^{4}$ & $C_{4}^{\star}=10^{5}$ \\
\hline$\gamma_{1}=0$ & ${ }^{\alpha}{ }_{1}=0.3$ & & $\begin{array}{l}\mathrm{E}_{3}^{*}=10 \\
(\mathrm{kcal} / \mathrm{mole})\end{array}$ & $\begin{array}{c}\mathrm{E}_{4}^{\star}=17.8 \\
(\mathrm{kcal} / \mathrm{mole})\end{array}$ \\
\hline$\gamma_{2}=0.5$ & $\alpha_{2}=0.5$ & $B_{2}=1$ & & \\
\hline$\gamma_{3}=0$ & $\alpha_{3}=1$ & $B_{3}=0.25$ & & \\
\hline & $\alpha_{4}=1$ & $\beta_{4}=0$ & & \\
\hline $\begin{array}{l}\mathrm{E}_{\mathrm{O}}^{*}=34 \\
(\mathrm{kca} 1 / \mathrm{mole})\end{array}$ & $\begin{array}{l}\mathrm{E}_{1}^{*}=24 \\
(\mathrm{kcal} / \mathrm{mole})\end{array}$ & $\begin{array}{l}B_{5}=0.5 \\
E_{2}^{*}=40 \\
(\mathrm{kca} 1 / \mathrm{mo} 1 \mathrm{e})\end{array}$ & & \\
\hline
\end{tabular}


factors. The calculated results are not very sensitive to catalytic kinetic parameters indicating mass transfer dominates the surface reactions. The choice of gas-phase hydrocarbon oxidation kinetic constants deserves some explanation, since kinetic rates for No. 2 Diesel fuel are hard to find. Ignition delay times as a function of initial temperature, however, do exist for long chain and cyclic hydrocarbons (Dryer and Glassman, 1978, Edelman, 1978), which are the ingredients of the Diesel fuel. The ignition delay time of No. 2 Diese1 is assumed to be the arithmetic mean of its ingredients. Model calculations are then performed for pure gas phase reactions and the ratio of calculated hydrocarbons disappearance times as a function of initial temperature is taken to be proportional to the ratio of ignition delay times as indicated in Fig. II.1. This provides some measure for the correct temperature dependence in the gas kinetic parameters for the diese1 fue1. The use of "hydrocarbon disappearance time" in this comparison reflects the difficulty of identifying ignition time in the theoretical study. The pre-exponential factor in reaction (B) is adjusted to fit the Co decay data of Anderson (1980a).

The model calculations for the catalytic combustors will be presented next. Effects of Catalytic Bed Length, Downstream Reaction Distance, Reference Velocity and Adiabatic F1ame Temperature

Figure II.2 shows the detailed profiles of two cases; one with a $5-\mathrm{cm}$ bed and the other with a $2.5-\mathrm{cm}$ bed. If we look at the $5-\mathrm{cm}$ case first, we see when mixture enters into the reactor channel, the fuel is quickly consumed on the surface by catalytic reaction, the surface temperature starts from a low value $\left(T_{S}=1.106\right)$, due to the fast heat and mass transfer rates at the entrance region, and rises sharply away from the channel entrance. The gas 


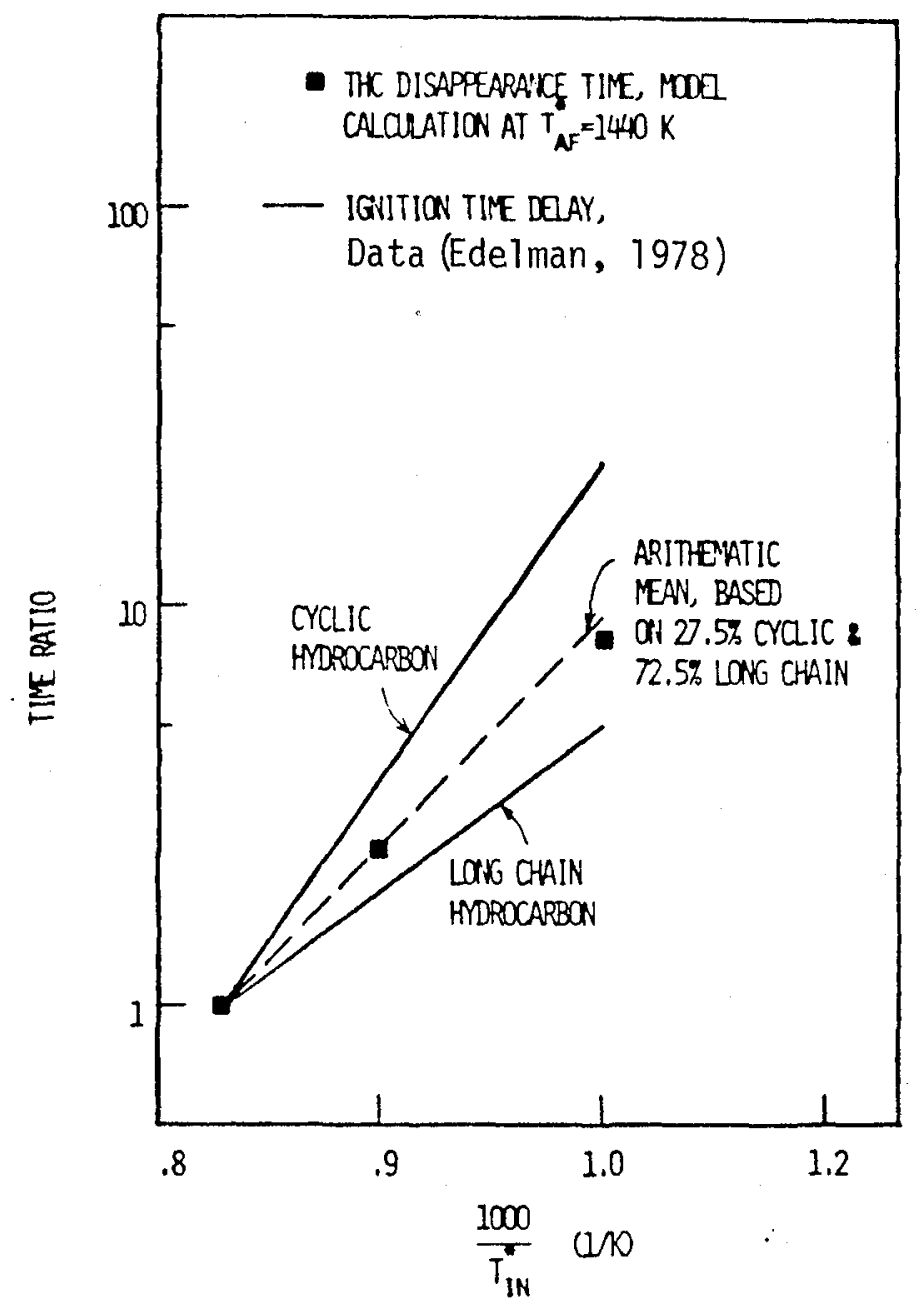

Fig. II.I Comparison of temperature dependence for the computed disappearance time (nondimensional) of Diesel No. 2 fuel with Ignition Delay Data (EdeIman, 1978). Reference time is taken at $1200 \mathrm{~K}$. 


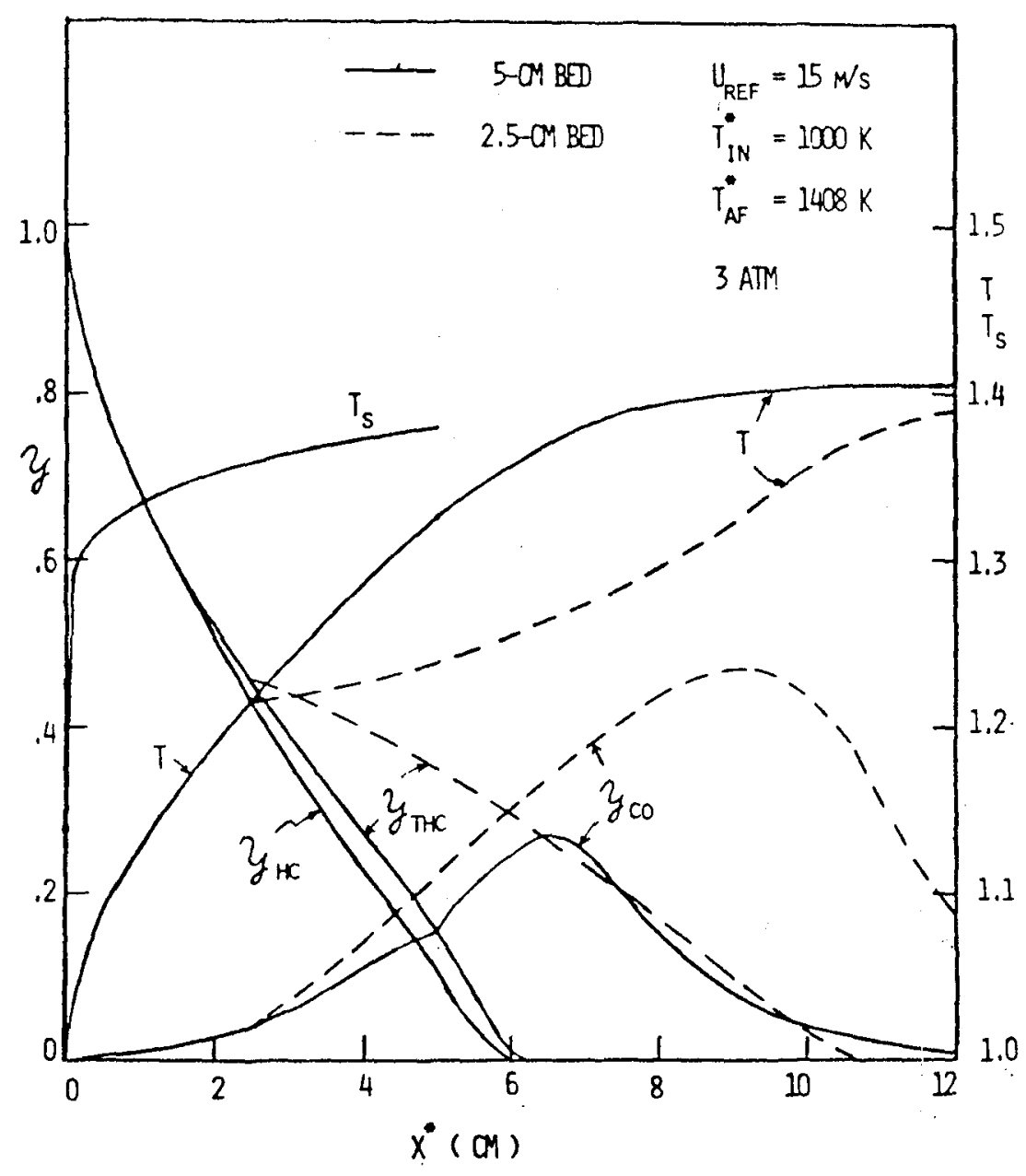

Fig. II.2 Computed temperature and species profiles for two similar cataTytic combustors with different bed lengths, $A^{*} / A_{T}^{*}=0.93$ and $d^{*}=1.382 \mathrm{~mm}$. 
temperature begins to rise due to the heat transfer from the substrate and when $T$ reaches 1.15 , gas-phase reaction is initiated and the hydrocarbon fue1 is converted to the "pyrolyzed hydrocarbon,", which is equal to the difference between $y_{\mathrm{THC}}$ (total hydrocarbon) and $y_{\mathrm{HC}}$ (origina1 hydrocarbon). At the same time, $\mathrm{CO}$, which is produced only in the gas-phase, begins to rise. The carbon monoxide in turn is consumed by both gas-phase and surface reactions to form $\mathrm{CO}_{2}$ until the bed exit is reached. After the exit, $\mathrm{CO}$ is consumed by gas-phase reaction only so a slope discontinuity of the co curve occurs at $x^{*}=5 \mathrm{~cm}$. Similar discontinuity can be found in temperature and hydrocarbons, although in the latter case, it is not very apparent. If at the bed exit the gas temperature is high enough, the gas-phase reaction will continue at a high rate and adiabatic flame temperature is reached at $x^{*}=12 \mathrm{~cm}$. As shown in Fig. II.2, a $\mathrm{CO}$ peak occurs when its production and oxidation rates become equal.

If the catalytic bed is cut short at $2.5 \mathrm{~cm}$. as shown in Fig. II.2, the total hydrocarbon $\left(y_{\mathrm{THC}}\right)$ oxidation rate decreases suddenly at the bed exit $(2.5 \mathrm{~cm})$ due to the absence of surface reaction. Since the gas temperature is not yet high enough, the gas-phase reaction downstream proceeds slowyly as shown by the slower increase of gas temperature. Because a larger fraction of the hydrocarbon fuel has to be consumed in the gasphase reaction, higher $C O$ peak occurs and the total combustor length required to reach the emission goal is accordingly longer than the case with longer catalytic bed.

It was shown in Chapter I that the effects of catalytic bed length, after-bed distance, gas velocity and open area percentage could be corre1ated using reference gas residence times in the reactor bed and in the after- 
bed space. For a fixed open area fraction, this correlation is simplified and can be expressed by the ratios of lengths over the reference velocity as given in Fig. II.3. For a fixed "gas residence time" in the bed ( $\mathrm{L}^{*} / \mathrm{U}_{\text {ref }}^{*}$ ), there is a corresponding minimum combustor residence time ( $\mathrm{L}_{\mathrm{EG}}^{*} / \mathrm{U}_{\text {ref }}^{*}$ ) for emissions goals to be satisfied. Although the residence time correlation is natural for gas-phase reactions, it is less obvious for surface reactions. The validity of this type of correlation is independent of the gas kinetic schemes used as illustrated here and in Chapter I where two-step kinetics and different sets of catalytic parameters were employed.

Fig. II.3 shows that as the catalytic bed length increases, the required combustor length decreases. This may lead one to choose a design which is all reactor bed without the downstream gas reaction space. However, as discussed in Chapter I, in many catalytic combustor applications (e.g., transportation engines), a fast combustor response is required. Longer reactor bed results in a longer response time due to the larger substrate thermal inertia. Therfore, certain compromises may have to be made between steady and nonsteady considerations. Take Fig. II.3, for example, one may want to choose a bed residence time of 4 milliseconds instead of 6 milliseconds. This increases the total combustor length by $15 \%$ but reduces the response time by $30 \%$. As the inlet temperature becomes higher, as preferred by the automotive gas turbine design, the required reactor bed will be drastically reduced, leaving most reactions to occur in the gas-phase. A shorter reactor bed also decreases the pressure loss.

The importance of downstream gas-phase reactions has been recognized by Anderson as demonstrated in much of his work (Anderson, 1977b, 1980a, T'ien and Anderson, 1979). Figure II.4 compares the model calculation with his recent data (Anderson, 1980a) on Co emission index as a function of downstream 


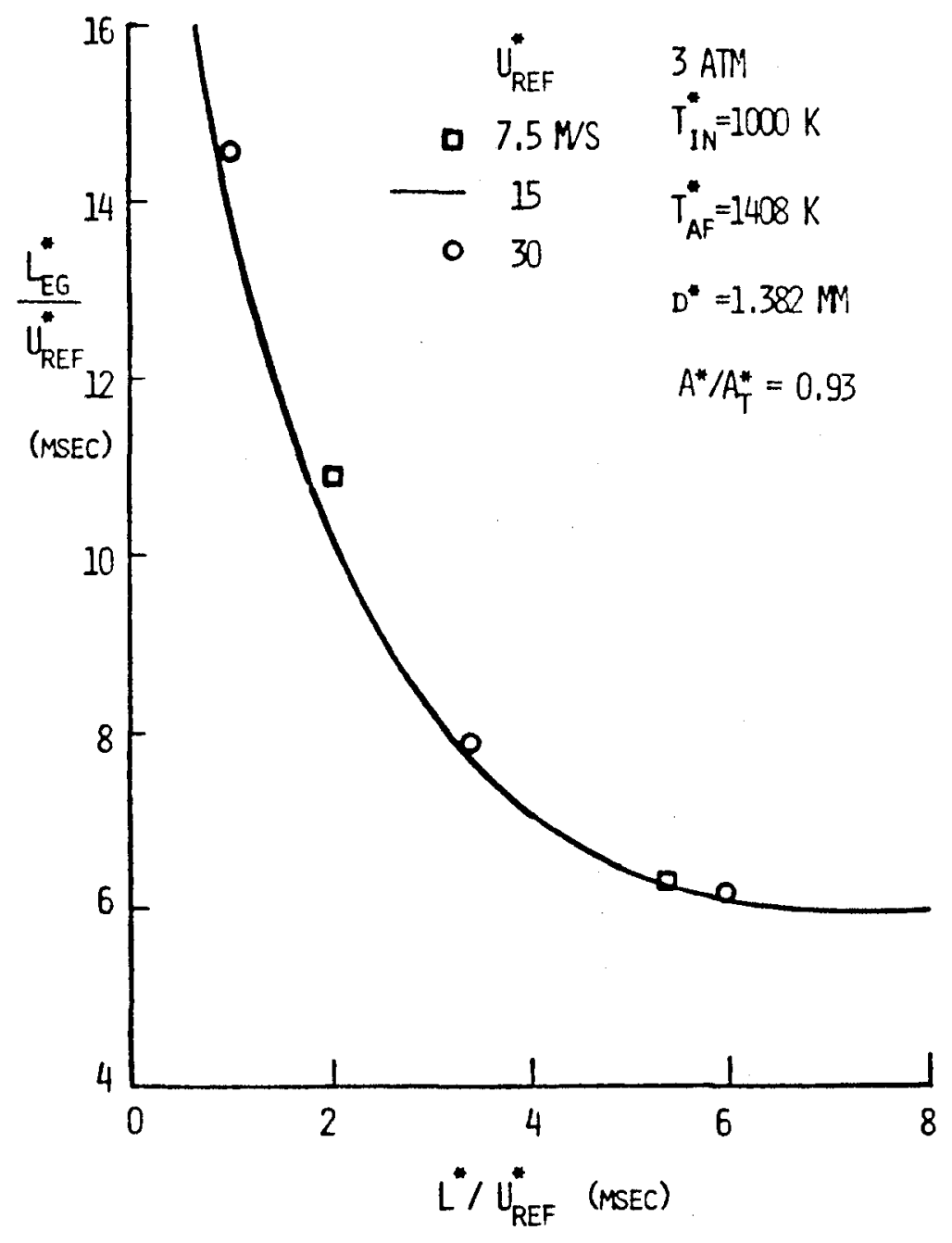

Fig. II.3 Computed "residence time" correlation: total residence time in combustor (bed plus after-bed) to reach emission goals vs. residence time in catalytic beds. 


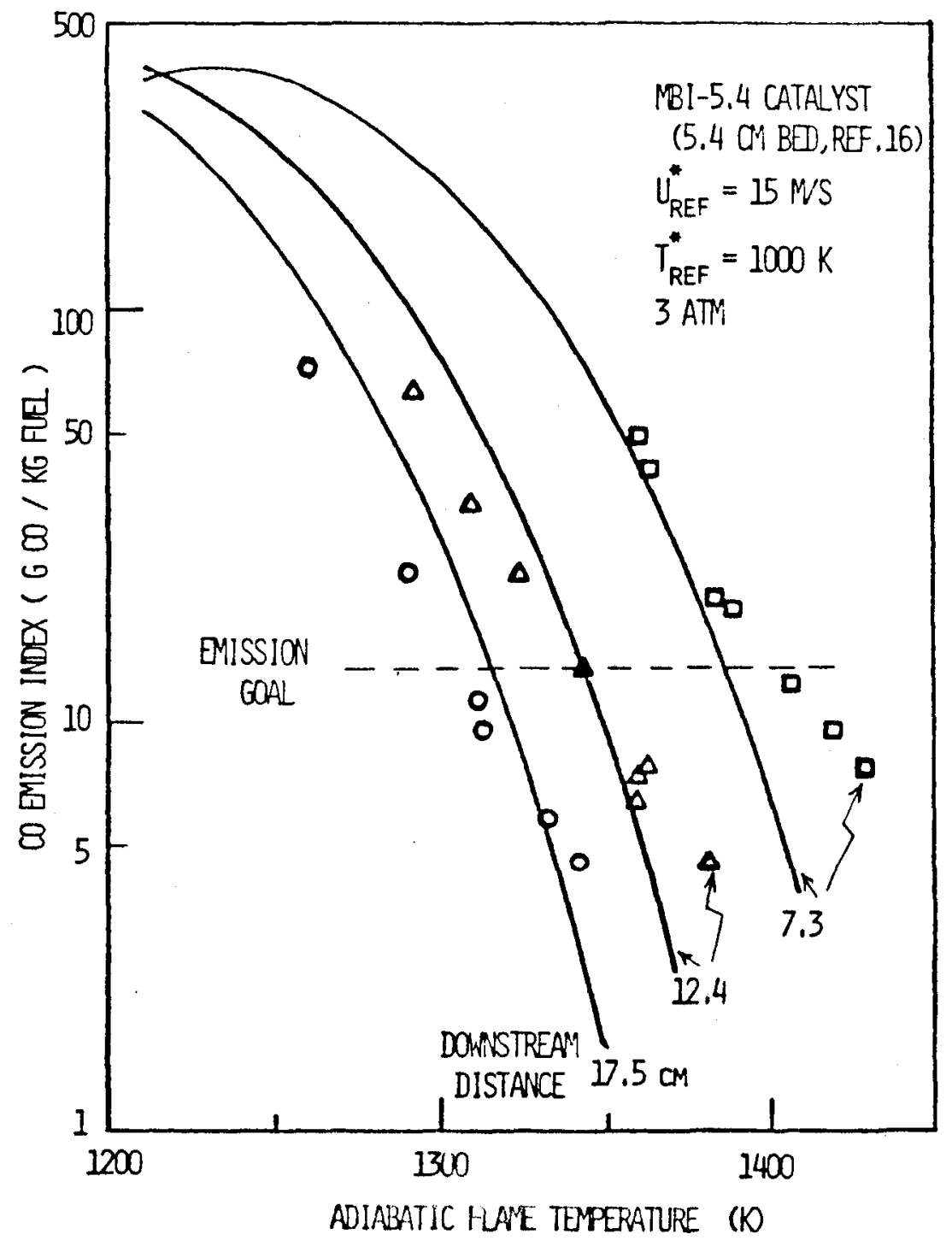

Fig. II. 4 Co emission index vs. adiabatic flame temperature: comparison of model calculation with Anderson's data (1980a). 
reaction distance and adiabatic flame temperature. Figure 11.5 compares the minimum operating flame temperature vs. the downstream reaction distance for two bed lengths and two velocities. The comparison between the model and data is reasonably good within the range of parameters varied.

The appearance of $\mathrm{CO}$ peak as indicated in Fig. II.2 has been reported in previous experimental work ( $T^{\prime}$ ien and Anderson, 1979, Bracco et al, 1980).

\section{Effects of Inlet Temperature and Pressure}

Figure II.6 shows the computed combustion efficiency as a function of adiabatic flame temperature for three inlet temperatures and two pressures at three different downstream locations. For a fixed pressure and adiabatic flame temperature, higher inlet temperature results in a higher efficiency at all three downstream positions. This is consistent with the experimental trend found by Anderson (1978). With higher inlet temperature, the gasphase reaction is initiated earlier which results in a higher efficiency at a fixed location. However, as more residence time is given to the mixture, the difference in efficiency diminishes as can be seen from curves at different locations in Figure II.6.

From Fig II.6, for inlet temperature of $1000 \mathrm{~K}$, the combustion efficiency at $3 \mathrm{~atm}$ is always higher than that at $6 \mathrm{~atm}$. This is because of the faster mass diffusion rate at lower pressure. For $1100 \mathrm{~K}$ inlet temperature, however, a portion of the $6 \mathrm{~atm}$ efficiency curve is higher than that of the 3 atm case as can be seen in Fig. II.6(b) and (c). This reversal phenomenon was first reported by Anderson (1978) who suggested that this was due to the competition between gas-phase and surface reactions. This model calculation 


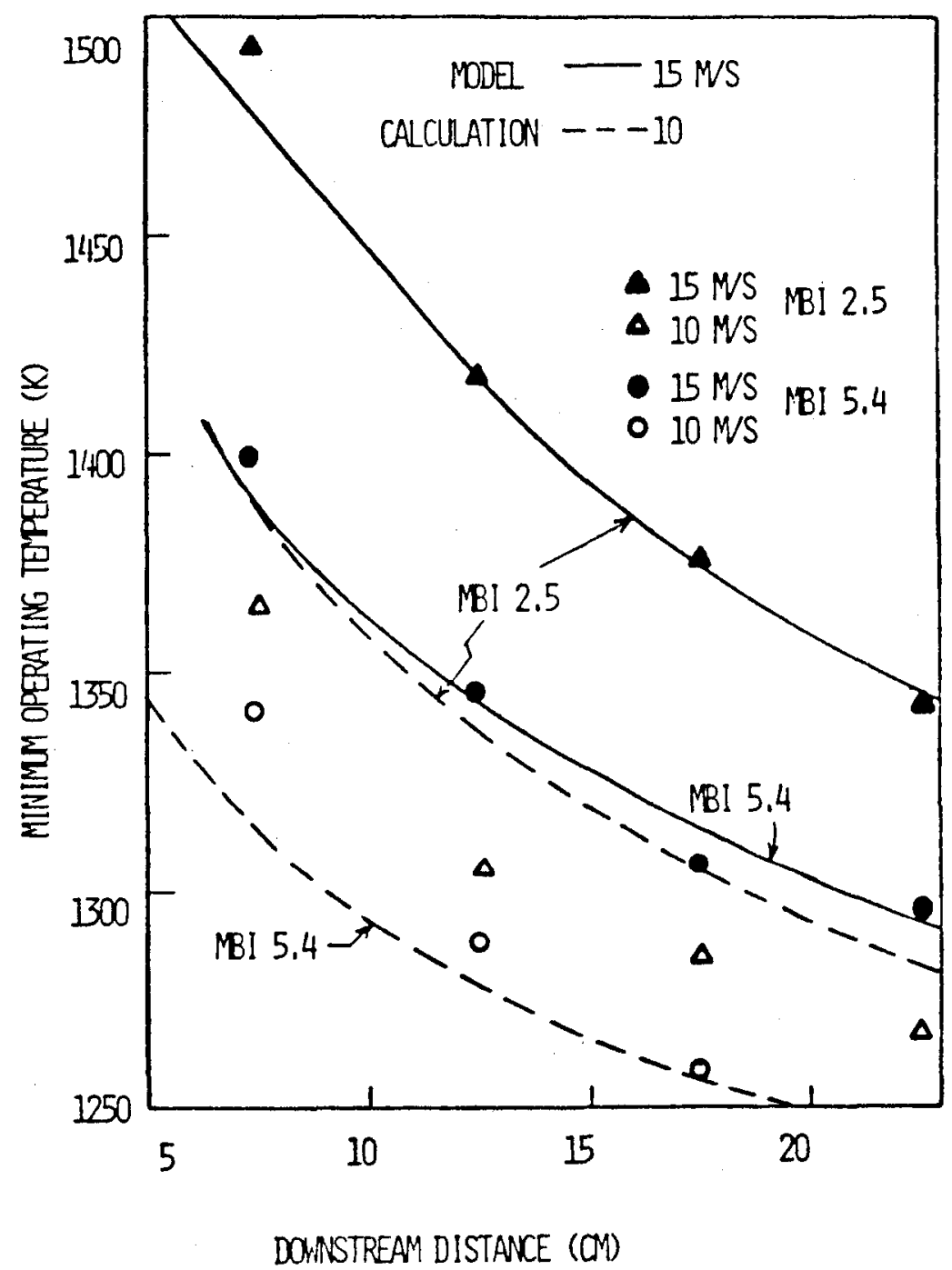

Fig. II.5 Minimum operating flame temperature (to reach emission goals) vs. downstream reaction distance: comparison of model calculation with Anderson's data (1980a). 

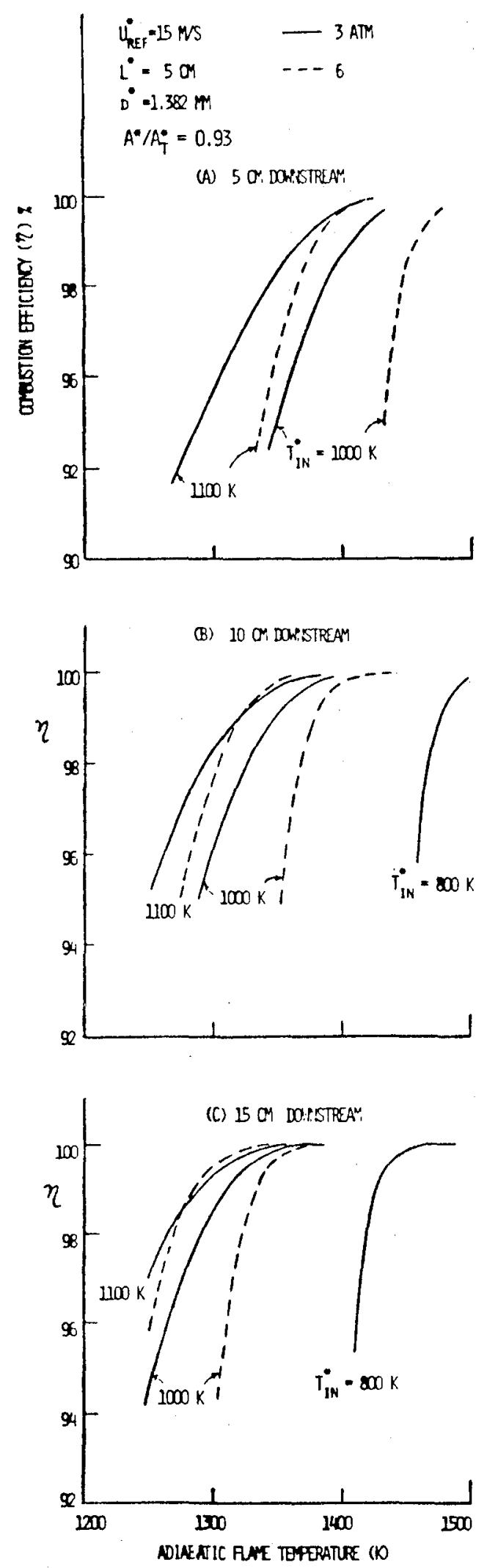

Fig. II.6 Combustion efficiency vs, adiabatic flame temperature for different inlet temperature and pressure at three downstream locations. 
supports this interpretation. High temperature and pressure support fast gas-phase reactions, but high pressure also retards surface reaction through slower mass diffusion rate. Taking the case of $1100 \mathrm{~K}$ inlet temperature and $1320 \mathrm{~K}$ adiabatic flame temperature for example: at the bed exit, the 6 atm case has a lower efficiency than the 3 atm case because inside the reactor channel, surface reaction dominates. At downstream distance of $5 \mathrm{~cm}$, the $6 \mathrm{~atm}$ case still has lower efficiency. But at $10 \mathrm{~cm}$ downstream, the two efficiencies become equal and at $15 \mathrm{~cm}$ downstream 6 atm has a higher efficiency. Since only gas-phase reaction exists in the after-bed space, the efficiency reversal occurs when the gas-phase reactions overpower the upstream influence of surface reactions. 
SUMMARY

A transient model of monolith catalytic combustor is presented in this work. The model assumes a quasisteady gas phase and a thermally-thin solid with the substrate thermal inertia responsible for the combustor response time delay. In the gas-phase treatment, several quasi-global chemical reactions are assumed which are capable of describing $\mathrm{CO}$ and unburnt hydrocarbon emissions in fuel-lean operations. By neglecting heat conduction along the flow direction in the gas and the solid in high speed approaching flows, the system of differential equations describing the combustor transient is simplified and Runge-Kutta integration scheme is applicable. The resulting computation scheme is highly efficient in computational time and is suitable for parametric calculation for both steady states and transients.

In the steady-state computation presented, the influence of selected operating and design parameters on the minimum combustor length is studied. Special attention is given to the effect of after-bed gas phase reaction space. Comparison with the data by Anderson indicates that the model is able to describe all the salient features found in the experiments including the appearance of $\mathrm{CO}$ peak and the efficiency reversal phenomena at high inlet temperature and pressure. Quantitative agreement with Co emission data is possible if a certain degree of rate constants adjustment is made. The model computation also suggests that for determining the condition of achieving the steady-state emission goals, the gas residence times in the catalytic bed and in the after-bed space are the similarity parameters absorbing the influence of catalytic bed and after-bed lengths, the gas velocity and the open area fraction of the catalytic element. Likewise, the nondimensional 
response time and the gas residence times are the proper similarity parameters in transient operations. A consequence of this is that the dimensional response time is proportional to the substrate crossectional area $\mathrm{A}_{\mathrm{S}}^{*}$ (all other parameters fixed) and so a thin substrate is necessary for fast response.

The computed time history provides an understanding of how a catalytic combustor responds to an upstream condition change. The leading edge of the substrate is the first to respond to an upstream variation, say, a change of fuel flow rate. The leading edge is closer to the source of variation and the mass transfer rate is higher in the flow entrance region of the gas channe1. As a result, the surface fuel concentration is perturbed first which, through the surface reaction, produces a surface temperature change. Heat transfer across the flow channel then causes the gas temperature to vary and this disturbance propagates downstream by convection. Since, the downstream part of the substrate always responds to the upstream substrate temperature variation, it is not difficult to see from the above description that a combustor with a longer catalytic bed residence time will take a longer time to reach a new equilibrium state.

The model calculation al so shows that higher combustor inlet temperature and adiabatic flame temperature shorten the response time. Smaller channe1 hydraulic diameter usually resulti in a faster response but there are exceptions. Since the requirements for faster transient response do not always coincide with the optimal steady-state design conditions, for applications where transient characteristics are important, both steady and transient studies have to be made simultaneously so that a good compromising design can be found. 
References:

Ablow, C.M. and Wise, H., (1979) "Theoretical Analysis of Catalytic Combustion in a Monolith Reactor," Combustion Science and Technology, 21, 35 (1979).

Anderson, D.N., Tacina, R.R., and Mroz, T.S., (1975) "Performance of a Catalytic Reactor at Simulated Gas Turbine Combustor Operating Conditions," NASA TM X-71747.

Anderson, D.N. (1976) "Preliminary Results from Screening Tests of Comercial Catalysts with Potential Use in Gas Turbine Combustors. Part I. Furnace Studies of Catalyst Activity," NASA TM-X 73410.

Anderson, D.N., (1977a) "Performance and Emissions of a Catalytic Reactor with Propane, Diese1, and Jet A Fuels," NASA TM-73786.

Anderson, D.N., (1977b) "Effect of Catalytic Reactor Length and Cel1 Density on Performance," presented at the 2nd EPA Workshop on Catalytic Combustion, Raleigh, N.C., June 21-22.

Anderson, D.N., (1978) "Effect of Inlet Temperature on the Performance of a Catalytic Reactor," NASA TM-78977.

Anderson, D.N., (1980a) "The Effect of Catalyst Length and Downstream Reaction Distance on Catalytic Combustor Performance," NASA TM-81475.

Anderson, D.N., (1980b) "Ultra-lean Gas-phase Combustion," presented at the Automotive Technology Development Contractor Coordination Meeting, Dearborn, Michigan, November 11 - 13 .

Bracco, F.V., Bruno, C., Yaw, Y. and Walsh, P.M., (1980) "Computed and Measured Emissions from the Catalytic Combustion on Propane/Air Mixtures," Fourth Workshop on Catalytic Combustion, EPA-600/0-90-035.

Cerkanowicz, A.E., Cole, R.B. and Stevens, J.G., (1977) "Catalytic Combustion Modeling: Comparison with Experimental Data," ASME paper, 77-GT-85.

DeCorso, S.M. and Car1, D.E., (1979) "Structural Analysis of a Preliminary Catalytic Combustion Ceramic Design," Proceedings: Third Workshop on Catalytic Combustion, EPA-600/7-79-038.

Dryer, F.L. and Glassman, I., (1973) "High Temperature Oxidation of CO and $\mathrm{CH}_{4}$," 14th Inter. Symp. on Combustion, the Combustion Institute, Pgh, $\mathrm{Pa}$.

Dryer, F.L. and Glassman, I., (1978) "Combustion Chemistry of Chain Hydrocarbons," in Alternative Hydrocarbon Fuels: Combustion and Chemical Kinetics, Vol. 62, Progress in Astron. and Aeronautics. Also discussion section, p. 295.

Edelman, R.J., (1978) Comments Section in the previous reference,p. 295. 
Edelman, R.B. and Fortune, O.F., (1969) "A Quasi-global Chemical Kinetic Model for Finite Rate Combustion of Hydrocarbon Fuels with Application to Turbulent Burning and Mixing in Hypersonic Engines and Nozzles," AIAA paper $69-86$.

Kays, W.M., (1966) Convective Heat and Mass Transfer, McGraw-Hill, New York.

Kelley, J.T., Kenda11, R.M., Chu, E. and Kesselring, J.P., (1977) "Development and Application of the PROF-HET Catalytic Combustor Code," paper presented at the 1977 Fall Meeting Western States Section, The Combustion Institute.

Kendall, R.M. Kelley, J.T., Chu, E.K. and Kesselring, J.P., (1979) "An Analysis of Catalytic Combustion in Monolithic Honeycomb Beds," Proceedings: Third Workshop on Catalytic Combustion, EPA-600/7-79-038.

Kuo, J.C.W. and Morgan, C.R., (1971) "Mathematical Models of the Monolith Catalytic Convertor," SAE Transaction, V. 80, 1971, 非10289.

Marteney, P.J., (1979) "Determination of the Rate of Hetrogeneous Reaction on Catalytic Surfaces," Proceedings: Third Workshop on Catalytic Combustion, EPA-600/7-79-038.

Schwartz, A., Holbrook, L.L. and Wise, H., (1971) "Catalytic Oxidation Studies with Platinum and Palladium," Journal of Catalysts, 21, 199-207.

T'ien, J.S., (1980) "Modeling of Transient Operation of Catalytic Combustor," Proceedings: Fourth Workshop on Catalytic Combustion, EPA-600/9-80-035.

T'ien, J.S. and Anderson, D.N., (1979) "Gas Phase Oxidation Downstream of a Catalytic Combustor," NASA TM-81551. 


\section{Nomenclature}

$$
\begin{aligned}
& A^{*} \quad \text { crossectional area of one gas channel } \\
& \text { substrate cross-sectional area associated with one gas channel, } \\
& \text { see Fig. } 1 \\
& A_{T}^{*}=A^{*}+A_{S}^{*} \text {, total crossectional area of one cell unit } \\
& B_{0} \quad=\frac{L^{*}}{U^{*}(0)} \frac{1}{\rho^{*}(0)} \frac{1}{Y_{H C}(0)} C_{0}^{*} p^{*}(0)^{\gamma_{1}} \stackrel{\gamma_{2}}{\gamma_{2}} T^{*}(0)^{\gamma_{3}} Y_{H C}^{\gamma_{2}}(0) W_{H C}^{\left(1-\gamma_{2}\right)}
\end{aligned}
$$

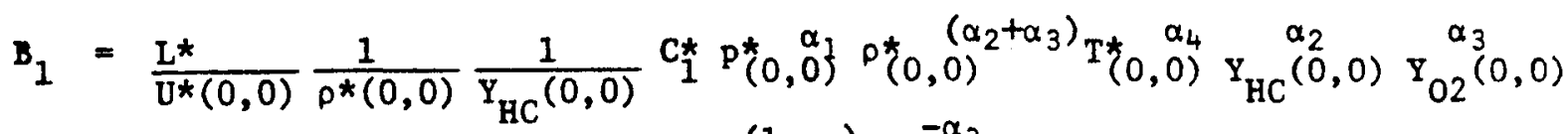

$$
\begin{aligned}
& x \mathrm{w}_{\mathrm{HC}}\left(1-\alpha_{2}\right) \mathrm{w}_{\mathrm{O} 2}^{-\alpha_{3}} \\
& B_{2}=\frac{L^{*}}{U^{*}(0,0)} \frac{1}{\rho^{*}(0,0)} \frac{1}{Y_{H C}(0,0)} C_{2}^{*} p^{*}(0,0)^{B_{1}} \rho^{*}(0,0)\left(B_{2}+B_{3}+B_{5}\right) T^{*}(0,0) Y_{H C}^{B_{4}} Y_{2}^{B_{2}}(0,0) \\
& x \mathrm{Y}_{02}^{B_{3}}(0,0) \mathrm{w}_{\mathrm{CO}}^{\left(1-B_{2}\right)} \mathrm{w}_{\mathrm{O} 2}^{-B_{3}} \mathrm{w}_{\mathrm{H}_{2} \mathrm{O}}^{-B_{5}} \\
& B_{3}=C_{3}^{*} d * / \alpha * W_{H C}{ }^{N} u_{\infty} \\
& B_{4}=C_{4}^{*} d * / \alpha * W_{C O} N_{\omega} \\
& \mathrm{c}_{\mathrm{n}}=\mathrm{n} \mathrm{w}_{\mathrm{CO}} / \mathrm{w}_{\mathrm{HC}} \\
& C_{5}^{*} \quad \text { specific heat of substrate } \\
& \mathrm{C}_{\mathrm{p}}^{\star} \quad \text { gas specific heat } \\
& d * \text { catalytic monolith combustor channel equivalent diameter } \\
& d * \text { half thickness of the substrate } \\
& E^{*} \quad \text { activation energy } \\
& \mathrm{J}_{3}^{*} \text { mass consumption rate of hydrocarbons per unit surface area } \\
& \text { through reaction (C) } \\
& \mathrm{J}_{4}^{*} \text { mass consumption rate of } \mathrm{CO} \text { per unit surface area through } \\
& \text { reaction (D) } \\
& J_{D i}=J_{B}\left(L_{i}\right)^{2 / 3} \\
& J_{H}=4 N u_{x}\left(\alpha *(0,0) / d \star^{2}\right)(L * / u *(0,0)(k \star / k *(0,0)
\end{aligned}
$$




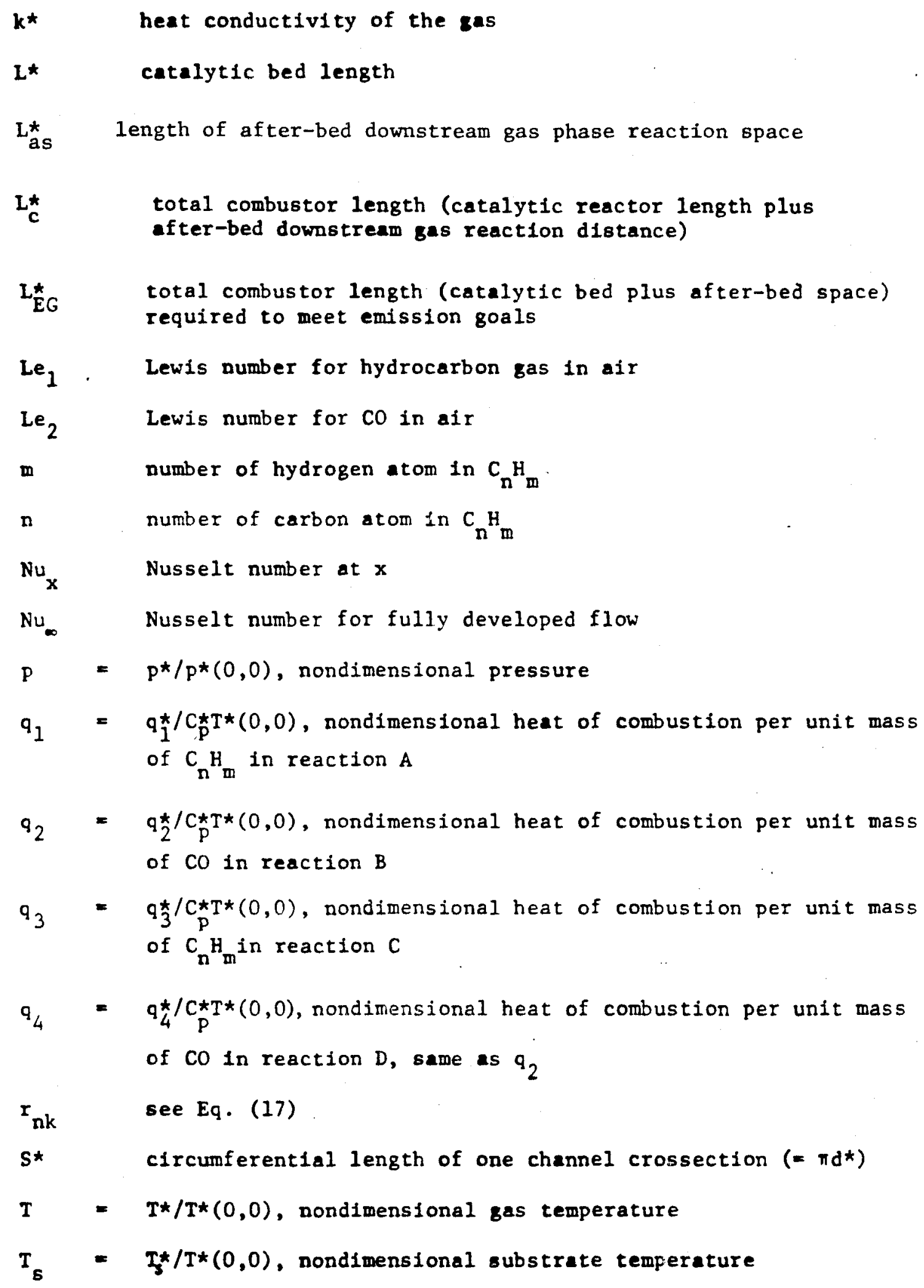




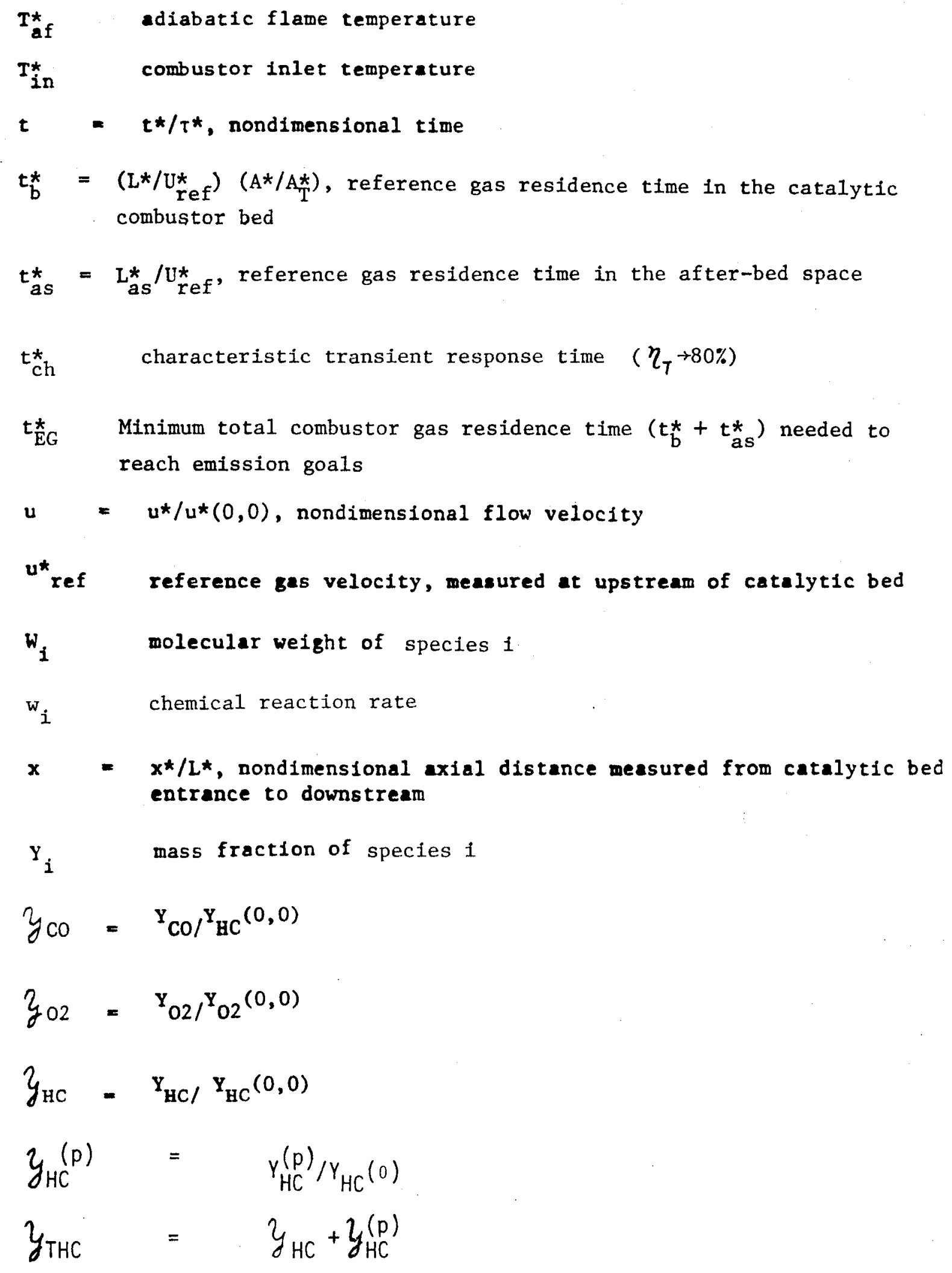




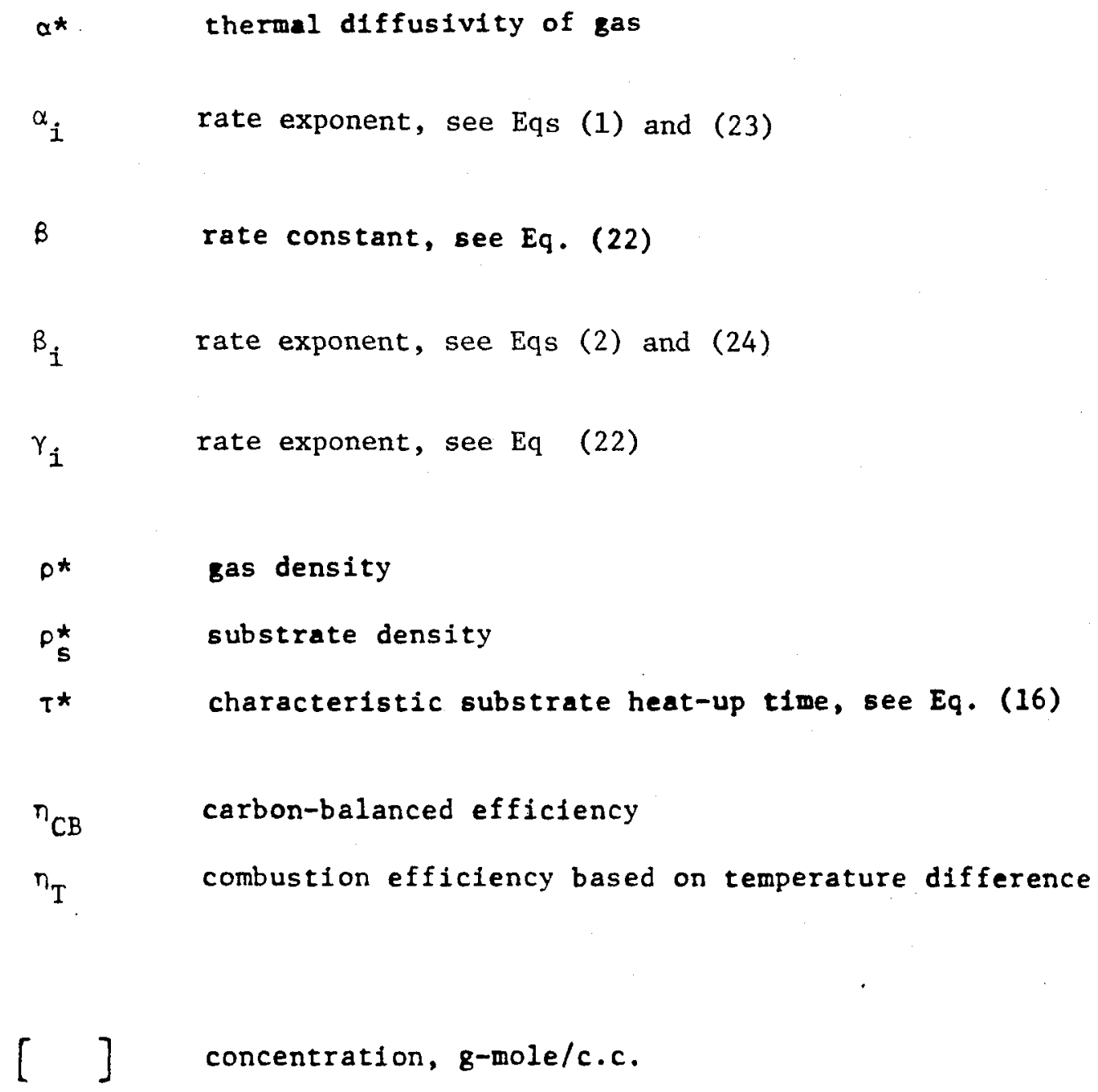




\section{APPENDIX I}

\section{LISTING OF COMPUTER PROGRAMS FOR CHAPTER I}

The numerical computations were performed using an interactive VAX 11/780 computer. FORTRAN Ianguage was used in writing the main program (e.g. IGNITION. FOR; 17) and the data program (e.g. BLOCK. FOR; 31). They were then compiled to form the objective programmes (e.g. IGNITION. OBJ; ** and BLOCK. OBJ; **). The two objective programmes were then linked together to form an executable program (e.g. IGNITION. EXE; 10). In performing a calculation, only the executable is needed.

The BLOCK program stores most of the data which are not likely to be changed from one calculation to the other, while the most frequently varied input data will be read in in each computer run. If the data stored in the BLOCK program are to be changed, the FORTRAN BLOCK program has to be modified (edited), re-compiled and linked with the main program to form a new executable program.

In the following, the FORTRAN programmes (IGNITION. FOR; 17 and BLOCK. FOR; 31) are listed together with a sample calculation showing input and output data.

The IGNITION program is presently set up to perform the start-up transient. With minor modification, it can read in any prescribed initial condition and to calculate the corresponding unsteady response. Given enough computational time, the IGNITION program will also result in the steady-state profiles.

More detailed instrictions (for IGNITION. FOR; 17):

1. The number of grid points used should be less than 300 . If more than 300 points are needed, line 600 has to be changed.

2. Read-in data ( 1 ines $10900-12300)$ :

$\mathrm{XPHI}=\phi=$ fue1-air equivalence ratio 
$\mathrm{TI}=\mathrm{T}(0,0)=$ upstream, initial temperature $(\mathrm{K})$

$\mathrm{XPI}=P(0,0)=$ upstream, initial pressure $(\Lambda \mathrm{tm}$.

UIUS $=U_{\text {ref }}=$ upstream (outside of the bed) initial gas velocity $(\mathrm{m} / \mathrm{s})$

$\mathrm{XLS}=$ reference length $(\mathrm{m})$, suggested to use $0.1 \mathrm{~m}(10 \mathrm{~cm})$

DS $=\mathrm{d}^{*}=$ channel hydraulic diameter $(\mathrm{m})$

AOAS $=A^{*} / A^{*}{ }_{S}=$ open-to-close area ratio

$D_{X}=$ nondimensional step size in $X$ (space). It is

nondimensionalized by XLS. So if XLS $=0.1 \mathrm{~m}$ and

$\mathrm{DX}=0.01$, dimensional step size is $0.001 \mathrm{~m}$ or

$1 \mathrm{~mm}$.

$\mathrm{DT}=$ nondimensional time step size

TMAX = maximum nondimensional time allowed for computation

IPRINT = time interval for printing out transient profiles.

For examp1e, if DT $=.01$ and $\operatorname{IPRINT}=25$,

Output will be printed out every $t=0.25$.

$\mathrm{N}=$ number of grid points (in $\mathrm{X}$ direction) in the

catalytic bed. The nondimensional catalytic bed

length is given by $(\mathrm{N}-1) \mathrm{x}(\mathrm{DX})$. For example,

if $\mathrm{N}=51, \mathrm{DX}=.01$, then the nondimensional bed

length is equal to 0.5 . If XLS $=.1 \mathrm{~m}$, then the

dimensional bed length is $.05 \mathrm{~m}(5 \mathrm{~cm})$.

NAS $=$ number of grid points (in X-direction) in the

downstream after-b d space. The length of the

downstream distance can be calculated in a similar

manner as in the above.

$\mathrm{Cl}, \mathrm{C} 2, \mathrm{C} 3, \mathrm{C} 4=\mathrm{C}_{1}, \mathrm{C}_{2}, \mathrm{C}_{3}, \mathrm{C}_{4}$ (See Table I.2)

$\mathbf{I T}=$ interval in $\mathrm{X}$ for printout. For example, if $\mathbf{D X}=0.01$

$\mathrm{IT}=5$, the printout will be at $\mathrm{X}=0,0.05,0.1,0.15, .$. etc.

3. Those data which are not read in will be defined by the BLOCK program. 
4. Some Symbol Definitions:

$\mathrm{PR}=$ Prandt1 number of air

REY = Reynolds number based on channel diameter and upstream velocity

ES, $S=E_{1} *, E_{2} *, E_{3} *, E_{4} *$ (See Table I.2)

$E, S=E_{1}, E_{2}, E_{3}, E_{4}$

$\mathrm{C}, \mathrm{S}=\mathrm{C}_{1} *, \mathrm{C}_{2} *, \mathrm{C}_{3} *, \mathrm{C}_{4} *$ (See Table I.2)

$\mathrm{GC}=$ gas constant (joule/kg K)

XLEW1 = Lewis number for $\mathrm{C}_{n_{m}} \mathrm{H}_{\mathrm{m}}$ in mixture

$\mathrm{XLEW} 2$ = Lewis number for $\mathrm{CO}$ in mixture

ROI = initial, upstream (I.U.) gas density $\left(\mathrm{kg} / \mathrm{m}^{3}\right)$

$\mathrm{XKI}=\mathrm{I}$.U. gas heat conductivity (ca1/m sec $\mathrm{K})$

$\mathrm{CP}=$ specific heat of gas at constant pressure $(\mathrm{cal} / \mathrm{kg} \mathrm{K})$

ALPHA $=$ I.U. gas diffusivity $\left(\mathrm{m}^{2} / \mathrm{sec}\right)$

$\mathrm{TS}=\mathrm{T}_{\mathbf{S}}$

$\mathrm{YFS}=y_{\mathrm{HC}, \mathrm{S}}$

$\mathrm{YCS}=y_{\mathrm{CO}, \mathrm{s}} \quad$ YO $=y_{\mathrm{O}_{2}}$

$\mathrm{YF}=\boldsymbol{y}_{\mathrm{HC}} \quad \mathrm{TMAX}=$ Maximum time for computation

$\mathrm{YC}=\boldsymbol{y}_{\mathrm{CO}}$

5. Output data (1ines 40300 to 42200 )

The following quantities are printed out as a function of axial distance and time:

Nondimensional gas and surface temperatures, Emission indices (x1000) of hydrocarbon fuel and co (both in the gas phase and on the surface) and carbon-balanced and thermal efficiencies. 
IGNITION. FOR; 17

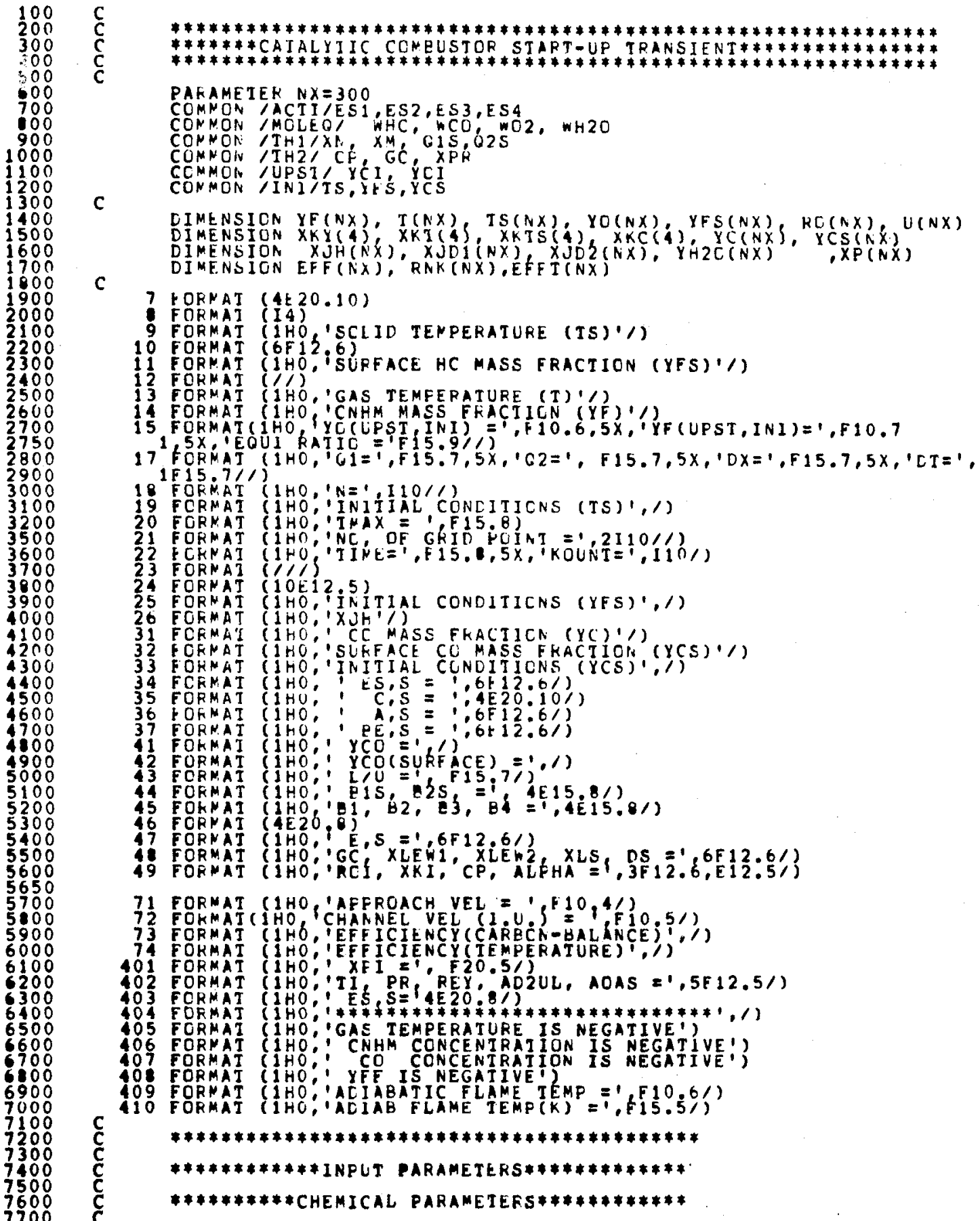

CHEMICAL REACIICN 1 , CNHM $+22=C O+H 2 C$ (GAS PHASE)

CHEMICAL REACTICN 2, CO + O2 2 CO2 (GAS PHASE)

CHEMICAL REACIICN 3! CNHM + O2 = CO2 + H2C (SOLID SURFACE) 


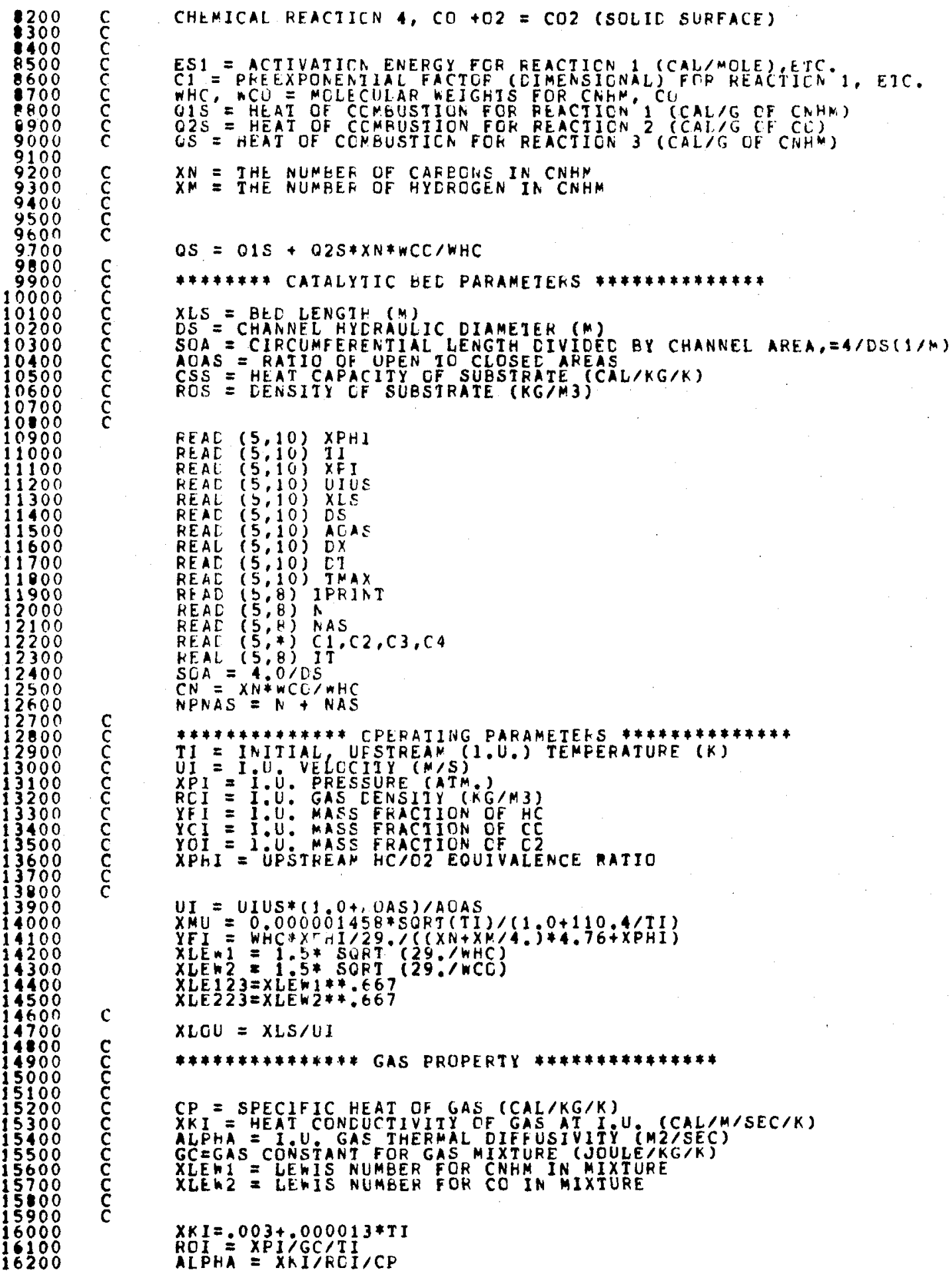


16300 16400 16500 16700 16700 16800 16900 17100 17200 17300
17400 17500 17600 17700 17900 18000 18100 1.200 18400 1 . 500 10600 1800 18900 19000 19200 19300 19400 19400 19600 19700 19800 29900 20100 20200 20300 20400

20500

20600 20700 20800 20900 21000 21100 21200 21300 21500 21600 21700 21800 21800 22000 22100 22200 22300 2500 22600 22700 22900 23000 23100 23200 23300 23500 23600 23600 23700 23500 24000 24100 34300

REY $=$ UIUS*CS*RCI/XMU

TO DESCRIBE CHEMICAL FEACTION RATE EXPRESSIONS REACIIUN I (GAS PHASE) $C(C N H M) / U T$ SSS XP*\#.3*T*SORT (YHC)*YO2/EXP(E1/RT) RFACTIUN 2 (GAS PHASE) D(CC)/DI \& SS YCC \&SOPT (YC2)*SCRT(YH2C)/EXP(E2/RT) REACTIUN 3 (SCLID SURFACE) D (CNHM) IDT SSS YHCS/EXP(E\}/RT)

REACTION 4 (SOLID SURFACK) $D(C C) / D T$ \&SS YCCS/EXF(EA/RT) To EVALUATE KINETIC RATE CONSTANTS

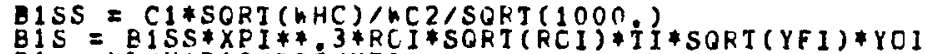
BI $=$ XLUU*B1S/RCI Y Y I I
SSHO2=SURT(SORT (WO2))

C

B2SS $=C 2 / 1000 * 75 / S S W 02 / S O R T(W H 2 O)$

SSRCI = SURT(SQRT(ROI))

SSYCI = SORT (SORT (YOI) )

D2S =B2SS*ROI*RCI SSRCI*YFI*SSYOI

$c$

$B 3=$ C3*OS/ALPHA/WHC/3.66

B. $=$ CAFDS/ALPHAIWCOI3:66

OI $=$ QIS/CFYT

$O_{0}=0 S / C P / T I$

TAE $=Y$ Y I I T I

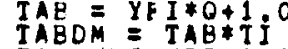

$E L=E S_{1} / T 1 / 1.967$

E2 = ESL 1 T1/1.967

E = ES4/TI I : 987

ADOLE = (ALFHA/CS/CS) (UI/XIS)

WRITE $(0,21)$ N, NAS

WRITE $(0,20)$ TMAX

WRITE $(6,15)$ YCI, YFI, XPHI

WPI IE $(6,71)$ litis

WRIIE $(0,72)$ UI

WRIIE $(6,17)$ OI, O2, CX, OT

WRIIE $(6: 402)$ II'XFK:REY: AD2UL, MOAS

WRITE $(6,409)$ TAB

WRIIE $(0,410)$ TABCM

WRIIE $(6,403)$ ES1 ES2 ES3, ES4

WFIIE $(6.47) E 1$ E2 E $E\}$

WRITE $(6,48)$ GC XLEMI XLEM $2, X L S$, DS

WRIE $(6,49)$ RCI XKI, CF, ALEHA

WRITE $(6,401)$ REI

WRITE $(6,401)$ XF

WRITE $(6,44)$ XIS B

WRIIE $(6,45)$ EI, B2, B3, B4

WRIIE $(6,19)$

WRIIE $(6,24)$ (TS (I), I=I,N,IT)

WR I $(0,25)$ (YFS(I), I=1,N,IT)

WRI IE $(6,33)$

WRITE $(6,24)(Y C S(I), I=1, N, I T)$

$\mathrm{c}$
$\mathrm{c}$
$\mathrm{C}$

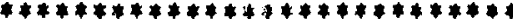

************ UPSTREAM CONDITICNS

$Y F(1)=1 \cdot 0$

Yo(1) $=1$.

$T(1)=1$.

$\operatorname{RO}(1)=1$.

$U(1)=1$.

c 


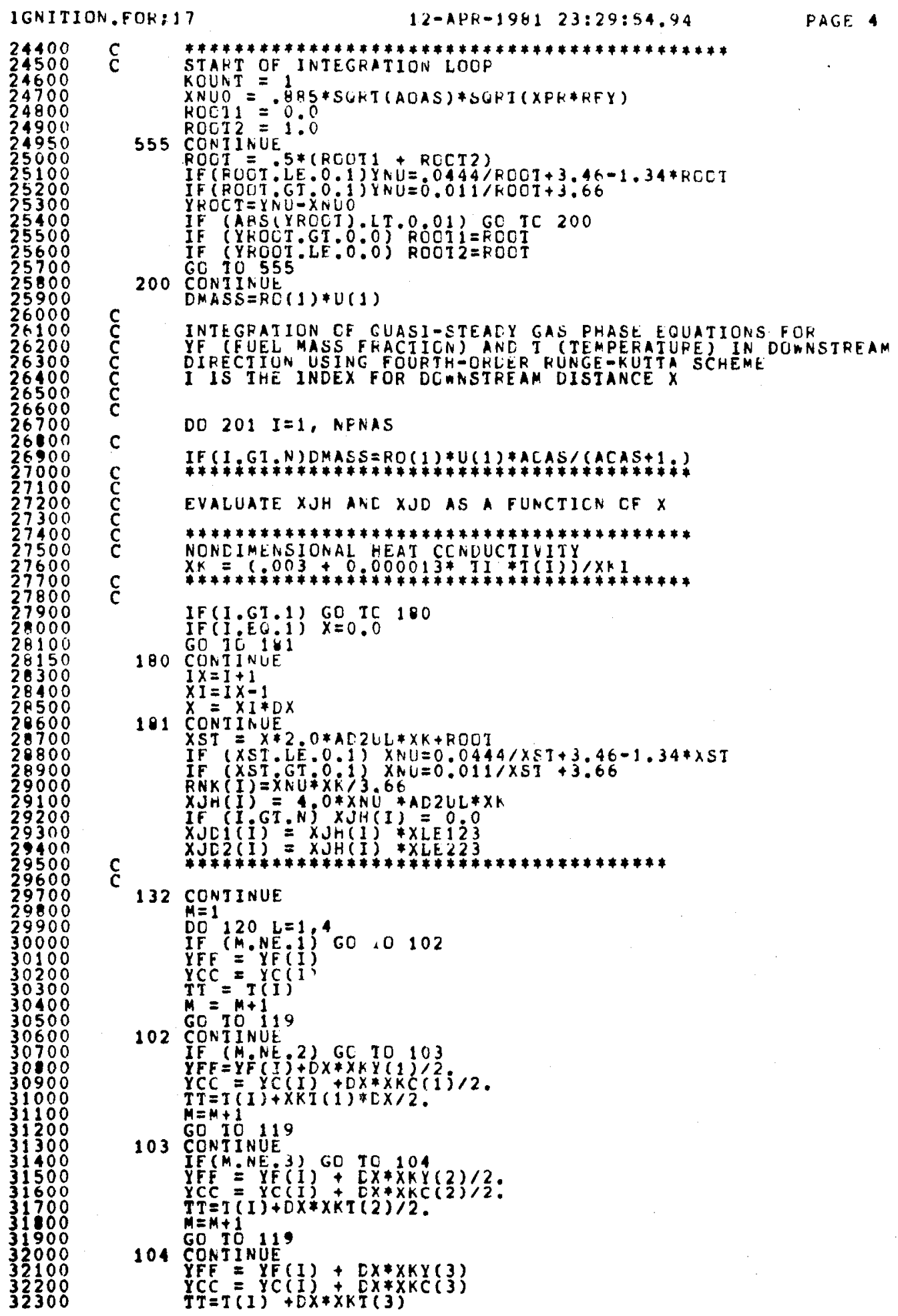




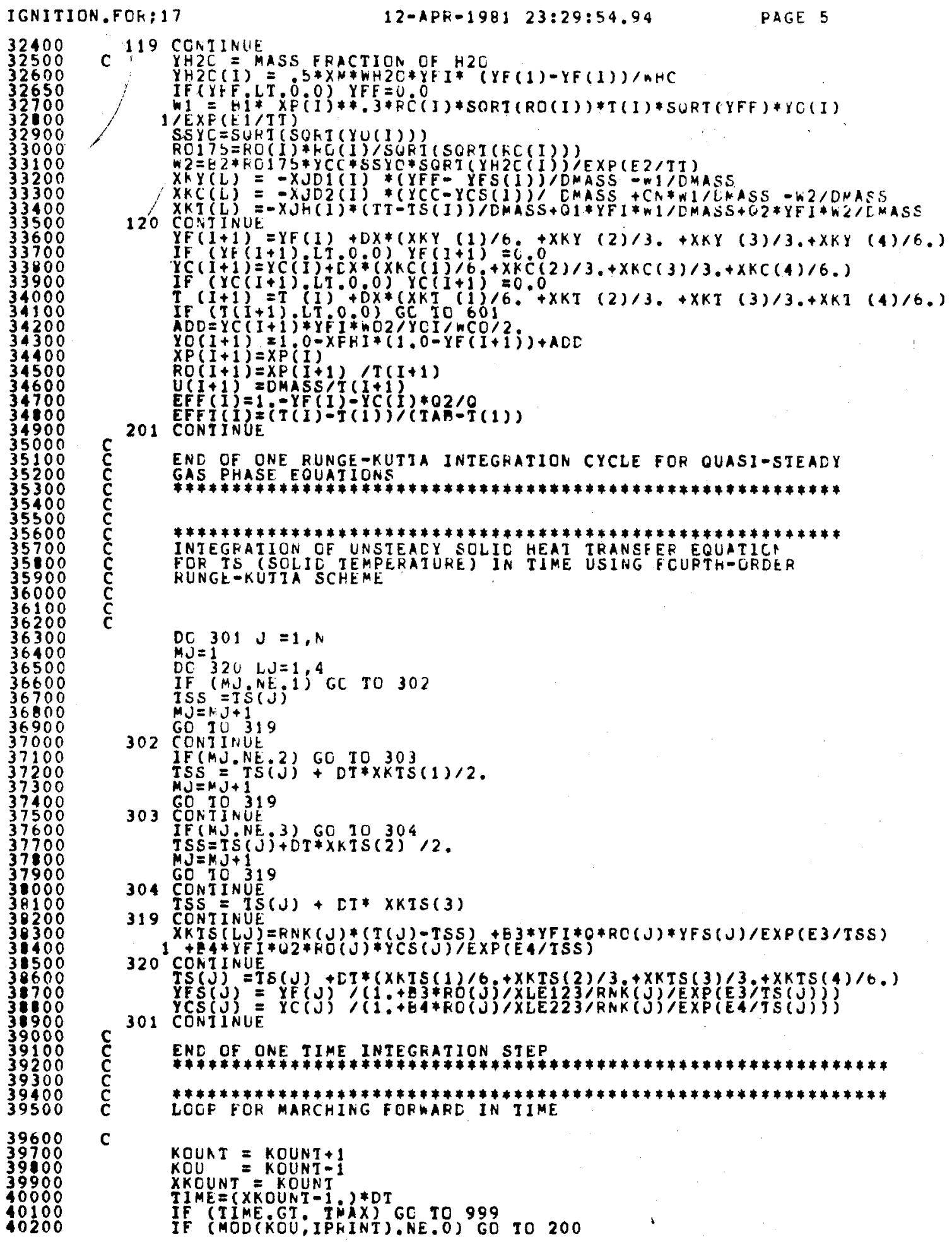




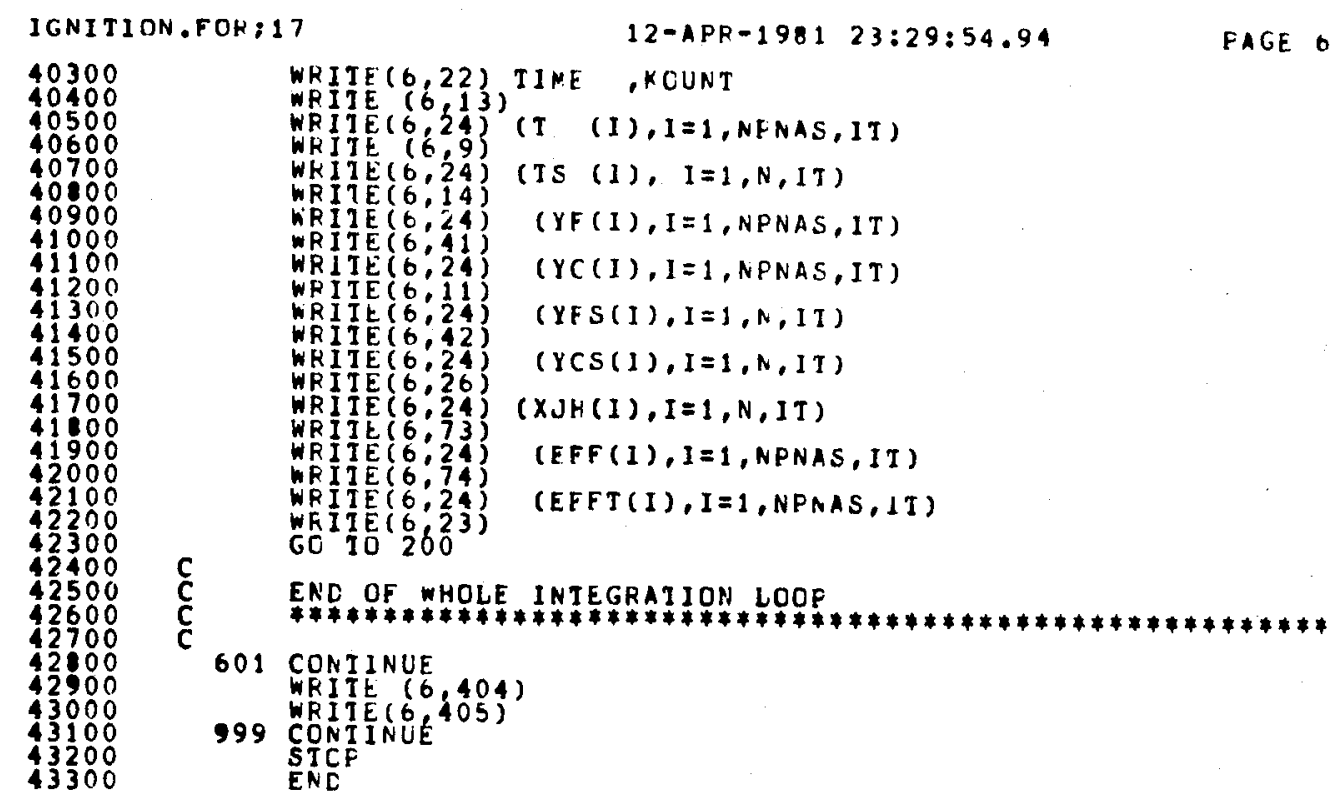




100
200
300
400
600
700
800
900
1100
1200
1400
1500
1600
1700
1800
2000
2100

BLOCK DATA

DIMENSION TS 300$)$ YFS(300) YCS(300)

CCMMCN AACIIIESI,ES2,ES3,ES4, WH2O

COMNGY /MOLEQY WHC, WCC. WCL, WH2O

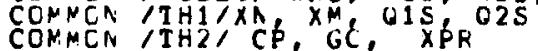

COMNCN TUPST, YCI $Y O 1$

COMMON IINI/TS,YFS, YCS

DATA ES1,ES2,ES3,ES4/24000,40000,10000,17800.1

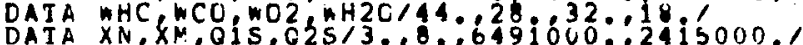

DATA CP,GC XPKI2S5.32:312E-3,0.7\%

DATA Y

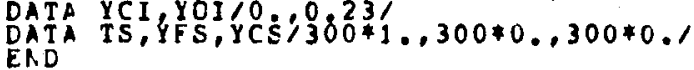

2100 
Example calculation:

5 RUIM IGNITIDH. EXE: 10

.18

10ib.

3

10.

1

M01e

E.

.01

.11

1.001

E⿺辶

1.5E5 0.71E14 Eं.5EO 1.ES 5

ND. OF ERII FOINT =
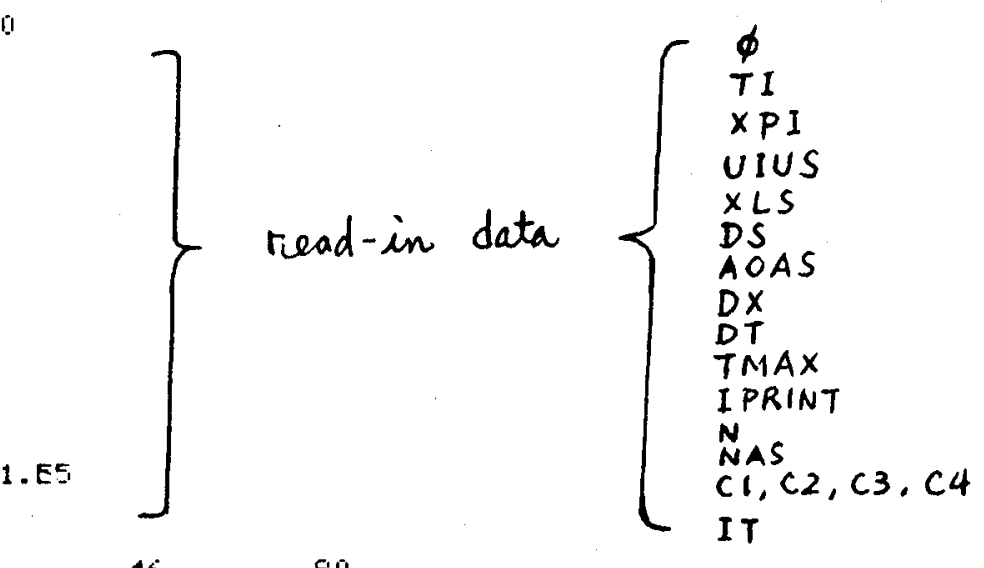

TMAX $=1.00100005$

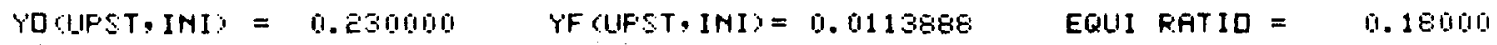
nour

FIPPRDACH YEL $=10.0010$

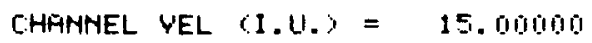




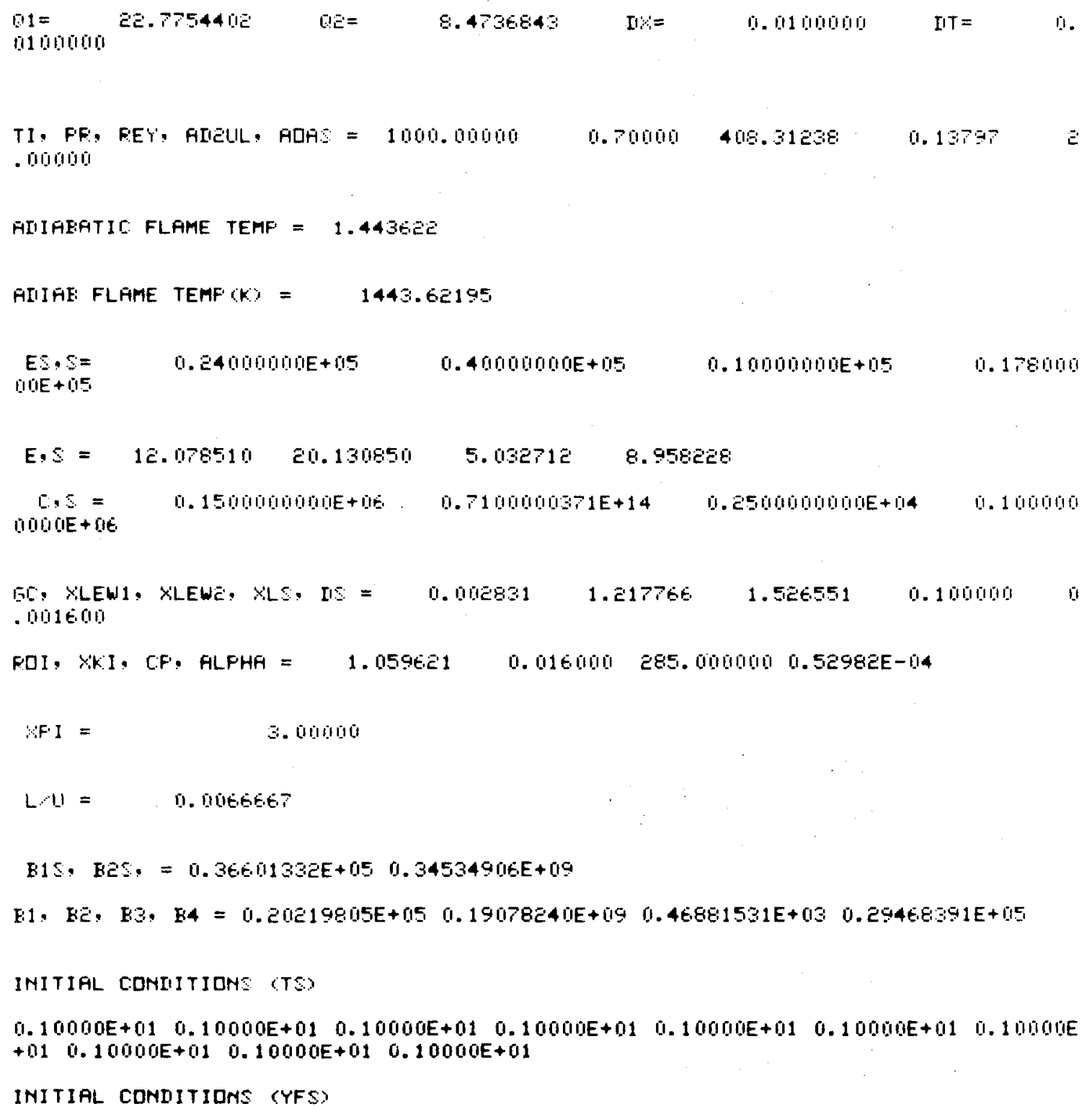




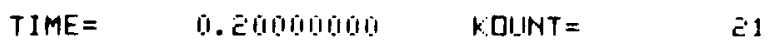

BA: TEMFERATUFE QT:

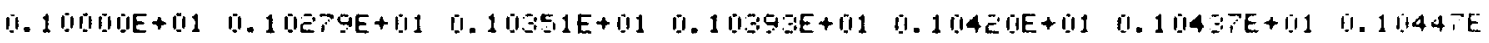
$+010.10451 E+010.10451 E+0110.10447 E+01$

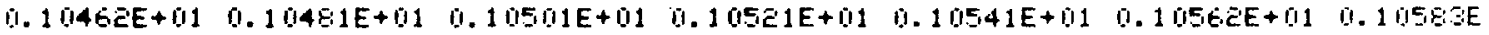

$+0110.10604 E+010.10625 E+010.10647 E+01$

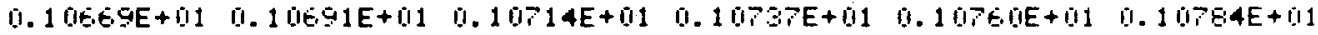

OLIII TEMFER.ATLIRE (TS)

$0.11390 E+01 \quad 0.1078 E E+01 \quad 0.10631 E+01 \quad 0.1054 \mathrm{E}+01 \quad 0.10477 E+01 \quad 0.10427 E+0110.10384 E$

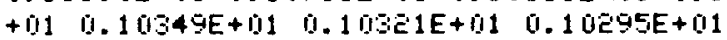

CNHM MASS FFACTION (YF)

$0.10000 E+01 \quad 0.82811 E+00 \quad 0.72848 E+00 \quad 0.64850 E+00 \quad 0.58054 E+00 \quad 0.52141 E+00 \quad 0.46932 E$ $+000.42307 E+00 \quad 0.38150 E+000.34400 E+00$

$0.33115 E+0100.32383 E+100.31646 E+000.3090 E E+00 \quad 0.30153 E+00 \quad 0.29398 E+00 \quad 0.28638 E$ $+000.27871 E+000.27100 E+00$ 0. $263224 E+00$

$0.2554 E E+0010.24756 E+00 \quad 0.2396 E E+00 \quad 0.23171 E+00 \quad 0.2 E 373 E+000.21571 E+00$

YOL $=$

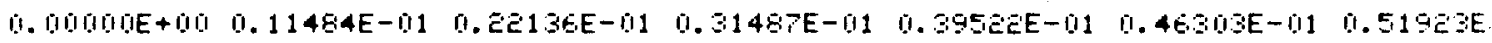

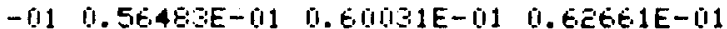

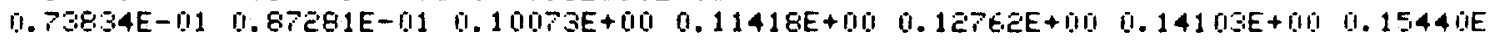
+00 0.16772E+ 010 0. $18098 E+100$ 0.19417E+00

$0.20726 E+00 \quad 0.22024 E+00 \quad 0.23309 E+000.24579 E+000.25839 E+000.27068 E+00$

SUFFAIE HE: MASS FRACTION CYFS

$0.53851 E+000.24678 E+000.20088 E+000.17326 E+00 \quad 0.15271 E+000.13598 E+1000.12175 E$ $+010.10985 E+0010.99795 E-010.90590 E-01$

YCOCSUFFACE) =

1. 00000E+00 0.

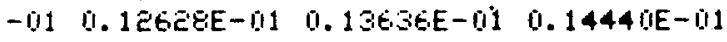

$x .1 \mathrm{H}$

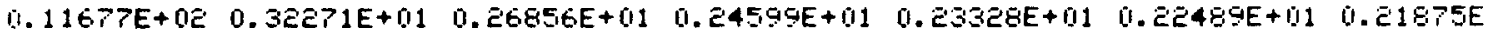
$+010.21536 E+010.21464 E+110.21403 E+01$

EFFICIENCY' (CAREDN-EFLANCE)

$0.00000 E+00 \quad 0.16939 E+00 \quad 0.26670 E+00 \quad 0.34465 E+00 \quad 0.41086 E+00 \quad 0.46852 E+00 \quad 0.51939 E$ $+00 \quad 0.56464 E+00 \quad 0.60544 E+00 \quad 0.64237 E+00$

$0.65279 E+00 \quad 0.65718 E+00 \quad 0.66163 E+00 \quad 0.66614 E+00 \quad 0.67071 E+000.67534 E+00 \quad 0.68004 E$ $+00 \quad 0.68480 E+00 \quad 0.68963 E+000.69452 E+00$

$0.69949 E+00 \quad 0.70453 E+00 \quad 0.70964 E+00 \quad 0.71482 E+00 \quad 0.72008 E+00 \quad 0.72541 E+00$

\section{EFFICIENCY (TEMFERATUFE)}

$0.00000 E+00 \quad 0.62838 E-01 \quad 0.79086 E-011 \quad 0.88607 E-01 \quad 0.94669 E-01 \quad 0.98477 E-01 \quad 0.10066 E$ $+00 \quad 0.10160 E+00 \quad 0.10161 E+000.10085 E+00$

$0.10409 E+00 \quad 0.10848 E+00 \quad 0.11292 E+00 \quad 0.11743 E+00 \quad 0.12200 E+00 \quad 0.12663 E+00 \quad 0.13133 E$ $+00 \quad 0.13609 E+00 \quad 0.14092 E+00 \quad 0.14582 E+00$

$0.15079 E+00 \quad 0.15582 E+00 \quad 0.16093 E+00 \quad 0.16611 E+00 \quad 0.17137 E+000.176 .70 E+0 j 0$ 
BAS TEMFEFATUFE CT:

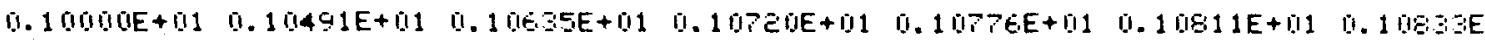
$+010.10543 E+010.10845 E+010.10841 E+01$

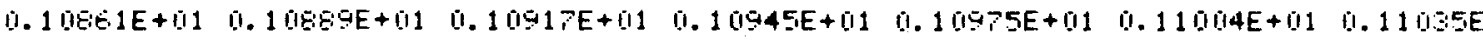
$+010.110 E 5 E+0110.11097 E+010.111 E 9 E+01$

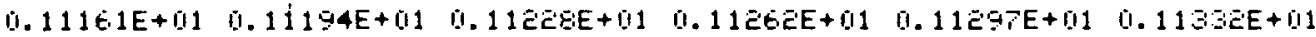

SQLIII TEMFER.ATURE (TS)

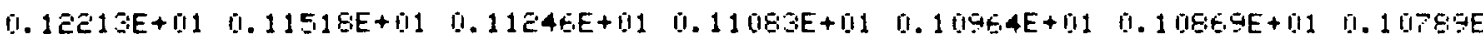
$+010.107 \varepsilon E E+010.1066 \mathrm{RE}+0110.10 E 17 E+01$

CNHM MASS FRACTION CYF:

$0.10000 E+010.80758 E+000.70137 E+000.61707 E+000.54601 E+000.48467 E+000.43108 E$ $+000.38389 E+000.34185 E+000.30433 E+00$

11. $28925 E+00 \quad 0.27908 E+00 \quad 0.26883 E+000.25851 E+00 \quad 0.24813 E+00 \quad 0.23769 E+00 \quad 0.22719 E$

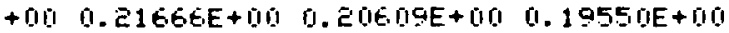

$0.18489 E+000.17429 E+30 \quad 0.16370 E+000.15314 E+00 \quad 0.14264 E+00 \quad 0.13 E 21 E+00$

$Y \mathrm{C}: \mathrm{B}=$

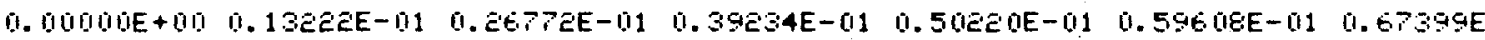
- 01 0.73E.5F-011 $0.7840 .4 E-01$ 0. $81781 E-01$

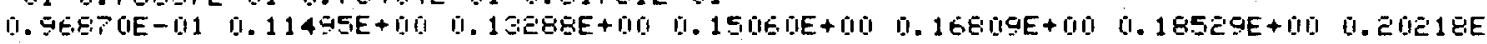
$+0010.218 E .9 E+000.23479 E+000.050100+00$

$0.26548 E+00$ 0. $27955 E+00$ 0. $2937 E E+00 \quad 0.3068 E E+00 \quad 0.31907 E+000.33043 E+00$

DIIFFACE HC MASE FPAC:TION (YFS

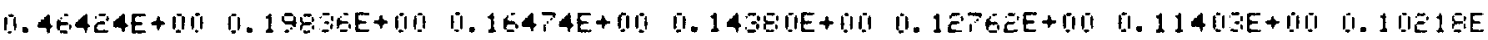
+00 0.92E>7E-01 0.83510E-01 0.75424E-011

YCOSSUFFACE) =

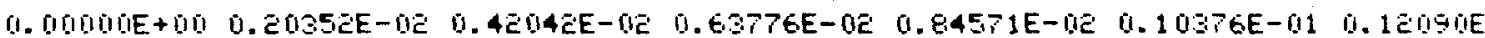
$-010.13661 E-010.15024 E-01 \quad 0.16140 E-01$

$\times \cdot \mathrm{JH}$

0. $1167 P E+0 z \quad 0.32624 F+01 \quad 0.27297 E+01 \quad 0.25095 E+01 \quad 0.23858 E+01 \quad 0.23039 E+0110.22435 E$

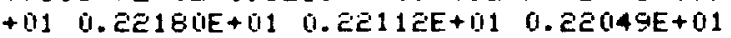

\section{EFFICI IENCY (CARBON-EALANCE)}

$0.00000 E+00 \quad 0.18954 E+000.29281 E+00 \quad 0.37440 E+00 \quad 0.44306 E+00 \quad 0.50236 E+000.55425 E$ $+00 \quad 0.60008 E+00 \quad 0.64109 E+00 \quad 0.67788 E+00$

$0.68968 E+00 \quad 0.69592 E+00 \quad 0.70227 E+00 \quad 0.70873 E+00 \quad 0.71531 E+000.72200 E+00 \quad 0.72882 E$ $+000.73577 E+000.74284 E+000.75003 E+00$

$0.75736 E+000.76481 E+00 \quad 0.77240 E+00 \quad 0.78011 E+000.78795 E+0000.79591 E+00$

\section{EFFICIENCY (TEMPERATURE)}

$0.00000 E+00 \quad 0.11074 E+00 \quad 0.14304 E+00 \quad 0.16233 E+00 \quad 0.17485 E+00 \quad 0.18292 E+000.18775 E$ $+00 \quad 0.19010 E+00 \quad 0.19058 E+00 \quad 0.18953 E+n 0$

$0.19407 E+00 \quad 0.20031 E+00 \quad 0.20666 E+00 \quad 0.21312 E+00 \quad 0.21970 E+00 \quad 0.22640 E+000.2332 E$ $+000.24016 E+000.24723 E+00 \quad 0.25443 E+00$

$0.26175 E+00 \quad 0.26921 E+00 \quad 0.27679 E+00 \quad 0.28451 E+00 \quad 0.29234 E+000.30031 E+010$ 
TIME $=$

EAS TEMFEFATUFE OT

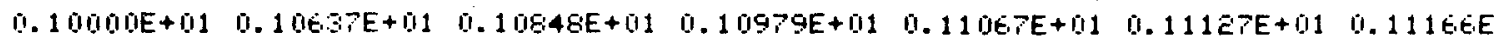
$+010.1118 \mathrm{E}+010.11198 \mathrm{Q}+010.11197 \mathrm{~F}+11$

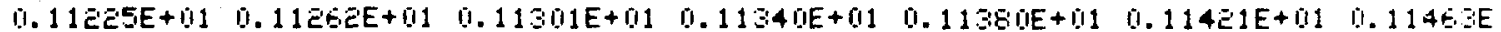

$+010.11506 E+010.11550 E+110.11594 E+11$

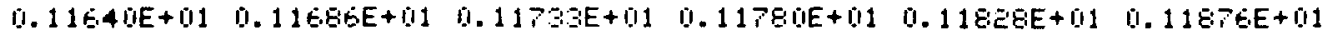

\section{DOL III TEMFERATLIFE (TS)}

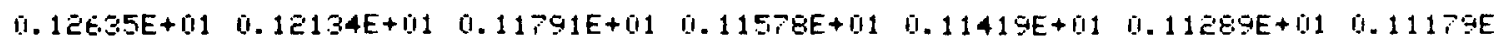
$+010.11088 E+010.11011 E+01$ 0. $10940+11$

CNHM MASS FRALTION CYF?

$0.10000 E+01 \quad 0.79629 E+00 \quad 0.68495 E+00 \quad 0.59669 E+000.5 E 239 E+000.45843 E+000.40 E 78 E$ $+010.35401 E+0010.31086 E+00$ 0. $27270 \mathrm{C}+100$

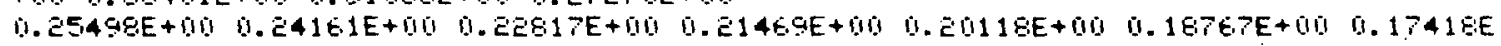
$+00.16074 E+010.14739 E+000.13416 E+00$

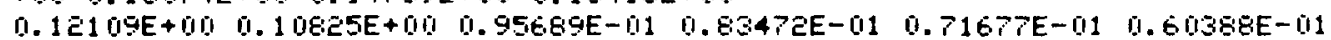

$\because \mathrm{C}=$

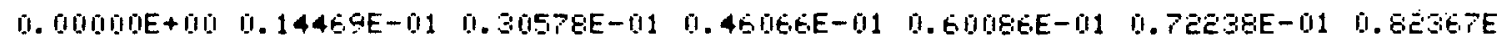
$-010.901438 E-010.96435 E-010.10054 E+001$

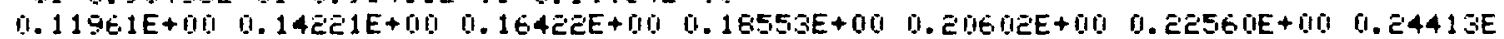
$+100.26148 \mathrm{E}+000.27750 \mathrm{E}+100.2920 \mathrm{EE}+00$

$0.30499 E+010.316 .14 E+00 \quad 0.32534 E+00 \quad 0.33244 E+00 \quad 0.337 e 8 E+000.33972 E+010$

SUFFACE HC: MASS FRFCTION CYFS:

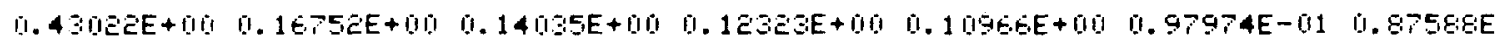
$-010.78891 \mathrm{E}-01$ 0.70GE1E-01 0. $0.553 E-01$

\section{YCO (SUIFFACE) =}

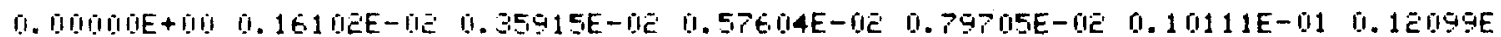
$-010.13980 \mathrm{E}-01$ 0.15E.1E.E-01 0.16983E-01

XIH

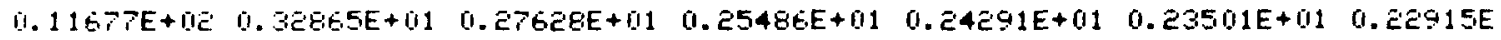

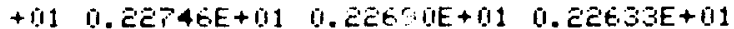

EFFICIENCY (CARPAN-BALANCE)

1. $00000 E+00 \quad 0.20056 E+00 \quad 0.30840 E+00 \quad 0.39329 E+00 \quad 0.46453 E+000.52586 E+000.57930 E$ $+000.62632 \mathrm{C}+100.66817 \mathrm{O}+000.70543 \mathrm{E}+00$

$0.71900 E+00 \quad 0.72746 E+00 \quad 0.73610 E+00 \quad 0.74495 E+00 \quad 0.75400 E+00 \quad 0.76325 E+000.77271 E$ $+000.78238 E+000.79225 E+000.80231 E+00$

$0.81256 E+000.82298 E+000.83354 E+00 \quad 0.84421 E+00 \quad 0.85495 E+00 \quad 0.86 .571 E+00$

EFF IC:IENC:Y' (TEMPERATURE)

$0.00000 E+00 \quad 0.14356 E+00 \quad 0.19111 E+00 \quad 0.22064 E+00 \quad 0.24056 E+00 \quad 0.25404 E+00 \quad 0.26275 E$ $+00 \quad 0.26777 E+00 \quad 0.26994 E+00 \quad 0.26975 E+00$

$0.27609 E+00 \quad 0.28455 E+00 \quad 0.29320 E+00 \quad 0.30204 E+00 \quad 0.31109 E+00 \quad 0.32034 E+00 \quad 0.32980 E$ $+00 \quad 0.33947 E+00 \quad 0.34934 E+00 \quad 0.35940 E+00$

$0.36 .965 E+00 \quad 0.380017 E+00 \quad 0.39063 E+00 \quad 0.40130 E+000.41204 E+00 \quad 0.42280 E+00$ 
TIME =

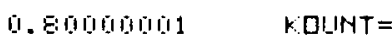

81

BAS TEMFERFTUFE (T)

0.10000E+01 0.1073EE+01 0.11008E+01 0.11183E+01 0.1130EE+01 0.1139EE+01 $0.1145 E E$ +01 0. $11490 \mathrm{E}+0110.11512 \mathrm{E}+01$ 0.11519E+01

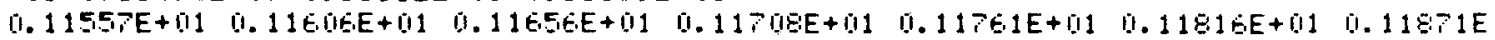
+11 0. $11928 E+11$ 0.1 $198 E E+01$ 0. $12045 E+01$

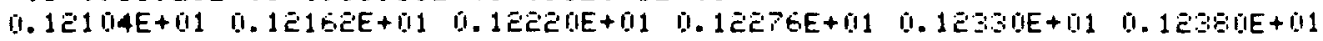

SQLIII TEMFERATLIRE CTS

$0.12842 E+01 \quad 0.12637 E+01 \quad 0.12 z 63 E+01 \quad 0.12021 E+01 \quad 0.11836 E+01 \quad 0.11683 E+01 \quad 0.11551 E$ $+110.1144 E E+11$ 0. $11347 E+01$ 0.1125EE+ 11

ENHM MASS FRACTIDN CYF'

$0.10000 E+010.78985 E+00 \quad 0.67457 E+000.58 \varepsilon 86 E+00 \quad 0.50547 E+000.43878 E+000.3808 E E$ $+1000.33013 E+000.28551 E+000.2463 E E+00$

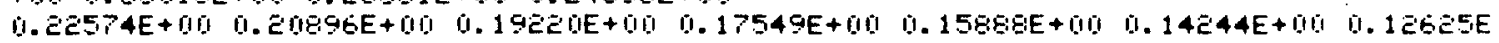
$+000.11038 E+00$ 0.94950E-01 $1.80009 E-01$

0.65879E-01 $0.52539 E-01 \quad 0.40 \mathrm{CEE}-010.29146 \mathrm{E}-0110.19511 \mathrm{E}-010.11553 \mathrm{E}-01$

$\because \mathrm{C}=$

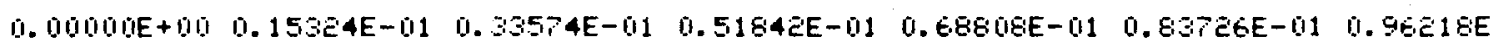
$-110.10609 E+000.113 E 8 E+00 \quad 0.11798 E+00$

$0.14070 E+000.16711 E+000.19204 E+000.215 E 9 E+00 \quad 0.23659 E+00 \quad 0.25571 E+0010.27238 E$ +00 0. $28632 E+00$ 0. $2972 \varepsilon E+000.30498 E+00$

$0.30918 E+000.30970 E+000.30638 E+000.29913 E+000.28799 E+000.27306 E+00$

SUIFFALE HC MASS FREACTIDN CYFS:

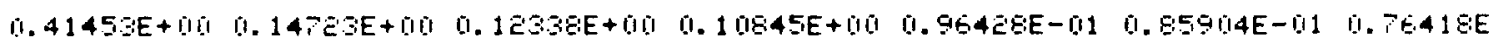
$-010.6844 \mathrm{E}-0110.60959 \mathrm{E}-0110.54010 \mathrm{E}-011$

YCDCUFFFCE $=$

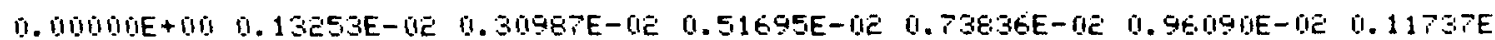
- 011 0.13799E-01 0.15599E-01 0.17119E-01

SIH

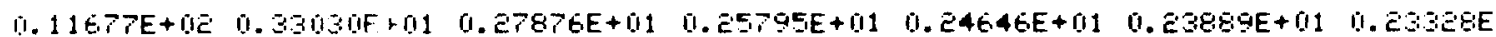

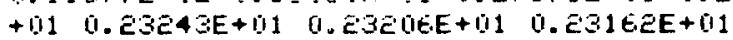

EFF ICIENCY (CAREDN-EALAMCE)

0. $00000 E+00 \quad 0.20682 E+00 \quad 0.31813 E+00 \quad 0.40586 E+00 \quad 0.47956 E+00 \quad 0.54301 E+00 \quad 0.598 E 5 E$ $+000.64679 E+00 \quad 0.68985 E+000.72798 E+00$

$0.74366 E+00 \quad 0.75469 E+00 \quad 0.76603 E+00 \quad 0.77768 E+00 \quad 0.78965 E+00 \quad 0.80193 E+00 \quad 0.81450 E$ $+000.82733 E+000.84038 E+000.85359 E+00$

$0.86686 E+000.88009 E+00 \quad 0.89312 E+010 \quad 0.90578 E+00 \quad 0.91784 E+00 \quad 0.92905 E+00$

\section{EFFICIENCY (TEMPERATURE)}

$0.00000 E+00 \quad 0.16600 E+00 \quad 0.22721 E+00 \quad 0.26670 E+00 \quad 0.29434 E+00 \quad 0.31389 E+00 \quad 0.32731 E$ $+00 \quad 0.33593 E+00 \quad 0.34078 E+00 \quad 0.34242 E+00$

$0.35100 E+00 \quad 0.36203 E+00 \quad 0.37337 E+00 \quad 0.38503 E+00 \quad 0.39700 E+00 \quad 0.40928 E+000.42185 E$ $+00 \quad 0.43468 E+00 \quad 0.44773 E+00 \quad 0.46093 E+00$.

$0.47421 E+00 \quad 0.48744 E+00 \quad 0.50047 E+00 \quad 0.51313 E+00 \quad 0.52519 E+00 \quad 0.53639 E+010$ 


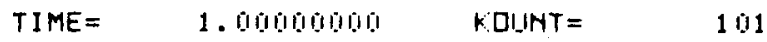

GAS TEMFERATUFE CT:

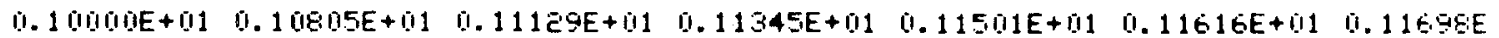
$+010.11755 E+010.1179 E E+010.11811 E+01$

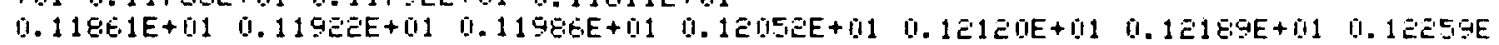
$+010.12300 \mathrm{E}+010.12401 \mathrm{E}+010.12470 \mathrm{O}+01$

0. $12536 E+010.12597 E+01$ 0. $12651 E+01$ 0. $12696 E+01$ 0. $12730 E+01$ 0.12757E+01

SOL II TEMFERATLEE (TS)

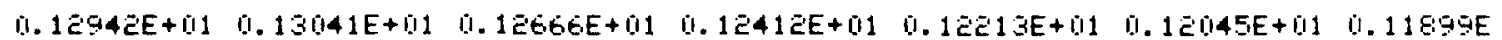
$+010.11778 E+01$ 0.116.70E+01 0.115EEE+01

ENHM MASS FRACTIOM CYF?

0. $10000 E+01 \quad 0.78602 E+00 \quad 0.66774 E+00 \quad 0.57313 E+00 \quad 0.49291 E+00 \quad 0.42358 E+00 \quad 0.36325 E$ $+0010.31050 E+100.26422 E+000.22386 E+00$

$0.2002 \varepsilon E+000.18011 E+00 \quad 0.15997 E+00 \quad 0.14021 E+00 \quad 0.12085 E+00 \quad 0.10 E 05 E+00 \quad 0.83957 E$ $-010.66901 \mathrm{E}-010.510 \mathrm{E} 5 \mathrm{E}-010.36667 \mathrm{E}-01$

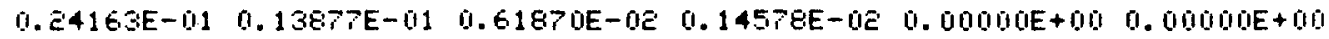

$Y C Q=$

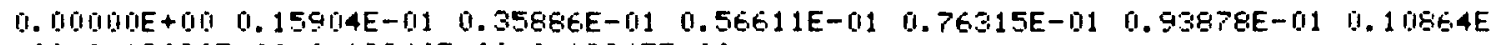

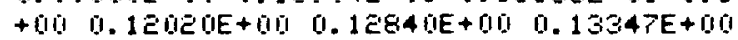

$0.15912 E+000.18804 E+000.21403 E+000.23668 E+00 \quad 0.25556 E+00 \quad 0.27025 E+0100.28033 E$

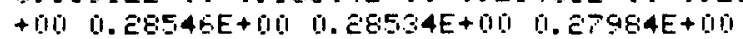

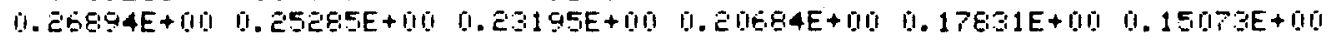

SUFFACE HC MASS FRFCTIDN CYFS

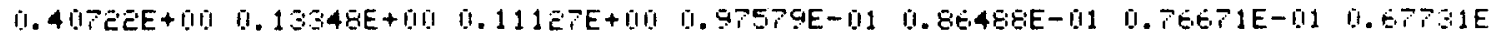
$-010.60191 \mathrm{E}-010.52984 \mathrm{E}-010.46 \mathrm{e} 8 \mathrm{SE}-011$

\section{YCD(SUFFACE) =}

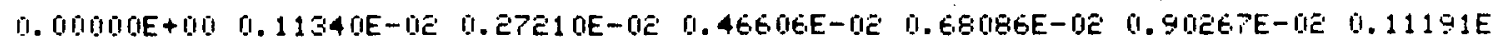
- 11 0.133E1E-01 0.1518UE-01 0.16751E-01

S.IH

$0.11677 E+0 \varepsilon \quad 0.33143 E+01 \quad 0.28063 E+01 \quad 0.26039 E+01 \quad 0.24936 E+01 \quad 0.24215 E+0110.23683 E$ $+010.23678 E+01$ 0. $230,7 E+0110.23641 E+01$

EFFIC:IENC:Y (CARRON-BFILANCE)

$0.00000 E+00 \quad 0.21052 E+00 \quad 0.32445 E+00 \quad 0.41456 E+00 \quad 0.49049 E+00 \quad 0.55600 E+000.61311 E$ $+000.66335 E+00 \quad 0.70785 E+000.74710 E+00$

$0.76517 E+00 \quad 0.77909 E+00 \quad 0.79347 E+00 \quad 0.80830 E+00 \quad 0.82355 E+00 \quad 0.83916 E+00 \quad 0.85502 E$ $+00.87100 E+00 \quad 0.88690 E+00 \quad 0.90246 E+00$

$0.91733 E+000.93112 E+00 \quad 0.94335 E+00 \quad 0.95355 E+00 \quad 0.96121 E+000.96721 E+00$

\section{EFF ICIEMCY (TEMPERATURE)}

$0.00000 E+00 \quad 0.18145 E+00 \quad 0.25441 E+00 \quad 0.30314 E+00 \quad 0.33837 E+00 \quad 0.36422 E+00 \quad 0.38283 E$ $+00 \quad 0.39570 E+00 \quad 0.40395 E+00 \quad 0.40818 E+00$

$0.41940 E+00 \quad 0.43332 E+00 \quad 0.44770 E+00 \quad 0.40253 E+00 \quad 0.47778 E+00 \quad 0.49339 E+00 \quad 0.50925 E$ $+00 \quad 0.52523 E+00 \quad 0.54113 E+00 \quad 0.55669 E+00$

$0.57156 E+00 \quad 0.58535 E+00 \quad 0.59758 E+00 \quad 0.60778 E+00 \quad 0.61546 E+0100.62146 E+00$ 
APPENDIX II

LISTING OF COMPUTER PROGRAMS FOR CHAPTER II

The computer programs for Part II (steady state) are quite similar, in structure, to those in Part $I$. In addition to using a three-reactions scheme as discussed in the text of Part II, only the final results are printed out (no intermediate transient).

More Detalled Instruction (for CALY1. FOR; 75):

1. Read-in data (Iines 10400 - 11475):

$\mathrm{XPHI}=\phi=$ fue1-air equivalence ratio

$\mathrm{TI}=\mathrm{T}(0,0)=$ upstream, initial temperature $(\mathrm{K})$

$\mathrm{XPI}=p(0,0)=$ upstream, initial pressure (Atm.)

UIUS $=U_{\text {ref }}=$ upstream (outside of the bed) initial gas velocity $(\mathrm{m} / \mathrm{s})$

XLS $=$ reference length $(\mathrm{m})$, suggested to use $0.1 \mathrm{~m}(10 \mathrm{~cm})$

$\mathrm{DS}=\mathrm{d} *=$ channel hydraulic diameter $(\mathrm{m})$

AOAS $=A^{*} / A_{S} *=$ open-to-close area ratio

$\mathrm{DXX}=$ nondimensional step size in $\mathrm{X}$ (space) inside the catalytic bed. It is nondimensionalized by XLS.

So if XlLS $=0.1 \mathrm{~m}$ and $\mathrm{DX}=0.01$, the dimensional step size is $0.001 \mathrm{~m}$ or $1 \mathrm{~mm}$.

$\mathrm{XAS}=$ ratio of step sizes between downstream and inside-bed regions. For example, (XAS) $x$ (DXX) is the integration step size in $X$ - direction in the downstream space.

$\mathrm{DT}=$ nondimensional time step size, recommended to be 0.2 or 0.1 for steady calculations.

TMAX = maximum nondimensional time allowed for computation. It should be large enough to allow the steady state to be reached. For bed length less than $5 \mathrm{~cm}$, TMAX = 8.001 is suggested, for bed length between $5-12 \mathrm{~cm}$, TMAX $=12.001$ is suggested. 
$\mathrm{N}=$ number of grid points (in $\mathrm{X}$ direction) in the catalytic bed. The nondimensional catalytic bed length is given by $(\mathrm{N}-1) \times(D X)$. For example, if $\mathrm{N}=51, \mathrm{DX}=.01$, then the nondimensional bed length is equal to 0.5 . If $X L S=.1 \mathrm{~m}$, then the dimensional bed length is $.05 \mathrm{~m}(5 \mathrm{~cm})$.

NAS = number of grid points (in $\mathrm{X}$ - direction) in the downstream after-bed space. The length of the downstream distance can be calculated in a similar manner as in the above.

IT = interval in $X$ for printout. For example, if $\mathrm{DXX}=.01$, IT $=5$, the printout will be at $\mathrm{x}=0,0.05,0.1,0.15$, etc. ...

$\mathrm{C} 0, \mathrm{Cl}, \mathrm{C} 2, \mathrm{C} 3, \mathrm{C} 4=\mathrm{C}_{1}, \mathrm{C}_{2}, \mathrm{C}_{3}, \mathrm{C}_{4}$ (See Table I) IPUTIN $=1$ (always)

2. Output data (1ines $37000-38586)$ :

The following quantities will be printed out as a function of downstream distance:

Gas and solid temperatures, Emission indices $(x 1000)$ for the original hydrocarbon, pyrolyzed hydrocarbon, total hydrocarbon and $\mathrm{CO}$ in the gas phase, the original hydrocarbon and $\mathrm{CO}$ at the wall and the combustion efficiency.

If TMAX is large enough, the above printuuts are the steady-state profiles. 


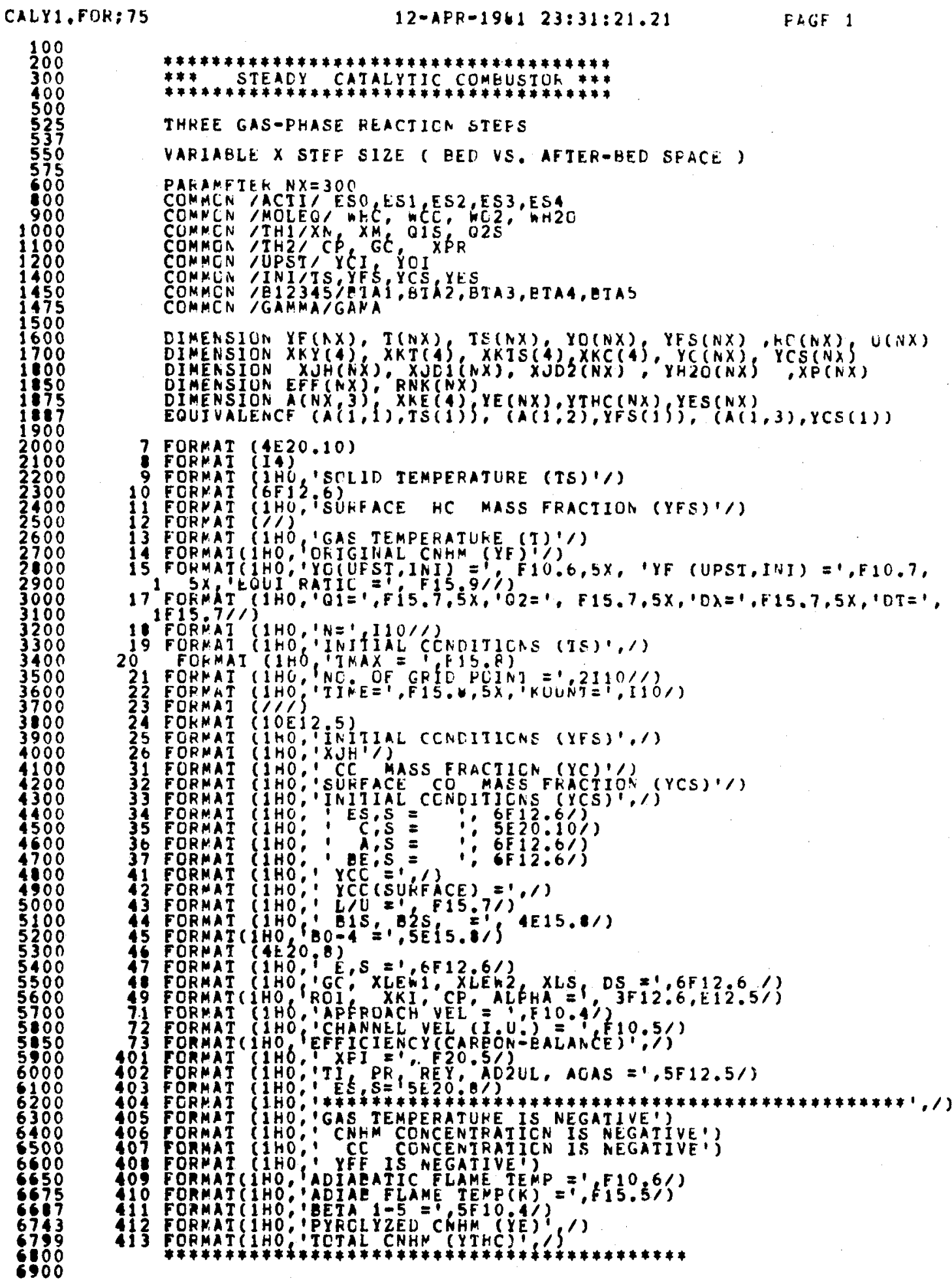

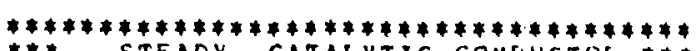

DIMENSIUN YF(AX), T(NX), IS(NX), YO(NX), YFS(NX), KC(NX), U(NX) DIMENSION XKY(4), XKT(4),XKIS(4)XKC(4), YC(NX), YCS(NX)

7 FORMAT (4E20.10)

9 FORMAT (IA) 'SCLID TEMPERATURE (TS) $1 /$ )

10 FORMAT (GFj\&.6)

1 FORVAT (1HO, ISUFFACE HC MASS FRACTION (YFS)'/)

14 FOPMAT 1 HO 'GAS TEMPERATURE (T)'/

15 FORMAT (1HO: YYC UFST, INI) = F10.6,5X, YYF (UPST,INI) = .,F10.7,

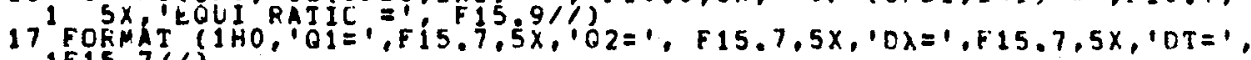
$1 F 15.7 \%$

10 FORHAI (1HO, $N=1,1101 /)$

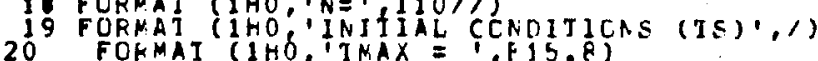

FOMAI (1HO TMAX = THSOR)

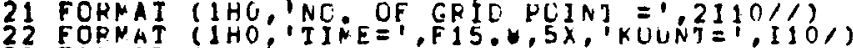

23 FORMAT

24 FOKMAT (1OEI2.5)

25 FORFAT (IHO, INITIAL CCNCITICNS (YFS),, 1$)$

26 FORMAT (IHO, $X \mathrm{XH}$ '

31 FORMAT (IHO, $C$ CC MASS FRACTICN (YC) I)

32 FORMAT (IHO: SURFACE COAMASS FRACTION (YCS) $/ 1)$

33 FORMAT (IHO, 'INITIAL CCNDITICNS (YCS)', )

34 FORMAT (1HO: ES,S = : 6F12.6\%)

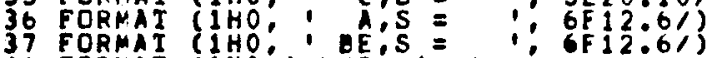

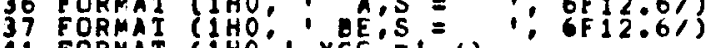

41 FORMAT (1HOO' YCC'=1, ()

T) FoRMAT

13 FORMAT (1HO:! YCC (SUKFACE) $=1,1)$

44 FORMAT (1HOP:BIS, B2S S :

46 FORMAT (4E20,8)

47 FORMAT (1HO, E, S = 6 ,6F12.6/)

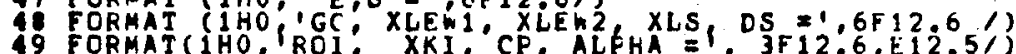

7 FORMAT (2HO, TAPFROACH VEL' = ALFAO

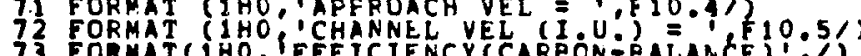

73 FORHAT ( 1 HO PEFFICIENCY (CAREON

402 FORMAT (1HO, TTI PR, "REY, AOLUL, ACAS $=1.5 F 12.5 /)$

403 FORMAT (IHO: TES,S=15E2O:O\%)

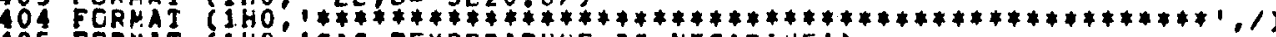

405 EORMAT (IHO, !GAS TEMPERATUKE IS NEGATIVE')

406 FORMAT (IHO: CNHM CONCENTRATICN IS NEGATIVE?

40 FORMAT (1HO: Y CC CONCENTRATIC

409 FORMAT(IHO, TADIAEATIC FLAME TEMP $=1, F 10,6 /)$

410 FORMAT (IHO: ADIAE FLAME TENP(K) = , FI5.5\%

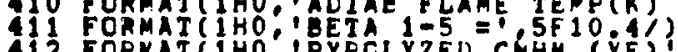

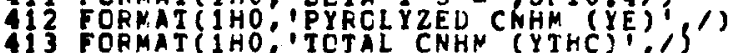

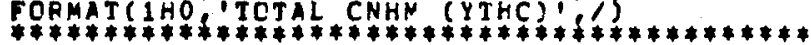




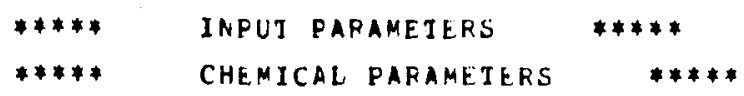

CHENICAL KEACIICA O, CNHN = CNHM (GAS PHASE PYFCLYEIS)

CHEMICAL REACTICN 1, CNHM + C2 = CO + H2C (GAS FHASE) CHEMICAL REACTICA 2: CO+O2 = CO2 (GAS PHASE) CHENICAL REACTICH 3 , CNHM +C $2=$ CO2 + H2O ( SOLIL SURFACE)

ESI = ACTIVATION ENEFGY FOP REACTION I (CAL/MOLE), ETC, CI = PREEXFONENIIAL FACTOR (DIMENSIONAL) FOR REACTIONI, EIC. WHC. WCU = MOLECULAR WEIGHTS FCR CAHM, CO QIS = HEAT OF CCNBUSTICN FCR REACTICN 1 (CAL/G OF CNHM) $02 S=H E A T$ OF CCNBUSTICN FOR REACIION 2 (CAL/G OF CC) OS = HEAT OF CORHUSTION FOF REACTION 3 (CAL/G OF CNHM) $X N=$ THE NUMBER CF CARPONS IN CNHM XM $=$ THE NUMBER CF HYCROGEN IN CNHM

$O S=01 S+02 S * X N * W C O / W H C$

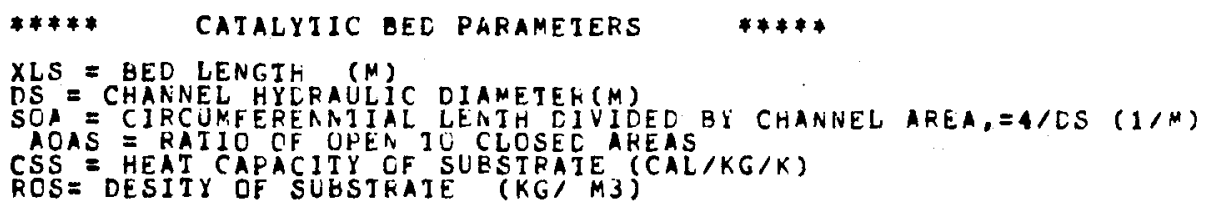

$X L S=B E D$ LENGIH $(M)$

DS = CHANNEL HYCRAULIC DIAMETEF(M)

SOA = CIRCUNFEREAAIIAL LENIH CIVIDED BI CHANNEL AREA, $=4 / C S(1 / \mathrm{M})$ AOAS = RAIIO OF OPEA TO CLOSEC AREAS

CSS = HEAT CAPACITY OF SUESTRAIE (CAL/KG/K)

10000

10200

10200

10400

10500

10600

10700

10000

10900

11000

11100

11200

11300

11400

11425

1135

15

11475 


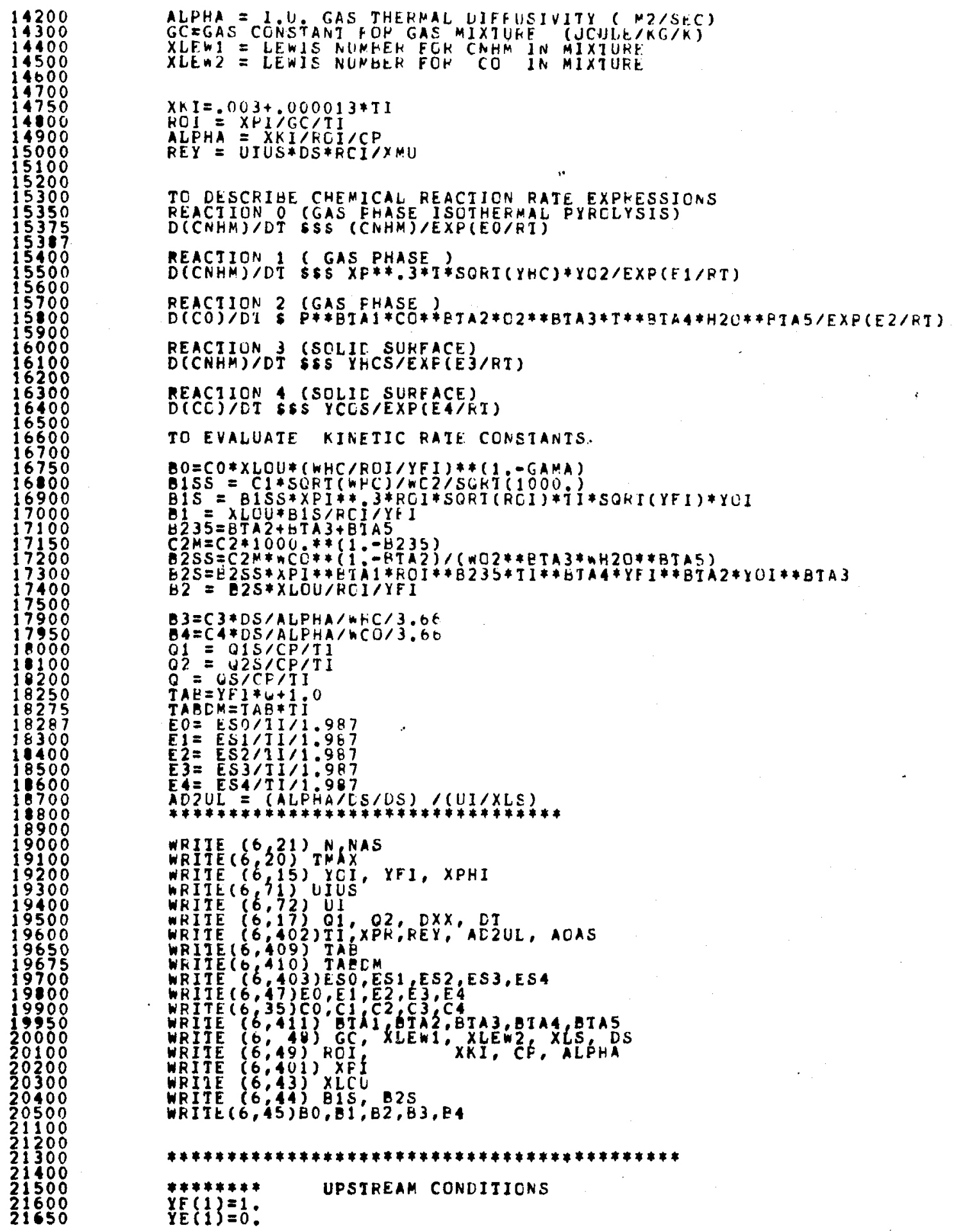


$x(1)=0.0$

$Y 0(1)=1$.

$R O(1)=i$

$X P(1)=\mathrm{i} .0$

YTHCII =

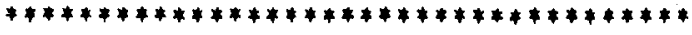

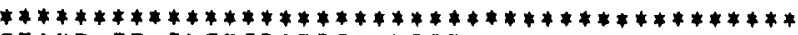

START OF IRTEGRATION LCOF

KOUAT $=1$
$X N U O D=.885 * S O R T(A C A S) * S O K T(X P F *$ KEY $)$

ROOT $1=0.0$

ROCT $=1: 0$ : ROT $1+R C O T 2)$

IF (RCOT.LE.0.1) YNU=.0444/ROCI+3.46-1.34*RCOT

IF (RCOT:GT:0:1) YNU=0.011/kOOT+3:66

$Y R O C T=Y N U-X N U O)$

IF (AES (YROOT).LT.0.01) GO TO 200

IF (YKOOT.GT.0:0) KUOT1 =ROOT

IF (YKOOT:LE:O:0) KOOT $2=R O U I$

DMASS $=R O(1) * U(1)$

INTEGRATION GK GUASI-STEACY GAS PMASE EQUATIONS FOK OIRECTION USING FOURTH-CRDER RUNGE-KUTTA SCHEME

I IS THE INDEX FCR DONSTREAM CISIANCF $X$

DO $201 I=1$, NPNAS

IF (I.LE.N) $D X=C X X$

IF $(I, G T: N)$ DX $=X A S * U X X$

IF (I.GT N) UMASSEFO(I)*U(1)*ACAS/ (AOAS+1.)

EVALUATE XJH ANL XUC AS A FUNCIION CF $x$

180

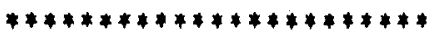

NONDIMENSIONAL TIEAT CCACUCIIVITY

$X K=(.003+0.000013 * 11 * \text { II }(1))^{\prime} / X K 1$

IF (I.GT.I) GC IC 180

$\operatorname{li}_{G 0}(1, E Q 1)$

CONTINUE

$1 x=1+1$

$X I=1 \times-1$

101

$X=X I * D X$

$X S T=X * 2,0 * A D 2 U L * X K+R O C T$

IF (XST.LE 0.1$)$ XNU $=0.0444 / X S T+3.46-1.34 * X S T$

IF XST.GT:0.1) XNU $=0.011 / X S T+3.66$

RNK (I) $=X N U * X K / 3.66$

$X \mathrm{X} H(I)=4,0 * X N U * A D 2 L L * X K$

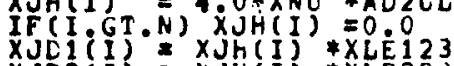

XJDL $(I)=X J H(I) * X L E 223$

1.32 CONTINUE
$M=1120 \quad L=1$
IF $\{M, N E=1\}^{4} G O$ TC 102
$Y F F=Y Y(I)$
$Y E E=Y E(I)$
$T C=T(I)$
$T_{M=M+1}=$
$M=M+1$
CONTINUE
IF
$Y F F=Y F(I ;+D X * X K Y(1), 12$.

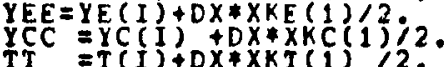

102 


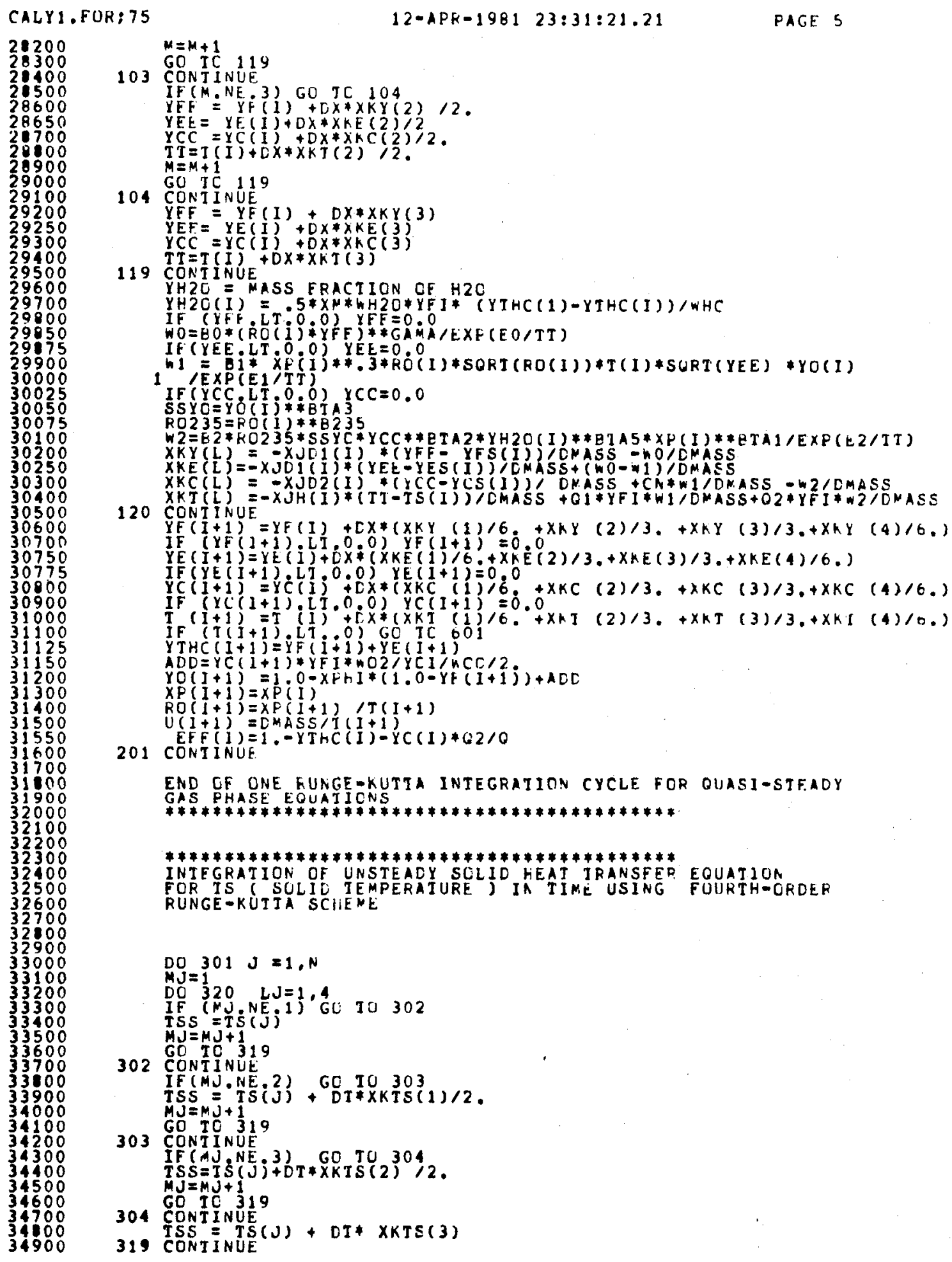




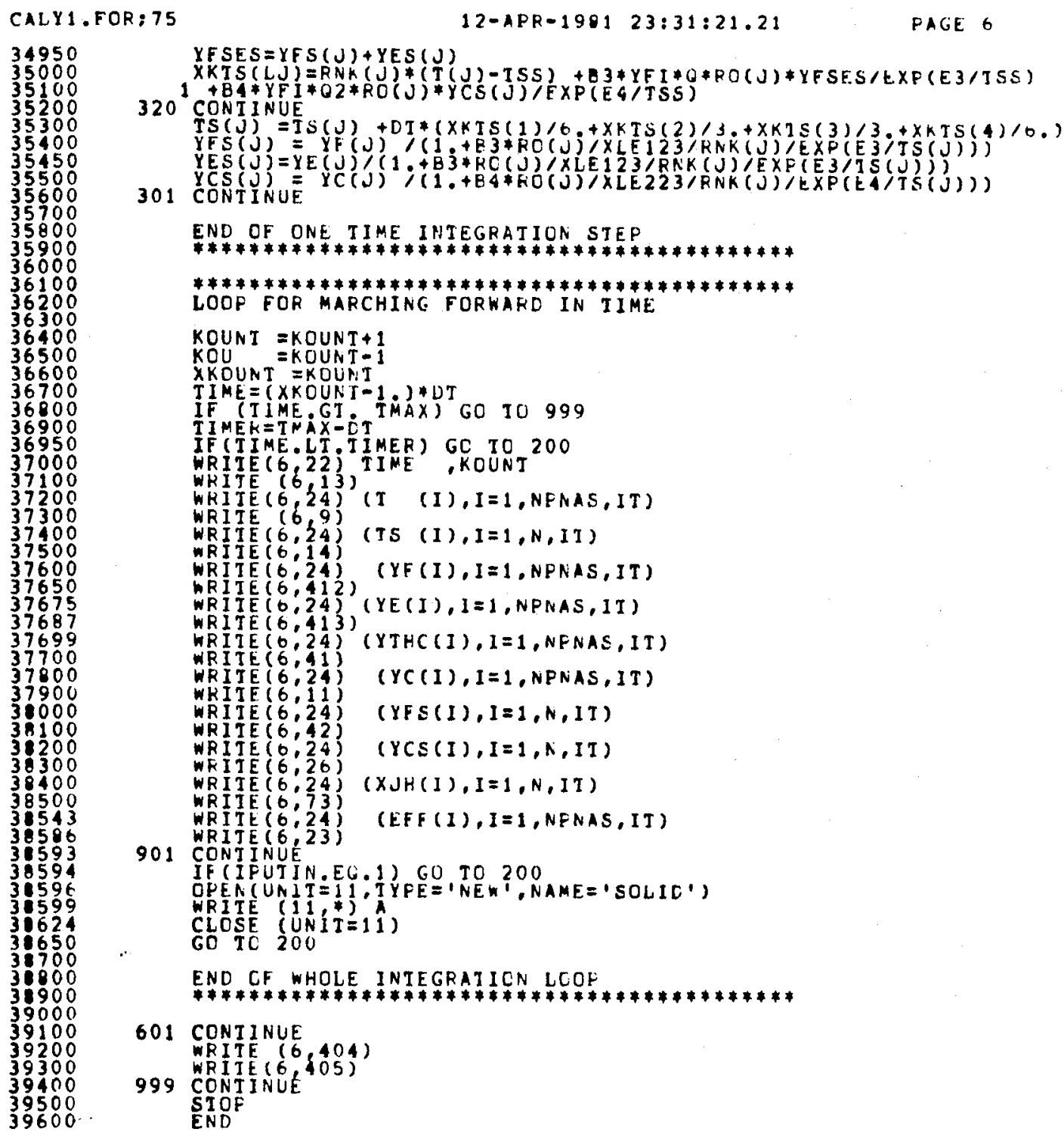


BLOCK.FOR; 29

100
200
300
400
600
700
800
900
1100
1150
1175
1200
1400
1500
1600
1700
1800
1900
1950
2000
2100

BLUCK DATA

DIMENSION IS $(300)$ YFS $(300)$ YCS $(300), Y$ Y S 300$)$

COMMCN , ACTI, ESO,ESI,ES2, ES Z, ES4

COMMCH

COMMCN THHIXN "XM" OIS' O2S"

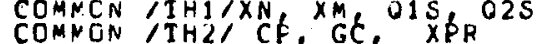

COMNON TIHZI CFE GC

COMMCN JUPST S Y Y Y Y Y

COMHCN TBI2345,BTAI, ETAZ, BTAB, ETAA, ETAS

COMMCN IGAMMATGANA

DATA ESO,ES1,ES2,ES3,ES4/34000,24000, 40000,10000,.17800.1

DATA WHC \& WCO WC2 WH2OK138.28

DA A X ',

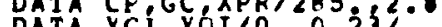

DATA RTAL,BTA2;ETA3,ETA4,BTA5/0,.1,0.25,0.,0.5/

DATA GAMA'US:5'CS,YES/300*1.,300*0.,300*0,.300*0.1

END 
Example calculation:

5 FIUN CALYI.EXE:SI

.165

1 1010.

3

15.

.1

.01380

13.29

.011 .

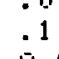

8. 0101

51

1 10!

5

1. EEE 1.8ES .54E14 1.5E4 1.EE

1

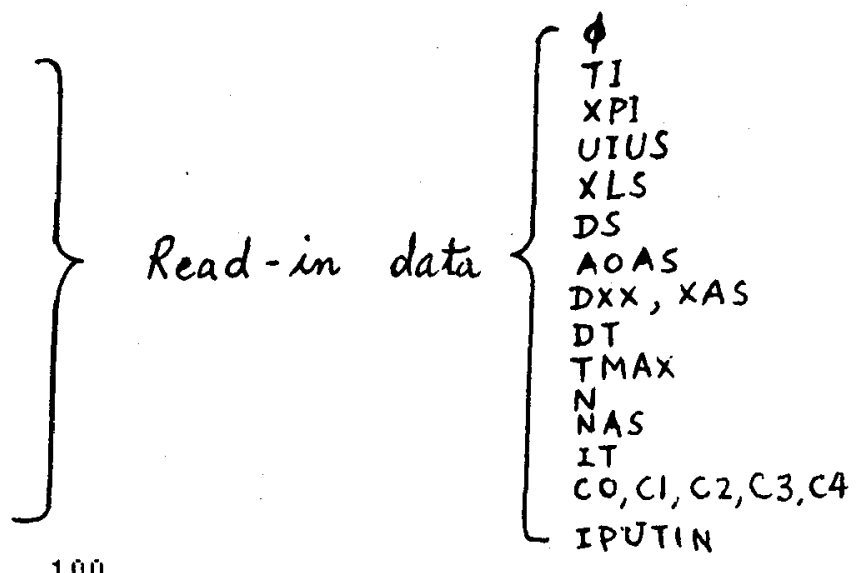

10. OF GEII FOINT =

51

100

IPUTIN

TMAX: $=\quad 8.00100040$

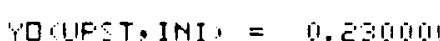
0000?

IF UIFT, INI = $=0.0113489$

EQUII RATID =

i. $1 E$

AFFFDACH VEL = 15.0001

CHAMAEL VEL O.U.) $=16.1286 .7$

$1=18.796491 t \quad Q \bar{c}=\quad 8.4736843 \quad I x=\quad 0.0100000 \quad I T=\quad 0$.

8. $796491 t \quad Q \vec{c}=$

TI, FR, REY, AIE'LIL, ADAS = 1000.00000

0.70000

529.01978

0.17199

13 .29000

AIIAEATIC: FLFME TEMF $=1.408440$

ADIAB FLAME TEMF $(K)=1408.44019$ 


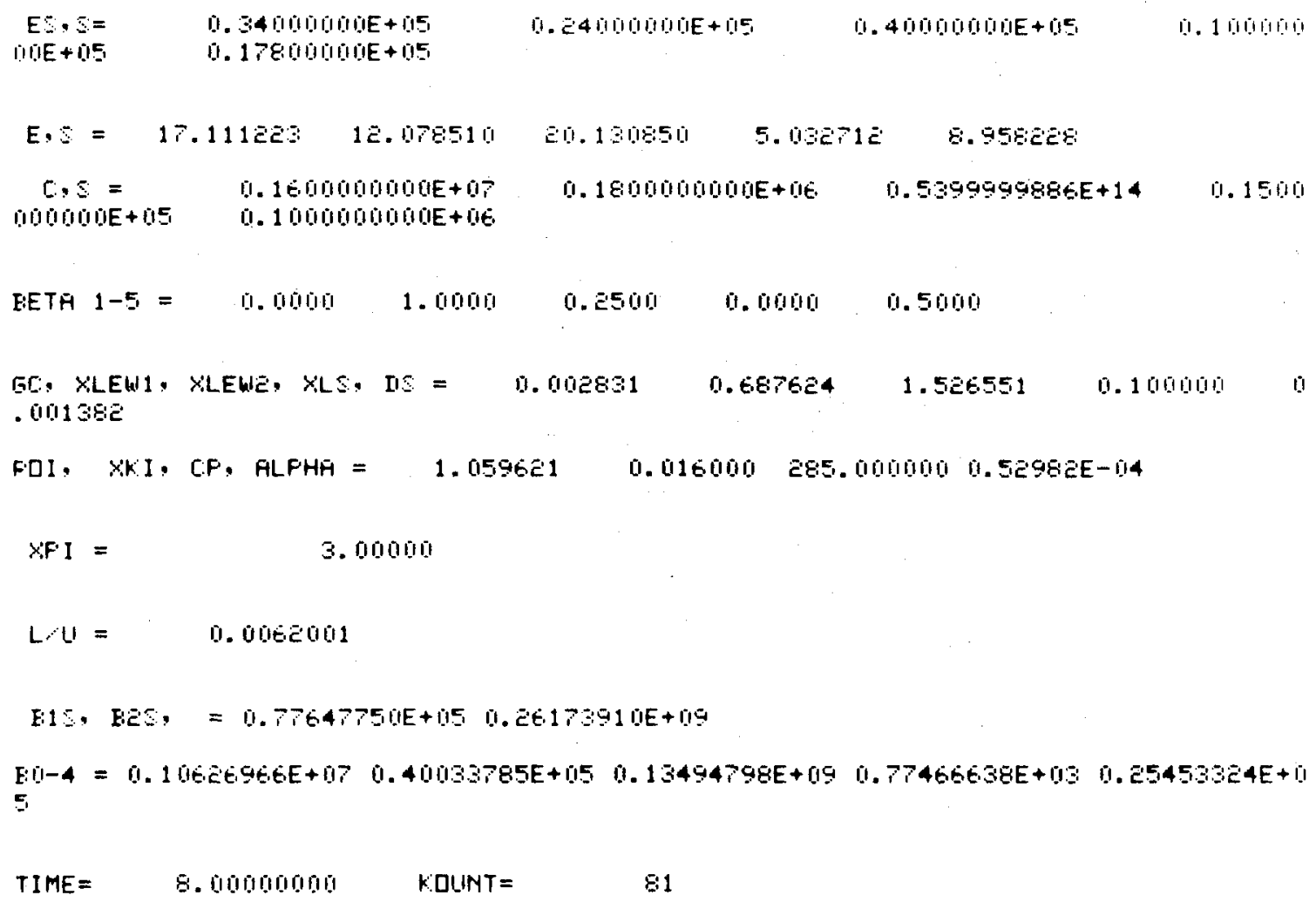


FYYOOLYZEI CNHM YYE.

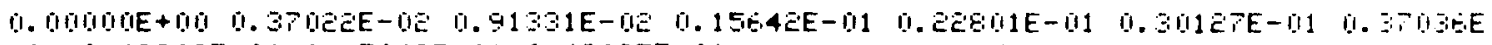

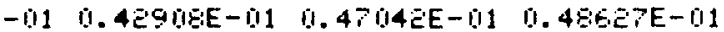

0. 4E.78E-01 $0.4431 \mathrm{EE}-01 \quad 0.36474 \mathrm{E}-01$ 0.

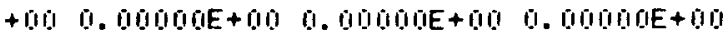

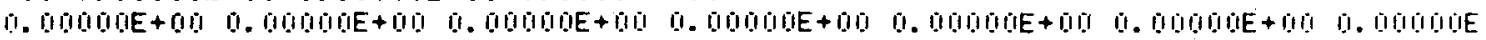

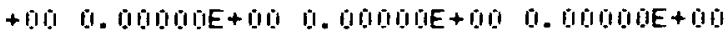

Q. $00000+00$

TOTAL C:NHM G'THC?

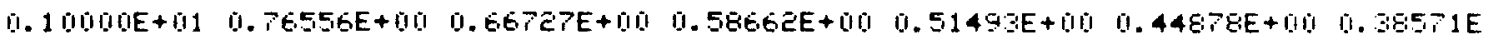
+000 0. $3246.3 E+000.26529 E+000.20776 E+00$

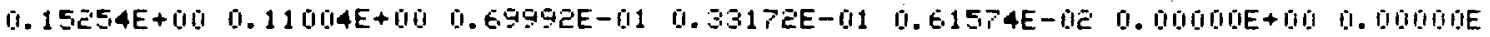

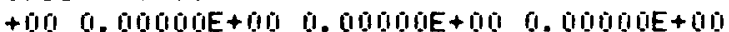

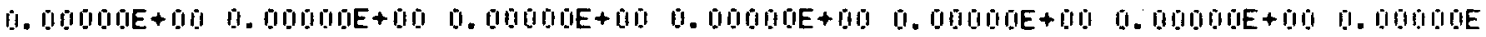

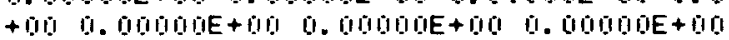

1. DOMOME + DO

$Y C D=$

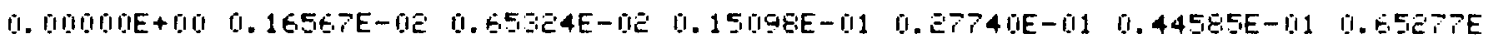
$-110.89093 E-0110.11487 E+001.14085 E+00$

$0.16454 E+000.21374 E+010.26066 E+000.28957 E+000.28939 E+000.24645 E+0010.1983 E E$ +100 0. $15831 E+010$ 0.12542E+00 0.98769E-01

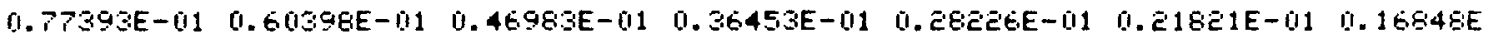
-01 0. 1299SE-011 0.10017E-01 0. 7 T1E.EE-0E

$0.59417 \mathrm{E}-0 \mathrm{C}$

DIRFACE HE MASE FRFCTIDN GYFS

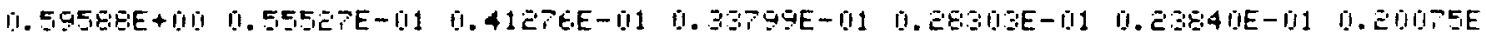

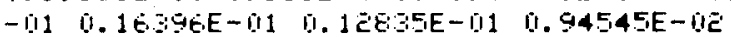

$0.6348 \mathrm{SE}-1 \mathrm{CE}$

YCDSSIRFACE) =

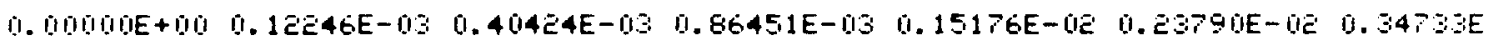
-

$0.8 E .84 \mathrm{E}-0 \mathrm{E}$

X.IH

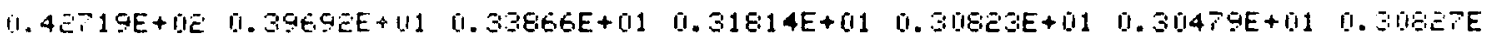
$+010.31189 E+0110.31556 E+01 \quad 0.31922 E+01$

0. $32283 \mathrm{E}+01$

\section{EFFICIENC: YCAFEON-BALANCE)}

$0.00000 E+00 \quad 0.23405 E+00 \quad 0.33119 E+00 \quad 0.40983 E+00 \quad 0.47854 E+00 \quad 0.54072 E+00 \quad 0.59893 E$ $+000.65439 E+00 \quad 0.70766 E+000.75908 E+00$

0. $81872 E+00 \quad 0.83963 E+000.86864 E+00 \quad 0.89865 E+00 \quad 0.92571 E+0100.94197 E+010.95930$ $+0100.96273 E+1000.97047 E+000.97674 E+010$

$0.98178 E+00 \quad 0.98578 E+00 \quad 0.98894 E+00 \quad 0.99142 E+00 \quad 0.99335 E+00 \quad 0.99486 E+00 \quad 0.99603 E$ $+00 \quad 0.996 .94 E+00 \quad 0.99764 E+00 \quad 0.99818 E+00$

$0.99860 E+00$ 


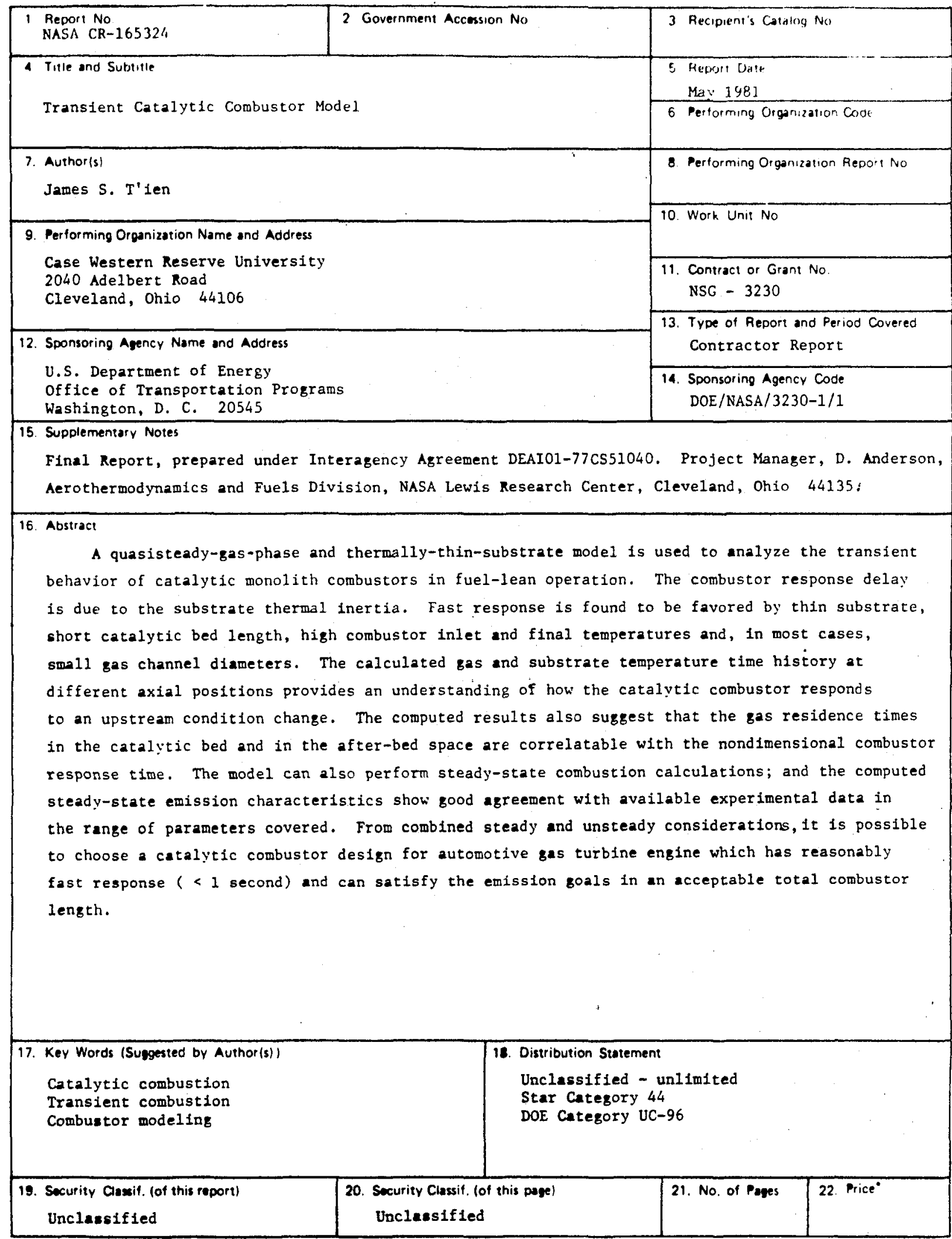

* For sale by the National Technical Information Service, Springfield. Virginia 22161

NASA-C-168 (Rev. 10-75) 

